\title{
Synthesis and reactivity of spiro-fused $\beta$-lactams
}

\author{
Girija S. Singh, ${ }^{1, *}$ Matthias D'hooghe, ${ }^{2}$ and Norbert De Kimpe ${ }^{2, *}$ \\ ${ }^{1}$ Chemistry Department, University of Botswana, Gaborone, Botswana \\ ${ }^{2}$ Department of Sustainable Organic Chemistry and Technology, Faculty of Bioscience Engineering, \\ Ghent University, Coupure Links 653, B-9000 Ghent, Belgium
}

\section{Contents}

1. Introduction

2. Synthesis of Spiro-fused $\beta$-Lactams

2.1 Cycloaddition reactions

2.1.1 Reactions of acyclic ketenes

2.1.2 Reactions of cyclic ketenes

2.1.3 Reactions of isocyanates with ketene- $N, S$-acetals

2.2 Cyclisation reactions

2.3 Transformations of substituents connected to monocyclic 2-azetidinones

2.4 Other methods

3. Reactions of Spiro-fused $\beta$-Lactams

3.1 Ring-opening reactions

3.2 Reactivity of substituents attached to the ring nitrogen atom

3.3 Reactivity of substituents attached to the ring carbon atoms

4. Bioactive Spiro-fused $\beta$-Lactams

5. Concluding Remarks

Acknowledgements

References

e-mail: singhgs@mopipi.ub.bw, matthias.dhooghe@UGent.be,norbert.dekimpe@UGent.be 


\section{Introduction}

2-Azetidinones, commonly known as $\beta$-lactams, are the key structural motifs in the most widely used class of antibiotics, i.e. $\beta$-lactam antibiotics such as penicillins, cephalosporins, carbapenems, etc. The development of novel synthetic methodologies for the preparation of functionalized $\beta$-lactams and the screening of their biological activity has occupied a pivotal position in medicinal chemistry for almost a century now. ${ }^{1}$ The increasing number of resistant pathogens and the discovery of $\beta$-lactamase inhibition properties of $\beta$-lactams gave further impetus to these studies. Besides being antibacterial agents, various other biological activities, such as cholesterol absorption inhibition, inhibition of different kinds of enzymes, and antitubercular, hypoglycemic and anticancer activity, have been discovered to be associated with $\beta$-lactams. ${ }^{2,3}$ In the literature, much attention has been paid to the study of the synthesis, chemistry and biological activity of either monocyclic or condensed bicyclic $\beta$-lactams, which is evident from many review articles published in this field. ${ }^{4}$ On the other hand, the synthesis and chemistry of C3 and C4 spiro-fused 2-azetidinones (Figure 1) has grown steadily over the years, and significant development has been made during the last two decades.

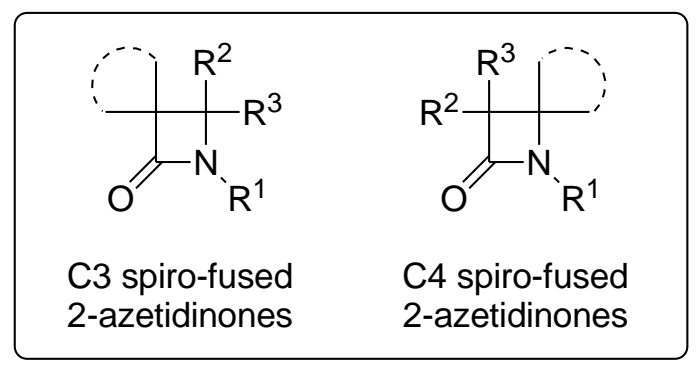

Figure 1

Many new synthetic methods focusing on the construction of the spiro-fused 2-azetidinone framework have been reported, which has resulted in the synthesis of 2-azetidinones, spirofused to diverse types of carbocyclic and heterocyclic rings. The chemistry of spiro-fused 2azetidinones has been explored for the synthesis of many biologically important compounds, 
such as the marine natural products, chartellines A-C 1-3 (Figure 2), in which a spiro-fused $\beta$ lactam entity is embedded in a larger architecture. ${ }^{5}$

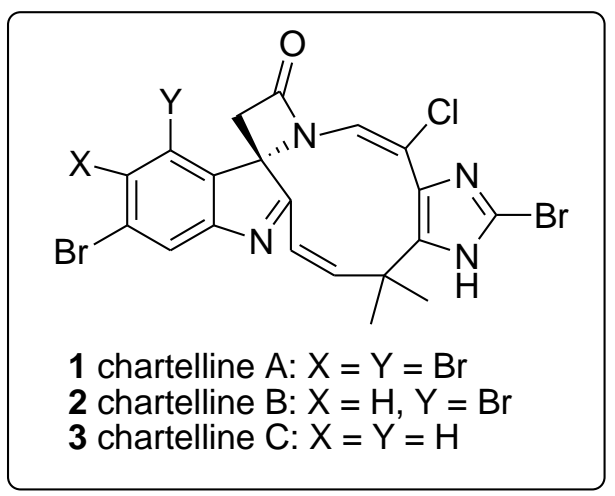

\section{Figure 2}

Furthermore, spiro-fused 2-azetidinones have been reported as cholesterol absorption inhibitors and poliovirus and human rhinovirus 3C-proteinase inhibitors (vide infra).

Since there is no review available in the literature focusing particularly on spiro-fused 2azetidinones, the present report describes the synthesis, reactions and biological relevance of spiro-fused 2-azetidinones for the first time in a comprehensive way.

\section{Synthesis of Spiro-fused $\beta$-Lactams}

Synthetic approaches to spiro-fused 2-azetidinones can be classified mainly as ketene-imine cycloadditions, cyclisations of $\beta$-amino acids or $\beta$-functionalized amides, and transformations of substituents connected to monocyclic 2-azetidinones. Many new spiro-fused 2-azetidinones are synthesised by transformation of functional groups/substituents present on other spiro-fused 2azetidinones. Such methods are described under the section on "Reactions of Spiro-fused $\beta$ Lactams".

\subsection{Cycloaddition reactions}

The cycloaddition of ketenes and imines, commonly known as the Staudinger [2+2] cycloaddition, is the most widely used and simple reaction for the synthesis of 2-azetidinones. 
Although it is often referred to as a [2+2] cycloaddition, it is now established that the reaction occurs in a stepwise manner. ${ }^{6}$ The spiro-fused 2-azetidinone framework can be constructed by a Staudinger reaction of either a ketene in which the carbon-carbon double bond is originating from a ring structure (cyclic ketene) with a compound bearing an imino group, or a Staudinger reaction of a ketene with an imine in which the carbon-nitrogen double bond is originating from a ring structure (cyclic imine). Both alternatives have been employed in the literature, leading to two different types of spiro-fused 2-azetidinones. The reaction of a cyclic ketene with an imine affords C3 spiro-fused 2-azetidinones, whereas the reaction of an acyclic ketene with a cyclic imine forms C4 spiro-fused 2-azetidinones (Figure 1). Furthermore, different methodologies are available for the generation of ketenes, such as the use of acid chlorides in the presence of a base, the direct use of acids in the presence of a suitable acid activator and a base, and thermal and photochemical decompositions of $\alpha$-diazoketones. Recent years have also seen the application of greener technologies in the generation of ketenes. For example, the microwaveassisted, solvent-free cycloaddition reaction of chloroacetyl chloride with 3 -indolylimines has been reported to form spiro-fused 2-azetidinones. ${ }^{7}$

\subsubsection{Reactions of acyclic ketenes}

The use of the Staudinger cycloaddition for synthesising spiro-fused 2-azetidinones dates back to the 1960s, when Bose and coworkers reported the reaction of $N$-phenyl imines derived from cyclohexanone, cycloheptanone and $\mathrm{N}$-methylpiperidone with various acid chlorides, such as phenoxyacetyl chloride and azidoacetyl chloride, in the presence of tertiary amines to prepare spiro-fused 2-azetidinones. ${ }^{8}$ Almost at the same time, Fahr and coworkers reported the reaction of fluorenone $\mathrm{N}$-benzoyl hydrazone with diphenylketene to form a spiro-2-azetidinone. ${ }^{9}$ In the early 1980s, $\mathbf{N}$-phenyl imine 4 has also been used as a substrate by Shridhar and coworkers in a reaction with phthalimido acetic acid 5 to form spiro-fused 2-azetidinone 6 (Scheme 1). ${ }^{10}$ 
<smiles>c1ccccc1</smiles>

4<smiles>O=C(O)CN1C(=O)c2ccccc2C1=O</smiles>

5

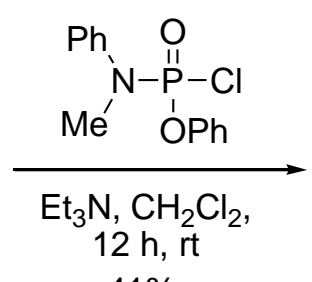

$41 \%$

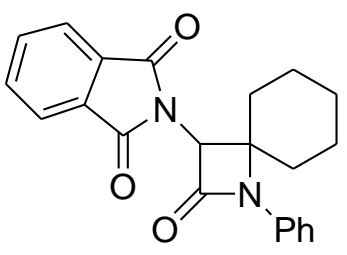

6

Scheme 1

Furthermore, Mehrotra and Singh have reported the reaction of diphenylketene, generated from the thermal decomposition of 2-diazo-1,2-diphenylethanone, with two acenaphthaquinone imines, forming the corresponding spiro- $\beta$-lactams. This reaction established the high reactivity of an imino group, as compared to a carbonyl group (ketone) towards diphenylketene. ${ }^{11}$ Benzil azine was isolated as a side product (3-5\%) in this reaction. Later on, this reaction was extended to 3iminobornan-2-ones and 3-arylimino- $N$-methylindolin-2-ones. ${ }^{12}$ This study has been further elaborated utilizing other diarylketenes such as di- $p$-tolylketene and di- $p$-anisylketene. ${ }^{13}$ Recently, the reactions of diarylketenes, obtained from 2-diazo-1,2-diarylethanones 7a-c, with 3-alkylimino$\mathrm{N}$-methylindolin-2-ones $\mathbf{8}$ have been reported to yield spiro-fused 2-azetidinones $\mathbf{9}$ in good yields (Scheme 2), but with poor-to-moderate antibacterial activity. ${ }^{13 c}$

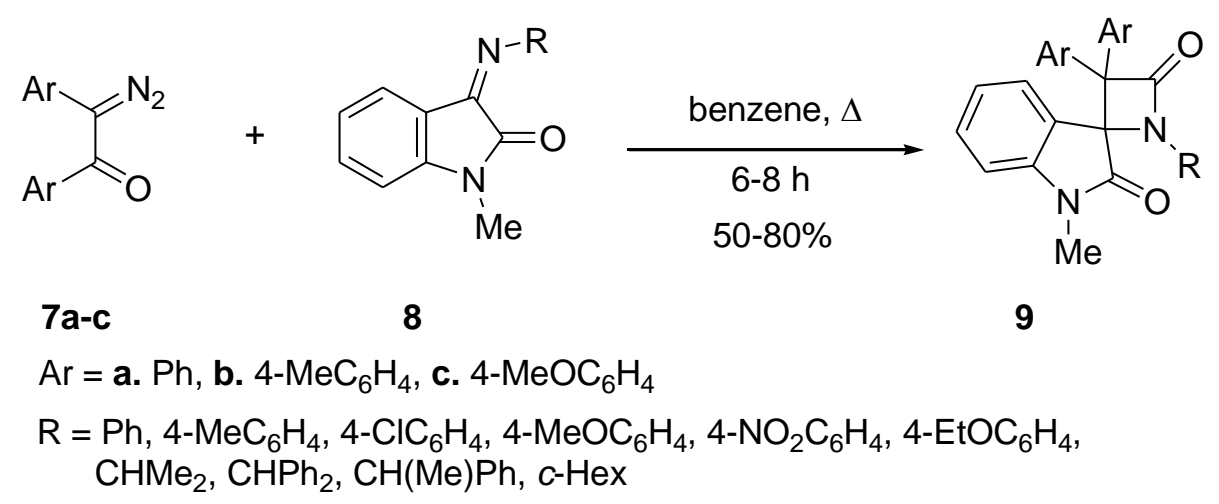

Scheme 2

In the recent past, the synthesis, reactivity and structure of isatin-derived, spiro-fused 2azetidinones have been studied by many groups. For example, the synthesis of isatin-derived mono- and bis-spiroazetidinones using the Staudinger reaction has been reported by Jarrahpour and Khalili. ${ }^{14}$ Bisimines $10 a-c$, obtained from the reaction of $\mathrm{N}$-benzylisatin with various diamines, 
were treated with different acyl chlorides 11a-d in the presence of triethylamine to give spirofused bis-2-azetidinones 12a-f in 50-70\% yield (Scheme 3). 3-Arylimino-1-methyl-2-indolinones have also been reacted with dichloroketene to afford the corresponding spiro-fused 2azetidinones. ${ }^{15}$ The reaction of acyclic ketenes with cyclic imines derived from indolin-2,3-dione has been reported to form spiroazetidin-2-ones as well. ${ }^{16,17}$

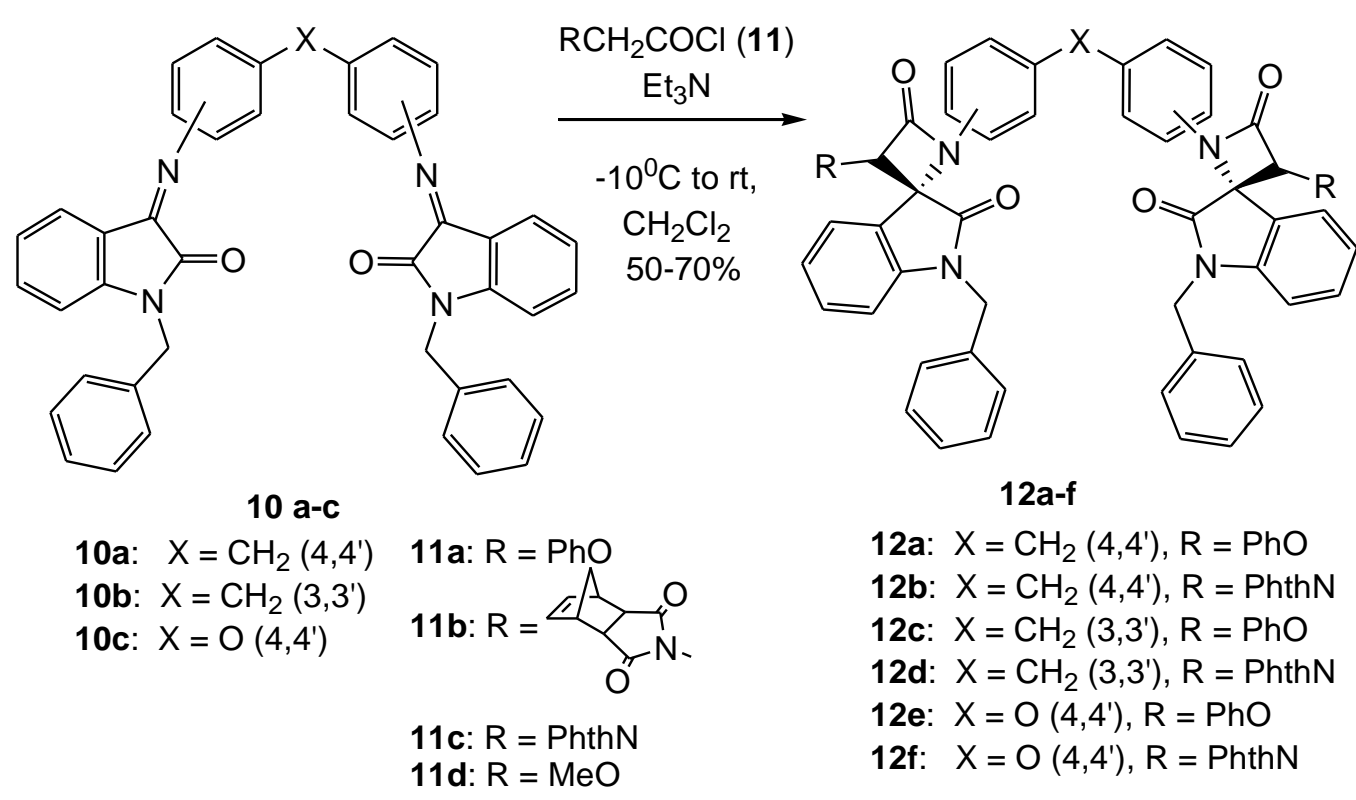

Scheme 3

The reactions of a variety of isocyanides (such as 13) with diphenylketene $\mathbf{1 4}$ have been shown to depend heavily on the concentration of diphenylketene. A high concentration of the ketene results in the formation of dioxolane derivatives, whereas the reactions follow an alternative path affording spiro-fused 2-azetidinones $\mathbf{1 5}$ and $\mathbf{1 6}$ at much lower concentrations, depending upon the molar ratios of isocyanide and diphenylketene used (Scheme 4). ${ }^{18}$ 

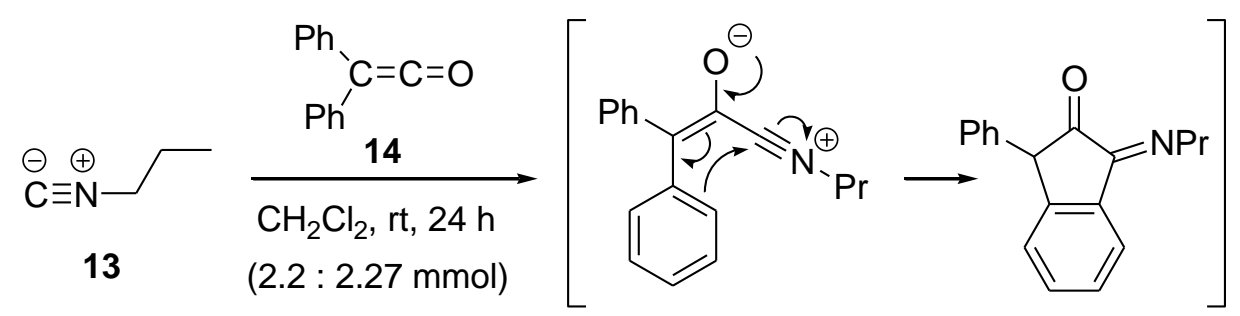

$(40 \%) \mid \begin{aligned} & \mathbf{1 4}(2.0: 4.0 \mathrm{mmol}) \\ & \mathrm{CH}_{2} \mathrm{Cl}_{2}, \mathrm{rt}, 16 \mathrm{~h}\end{aligned}$
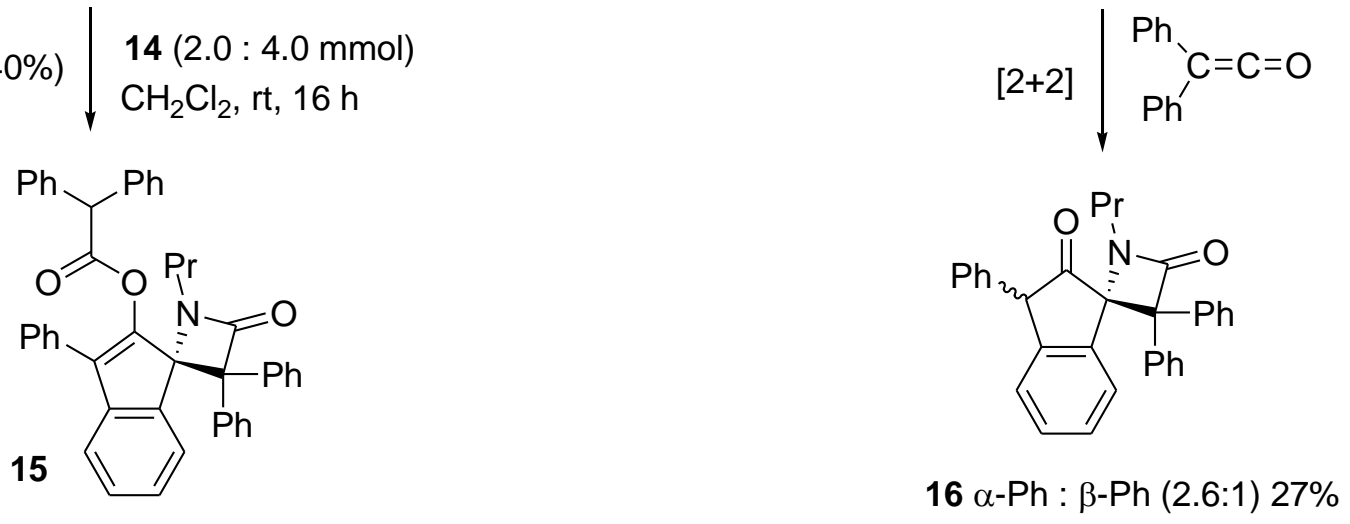

\section{Scheme 4}

The Staudinger reaction of isomaleimides 17 with acid chlorides 18 and 19 has been reported by Barba and co-workers to afford spiro-fused 2-azetidinones 20 and 21, respectively (Scheme 5). ${ }^{19}$ The reaction, however, required a low temperature of $-70{ }^{\circ} \mathrm{C}$ and a very long reaction time of over 30 hours. The Staudinger reaction of $N$-substituted bicyclic imine $\mathbf{2 2}$ with acid chlorides 11a and 23 led to the synthesis of spiro-fused 2-azetidinones 24 (Scheme 6). It was observed that the Staudinger reaction of imines derived from 7-oxanorbornenone with 2-alkoxyacetyl chlorides afforded the corresponding spiro-2-azetidinones with an exo geometry. ${ }^{20}$ The synthesis of some sulfur-containing spiroazetidinones has been reported as well using chloroacetyl chloride and thioglycolic acid as the ketene precursor. ${ }^{21}$ 


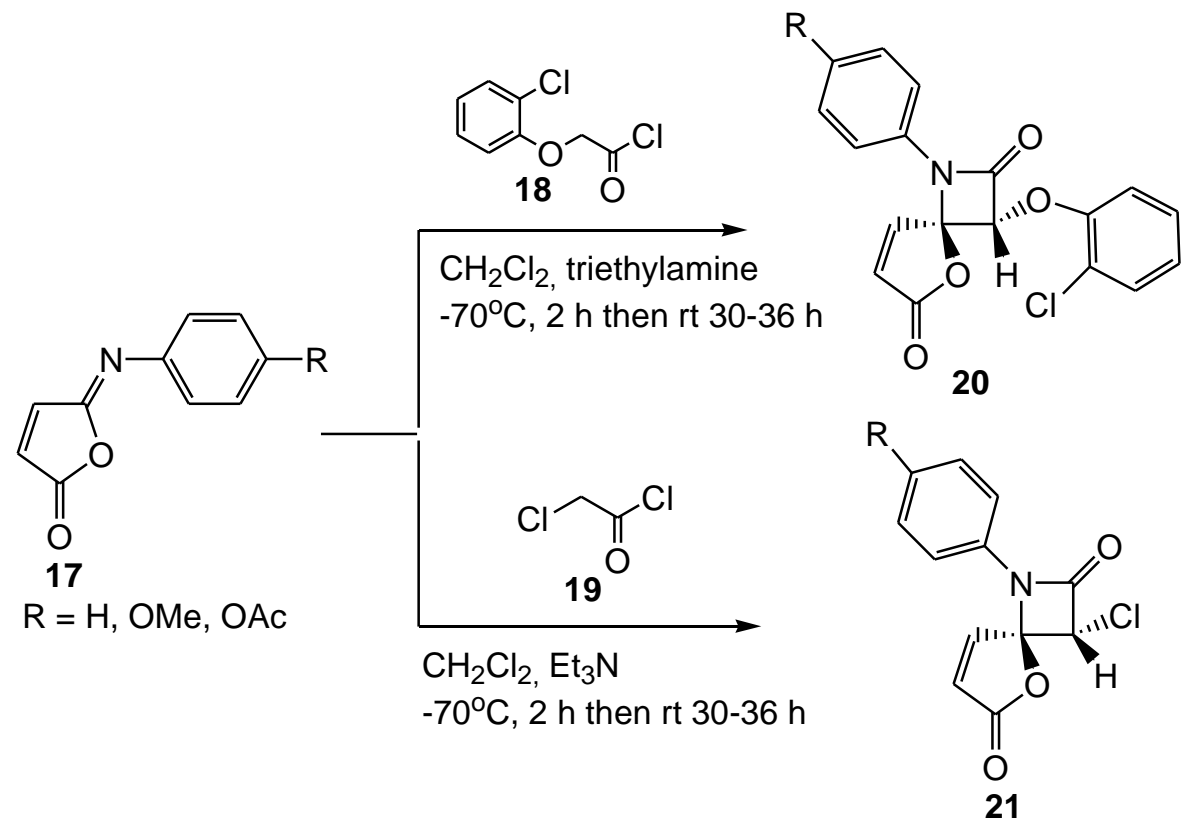

Scheme 5

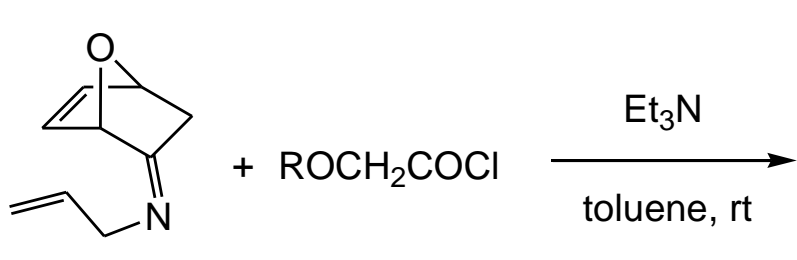

22

$11 a, 23 a, b$

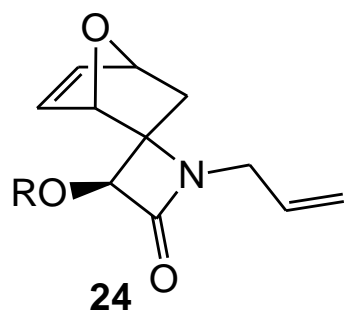

$\mathrm{R}=\mathrm{Ph}(\mathbf{1 1 a})(70 \%), \mathrm{Bn}(\mathbf{2 3 a})(70 \%), \mathrm{Ac}(\mathbf{2 3 b})(80 \%)$

Scheme 6

Rojas-Lima and co-workers have carried out the reactions of isomaleimides $\mathbf{2 5}$ with carboxylic acids $\mathbf{2 6}$ and $\mathbf{2 7}$ in the presence of triphosgene to synthesise spiro-fused 2-azetidinones $\mathbf{2 8}$ and 29, respectively, as mixtures of diastereomers (Scheme 7). ${ }^{22}$ 

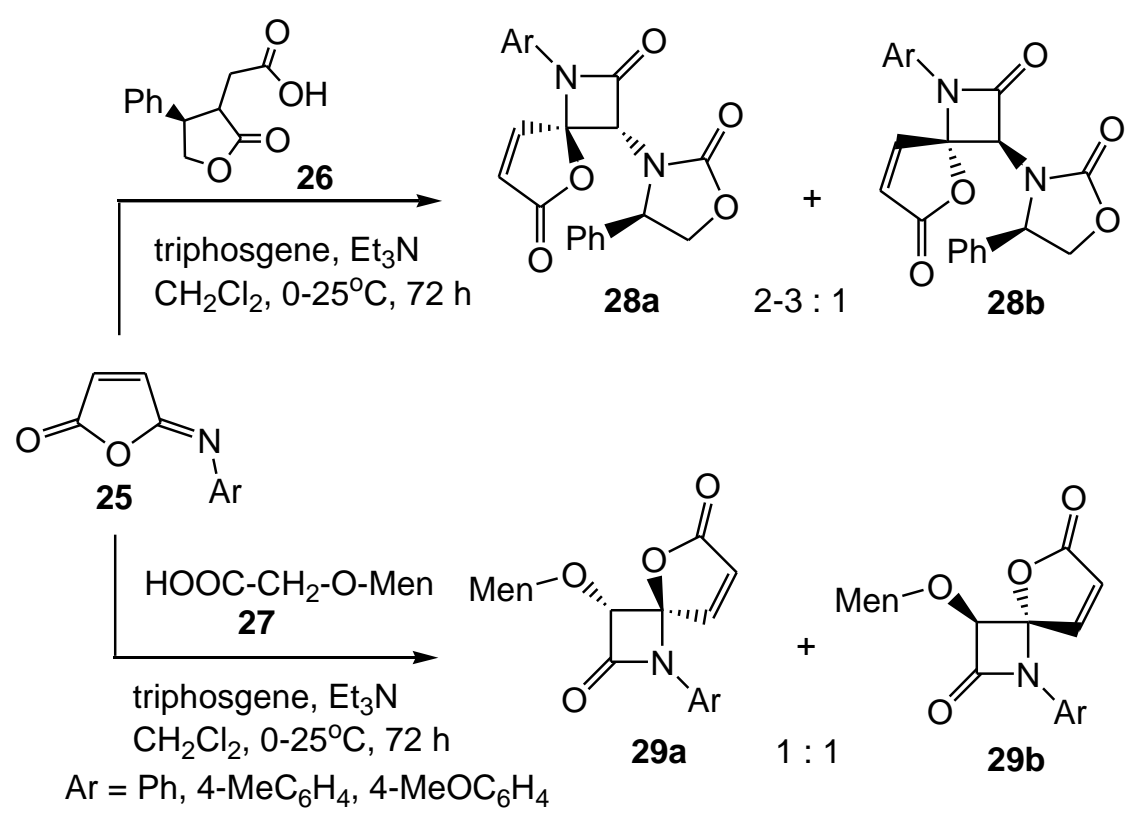

Scheme 7

\subsubsection{Reactions of cyclic ketenes}

Recently, the reactions of cyclic ketenes with imines have drawn considerable interest for the synthesis of spiro-fused 2-azetidinones. L-Proline, thiazolidine-2-carboxylic acids, xanthene carboxylic acid and some other suitably substituted acetic acids have been explored as precursors of ketenes in the synthesis of C3 spiro-fused 2-azetidinones. Reactions of imines $\mathbf{3 0}$ with unsymmetrical cyclic ketenes, derived from 2-tetrahydrofuroyl chloride $\mathbf{3 1}$ and 3tetrahydrofuroyl chloride 32, in the presence of triethylamine afforded cis- and trans-2azetidinones $\mathbf{3 3}$ and $\mathbf{3 4}$, respectively (Scheme 8). ${ }^{23}$ The nature of the substituents on the imines had a significant role in determining the stereochemical outcome of these reactions, as imines with at least one electron-donating substituent favoured the formation of cis-isomers, whereas imines with at least one electron-withdrawing substituent favoured the formation of transisomers. According to preliminary $a b$ initio calculations, the torquoelectronic effect was an important factor in determining the stereochemical course of the reaction. The experimental findings, however, showed steric and other electronic effects to be additionally important in determining the stereoselectivity of the reaction. 


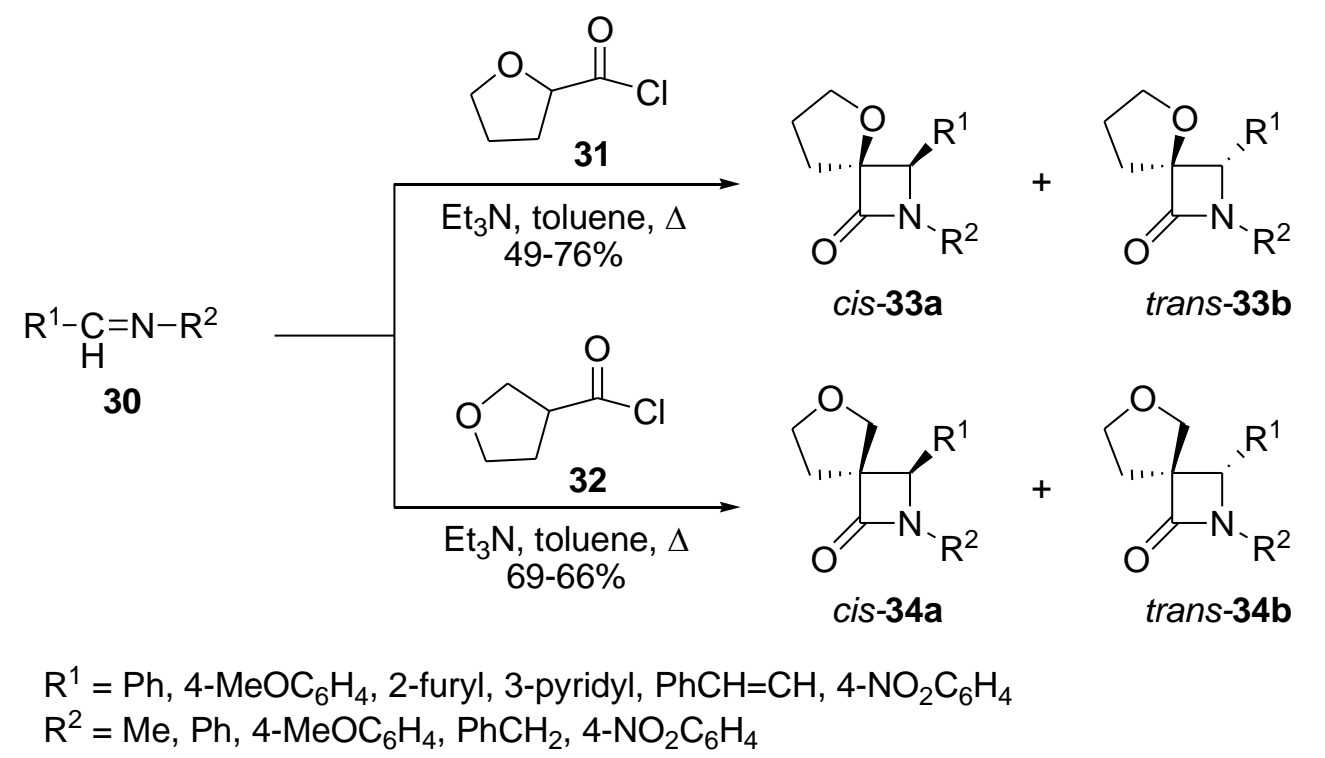

Scheme 8

The reactions of heterocyclic carboxylic acids/chlorides, such as $\mathrm{N}$-acylthiazolidine-2-carboxylic acids and the corresponding chlorides, oxazolidinecarboxylic acid and pyrrolidinecarboxylic acid, etc., have been explored by La Rosa and coworkers for the synthesis of spiro-fused 2azetidinones. ${ }^{24}$ The cyclodehydration of $\mathrm{N}$-acylthiazolidine-2-carboxylic acids leads to the formation of meso ionic compounds and their tautomeric ketenes. The cycloaddition reaction of ketenes derived from $\mathrm{N}$-acylthiazolidine-2-carboxylic acids 35a,b with $\mathrm{N}$ (phenylmethylene)benzenesulfonamide $\mathbf{3 6}$ led to the synthesis of diastereomeric spiro-2azetidinones 37a,b (minor) and 38a,b (major) (Scheme 9). ${ }^{24 a}$ An imidazole 39a,b was also formed in varying amounts when the reaction was carried out using acetic anhydride or DCC. 

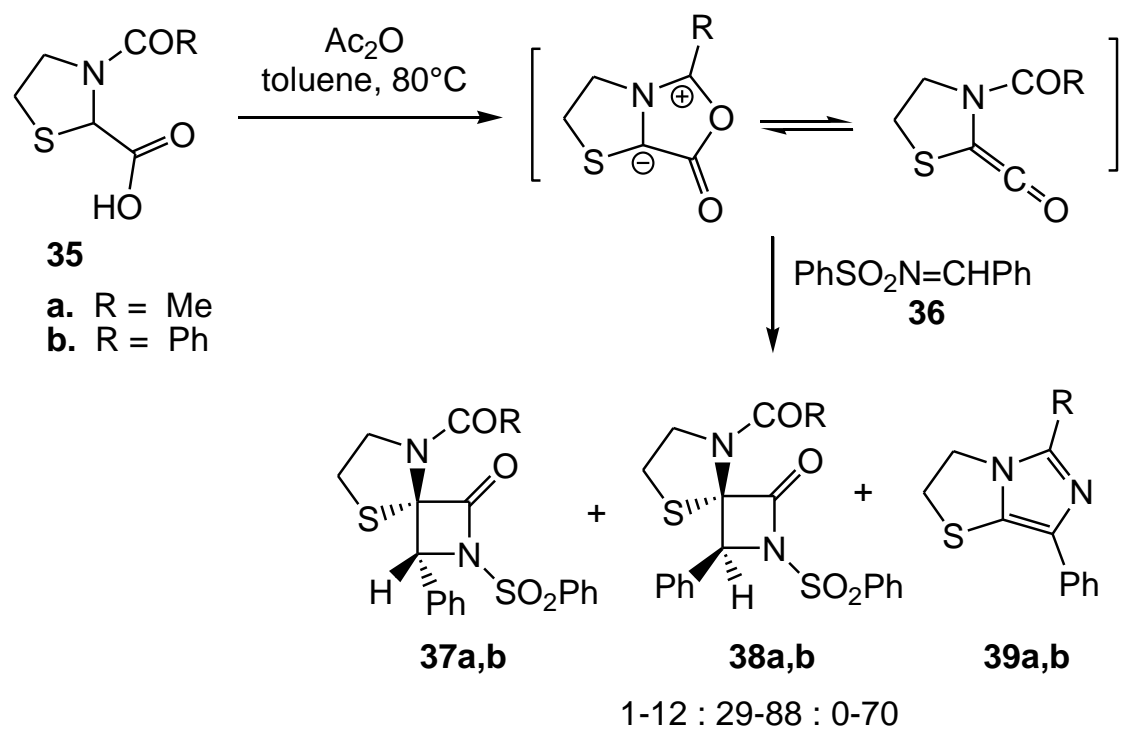

Scheme 9

The quest for a method for exclusive formation of spiro-fused 2-azetidinones revealed Mukaiyama's reagent - in the presence of a base - as the most appropriate acid activator. The reaction of an equimolar quantity of thiazolidine carboxylic acid 40 with $\mathrm{N}$ (benzylidene)benzylamine $\mathbf{3 0}\left(\mathrm{R}^{1}=\mathrm{Ph} ; \mathrm{R}^{2}=\mathrm{Bn}\right)$ in the presence of 2-chloro-1-methylpyridinium iodide (Mukaiyama's reagent) and triethylamine in dichloromethane under reflux afforded spiro-2-azetidinones 41a and 41b as a 1.8:1 mixture of diastereomers (Scheme 10). ${ }^{24,25}$ The reaction proceeded with excellent stereoselectivity, furnishing 2-azetidinones with a relative cisdisposition of the $\mathrm{N}$-Boc group and the phenyl group (trans according to the Cahn-Ingold-Prelog priority rules).

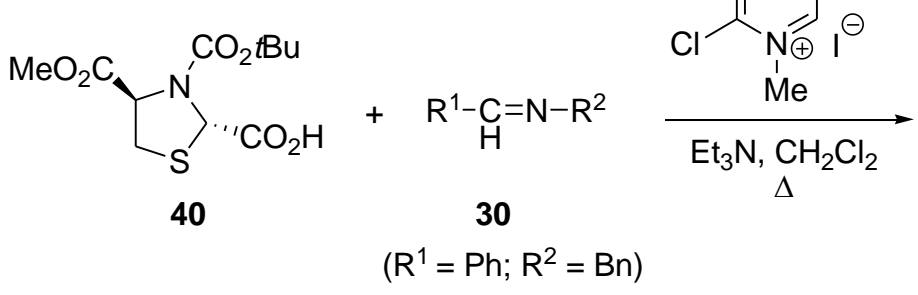

Scheme 10

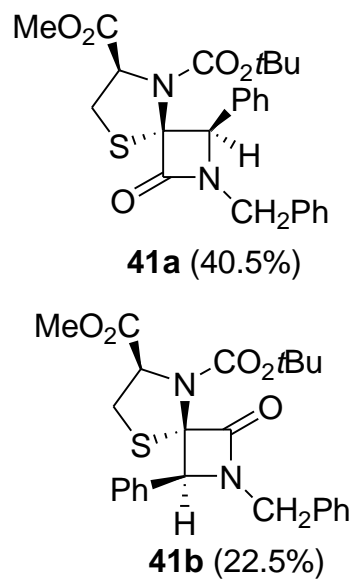


The reaction of the unsymmetrical cyclic ketenes derived from L-N-benzyloxycarbonylproline acid chlorides $\mathbf{4 2}$ with imine $\mathbf{3 0}\left(\mathrm{R}^{1}=\mathrm{Ph} ; \mathrm{R}^{2}=\mathrm{PMP}\right)$ to form 4-phenyl spiro-2-azetidinones $\mathbf{4 3 a}, \mathbf{b}$ (Scheme 11) has been reported by Gonzalez and coworkers. ${ }^{26}$ The products showed a cis relationship between the pyrrolidine nitrogen and the phenyl substituent at the C4-carbon of the azetidinone ring. This group then reported the reaction of acid chloride $\mathbf{4 2}$ with chiral imines 44a,b and 44c derived from glyceraldehyde acetonide and $N$-Boc-protected 1,3-oxazolidine-4carbaldehyde, respectively (Scheme 12), to prepare the corresponding spiro-fused 2azetidinones $\mathbf{4 5}$ a,b and $\mathbf{4 6}$ in enantiomerically pure forms. ${ }^{26,27}$ The reaction of this acid chloride has also been performed using methyleneimines to produce spiroazetidinones. ${ }^{28} \mathrm{~N}$ Benzyloxycarbonyl-4-mesyloxylproline acid chloride $\mathbf{4 7}$ has been treated with $\mathrm{N}$ (benzylidene)benzylamine $30\left(R^{1}=P h ; R^{2}=B n\right)$ to afford the spiroazetidinones $48 a$ and $48 b$ (Scheme 13). ${ }^{29}$ The formation of these products was explained by attack on the less hindered side of the ketene carbonyl by the imine, either via the $\alpha$ - or $\beta$-face approach, followed by conrotatory ring closure. The reaction of natural $\mathrm{O}, \mathrm{N}$-protected trans-4-hydroxy-L-prolines with $\mathrm{N}$-(benzylidene)benzylamine in the presence of Mukayama's reagent and triethylamine led to mixtures of diastereomeric, enantiomerically pure spiro-fused 2-azetidinones. ${ }^{30}$ Gonzalez and coworkers performed molecular modelling calculations using $a b$ initio methods on the spiroazetidinones synthesised from the reaction of the ketene derived from $\mathrm{N}$ benzyloxycarbonyl L-proline acid chloride with some imines. ${ }^{31}$ These calculations predicted that these systems could adopt a $\beta$-turn secondary structure in solution, with strong intramolecular hydrogen bonds stabilizing the U-turn conformation with a geometry that is very close to the ideal type II $\beta$-turns.

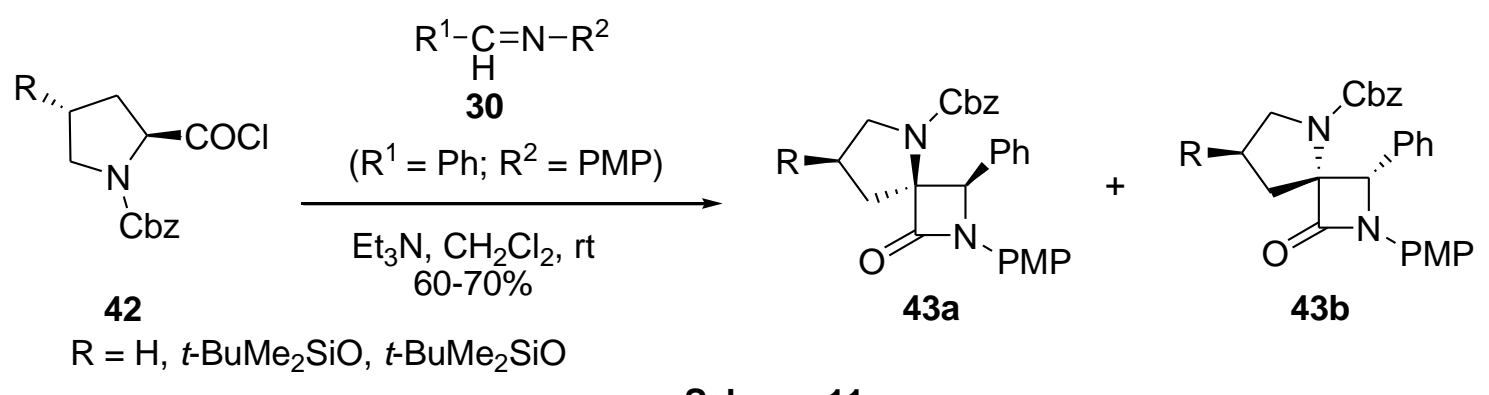

Scheme 11 

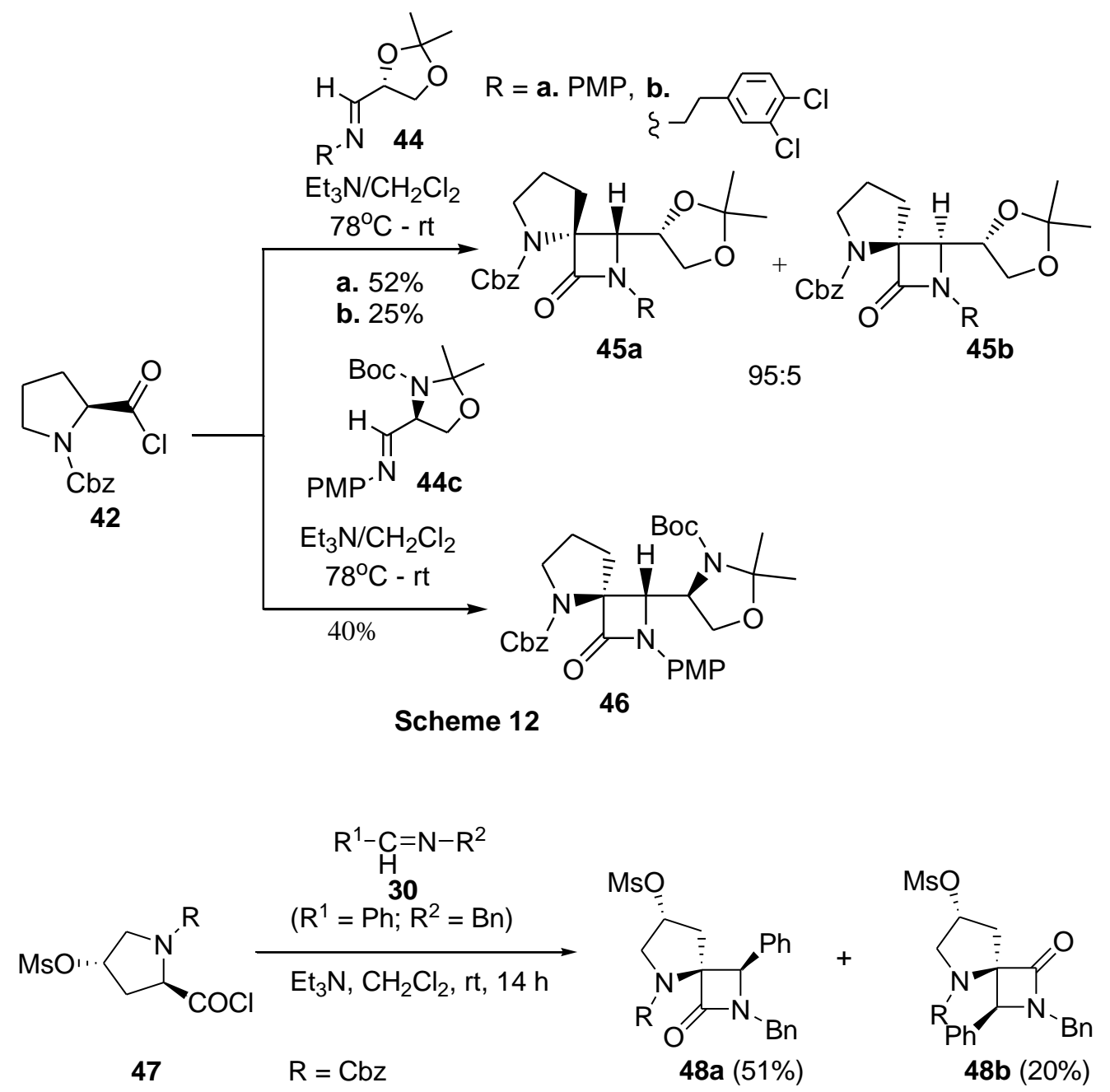

Scheme 13

A rigid bicyclic ketene derived from a bicyclic acyl chloride $\mathbf{4 9}$ and imines $\mathbf{3 0}$ has been used to synthesise highly constrained polycyclic spiro-2-azetidinones 50 (Scheme 14). ${ }^{32}$ Depending on the imine component, high diastereoselectivity was observed in the process, leading mainly to the cis diastereomer in the case of aromatic imines. This observation was attributed to an anti addition of the imine to the ketene, followed by a conrotatory ring closure in which the heteroatom at the 6-position of the scaffold rotates outwards because of torquoelectronic effects. The substituents on the imine nitrogen had a significant effect on the yields of products. The imine with an $N$-benzyl group afforded the highest yield of $66 \%$, whereas the imine with a 
p-tolyl group afforded the minimum yield of $14 \%$. The imine with a 4 -nitrophenyl group on the nitrogen did not react.

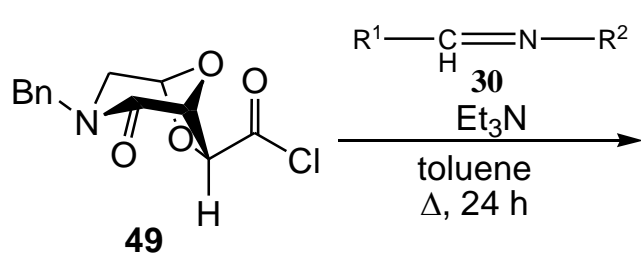

$$
\begin{aligned}
\mathrm{R}^{2}= & \mathrm{Bn}, 4-\mathrm{MeC}_{6} \mathrm{H}_{4}, \mathrm{CH}(\mathrm{Bn}) \mathrm{COOMe}, \\
& 4-\mathrm{NO}_{2} \mathrm{C}_{6} \mathrm{H}_{4} \text { or } 4-\mathrm{MeOC}_{6} \mathrm{H}_{4} \\
\mathrm{R}^{1}= & \mathrm{Ph}, 4-\mathrm{NO}_{2} \mathrm{C}_{6} \mathrm{H}_{4}, 4-\mathrm{MeOC}_{6} \mathrm{H}_{4} \text { or } 4-\mathrm{BrC}_{6} \mathrm{H}_{4}
\end{aligned}
$$

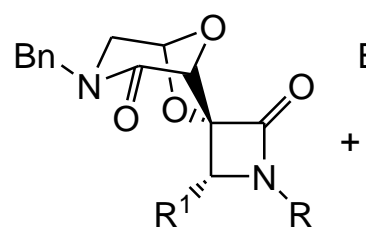

cis-50

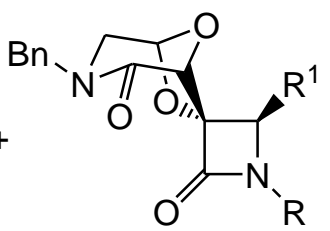

trans-50 $14-66 \%$

30

Scheme 14

The reaction of the chiral ketene, derived from D-(+)-glucose 51, with imines 30 led to the diastereoselective synthesis of spiro-2-azetidinones 52 (Scheme 15). ${ }^{33}$ From the four possible diastereoisomers, the reaction afforded only two diastereoisomers, with $\mathbf{5 2 a}$ being the major isomer and $\mathbf{5 2} \mathbf{b}$ the minor isomer. The formation of these stereoisomers led to the assumption that the torquoelectronic effect dominated the steric constraints. The diastereoselectivity was only moderate (Table 1), which was rationalised by proposing that the bulky 6,7-Oisopropylidene moiety, to some extent, prevented the attack of the imine from the bottom face, so that the zwitterionic intermediate 2 (Scheme 16) was formed to a lesser extent than the zwitterion 1 (Scheme 17), resulting in the observed proportion of diastereoisomers. A similar mechanism was proposed earlier by Khasanov and coworkers for explaining the formation of spiro-fused 2-azetidinones. ${ }^{29}$ 

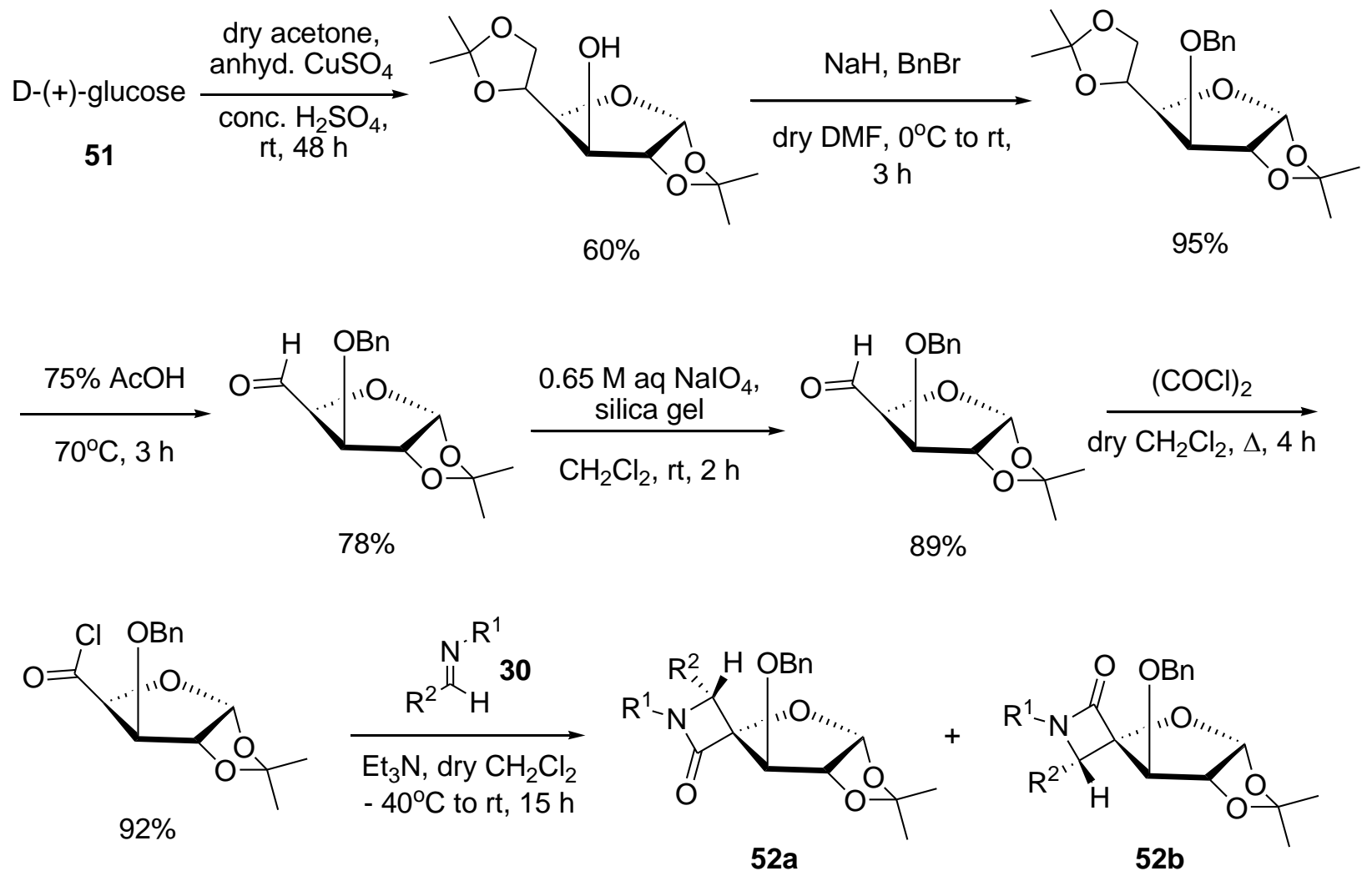

Scheme 15

Table 1. Synthesis of spiro-fused $\beta$-lactams $52 a, b$

\begin{tabular}{|c|c|c|c|c|}
\hline entry & $\mathrm{R}^{1}$ & $\mathbf{R}^{2}$ & $\begin{array}{c}\text { Yield } \\
\text { (\%) }\end{array}$ & $\begin{array}{c}d r \\
\text { (52a:52b) }\end{array}$ \\
\hline 1 & PMP & PMP & 65 & $70: 30$ \\
\hline 2 & $\mathrm{Ph}$ & PMP & 71 & $72: 28$ \\
\hline 3 & $\mathrm{Ph}$ & $\mathrm{Ph}$ & 62 & $70: 30$ \\
\hline 4 & PMP & $\mathrm{Ph}$ & 62 & $68: 32$ \\
\hline 5 & $4-\mathrm{ClC}_{6} \mathrm{H}_{4}$ & $\mathrm{Ph}$ & 59 & $65: 35$ \\
\hline 6 & $\mathrm{Ph}$ & styryl & 69 & 71:39 \\
\hline 7 & PMP & styryl & 67 & $68: 32$ \\
\hline 8 & $4-\mathrm{MeC}_{6} \mathrm{H}_{4}$ & $\mathrm{Ph}$ & 72 & $64: 36$ \\
\hline 9 & $\mathrm{Ph}$ & 4- $\mathrm{MeC}_{6} \mathrm{H}_{4}$ & 70 & $64: 36$ \\
\hline
\end{tabular}




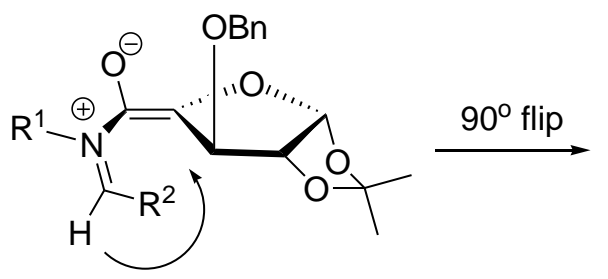

zwitterion 2

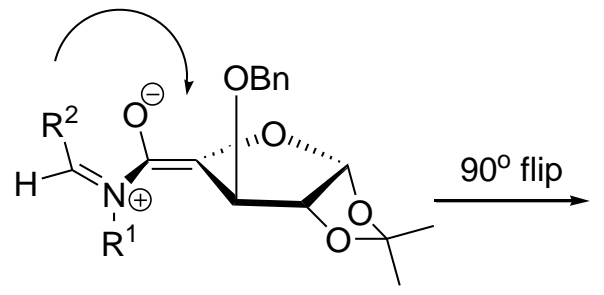

zwitterion 1

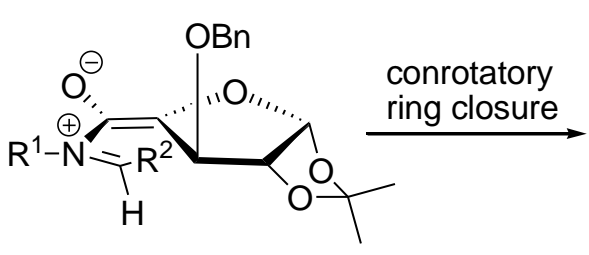

Scheme 16

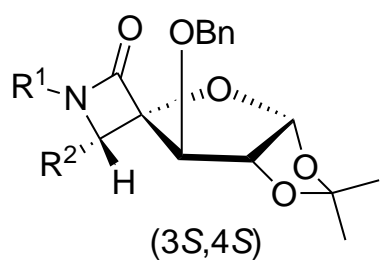

$(3 S, 4 S)$

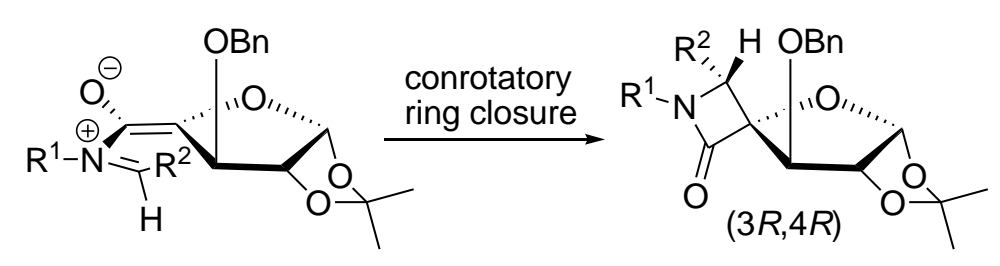

Scheme 17

The reactions of $9 \mathrm{H}$-xanthene-9-carboxylic acid $\mathbf{5 3}$ with imines 54, derived from the treatment of anthracene-9-carbaldehyde with several amines, in the presence of tosyl chloride and triethylamine have been reported recently to afford polycyclic spiro-fused 2-azetidinones $\mathbf{5 5}$ as single diastereomers (Scheme 18). ${ }^{34}$ The proposed spiro configuration at C3 was confirmed by X-ray crystallography of $\beta$-lactam $\mathbf{5 5}$ bearing a 4-methoxyphenyl group. The X-ray crystallography also showed that the 2-azetidinone ring was planar and perpendicular to the xanthene ring. The anthracene ring was observed to have a dihedral angle of $51.8^{\circ}$ with respect to the 2-azetidinone ring. Two imines derived from the reaction of 2-naphthaldehyde with $p$ anisidine and with 1-naphthylamine also yielded the corresponding spiroazetidinones in 40 and $50 \%$ yields, respectively. ${ }^{34}$ The reaction of $9 H$-xanthene-9-carboxylic acid $\mathbf{5 3}$ was extended to some bis-imines, derived from treatment of anthracene-9-carbaldehyde with diamines, forming novel bis-spiro-fused 2-azetidinones 56a-e (Figure 3). ${ }^{34}$ 
<smiles>O=C(O)C1c2ccccc2Oc2ccccc21</smiles>

53

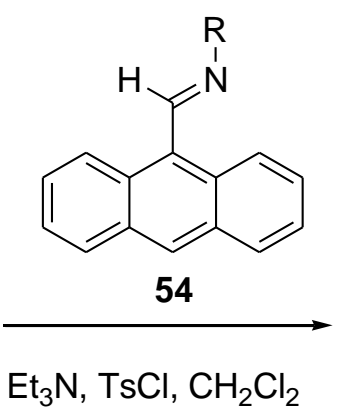

$25-91 \%$

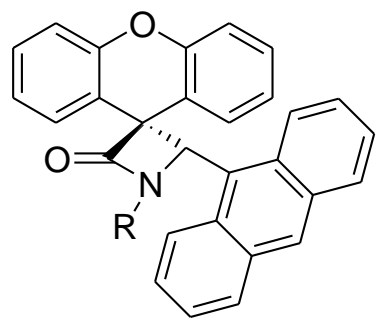

55

$\mathrm{R}=4-\mathrm{MeOC}_{6} \mathrm{H}_{4}, 3-\mathrm{MeOC}_{6} \mathrm{H}_{4}, 2-\mathrm{MeOC}_{6} \mathrm{H}_{4}, \mathrm{Ph}, 4-\mathrm{ClC}_{6} \mathrm{H}_{4}, 3-\mathrm{NO}_{2} \mathrm{C}_{6} \mathrm{H}_{4}$,

2-Et, 3- $\mathrm{BrC}_{6} \mathrm{H}_{4}, 2,4-$ di- $\mathrm{MeOC}_{6} \mathrm{H}_{3}, 3,4-$ di- $-\mathrm{MeOC}_{6} \mathrm{H}_{3}, c$ - Hex, 1-naphthyl

Scheme 18

The $\alpha$-oxoketenes, generated by pyrolysis of 2 -aryl-substituted 1,5,7-trioxaspiro[2,5]octane-4,8diones $\mathbf{5 7}$, reacted with imines $\mathbf{3 0}$ to give diastereomeric 2 -azetidinones, spiro-fused to $1,3-$ dioxolan-4-ones 59 and 60 (Table 2). ${ }^{35}$ The proposed mechanism for the generation of ketenes involves an intramolecular rearrangement between the oxirane ring and the carbonyl group in compounds 57 forming bicycles 58, which undergo another intramolecular rearrangement under anhydrous conditions forming $\alpha$-oxoketenes (Scheme 19). 


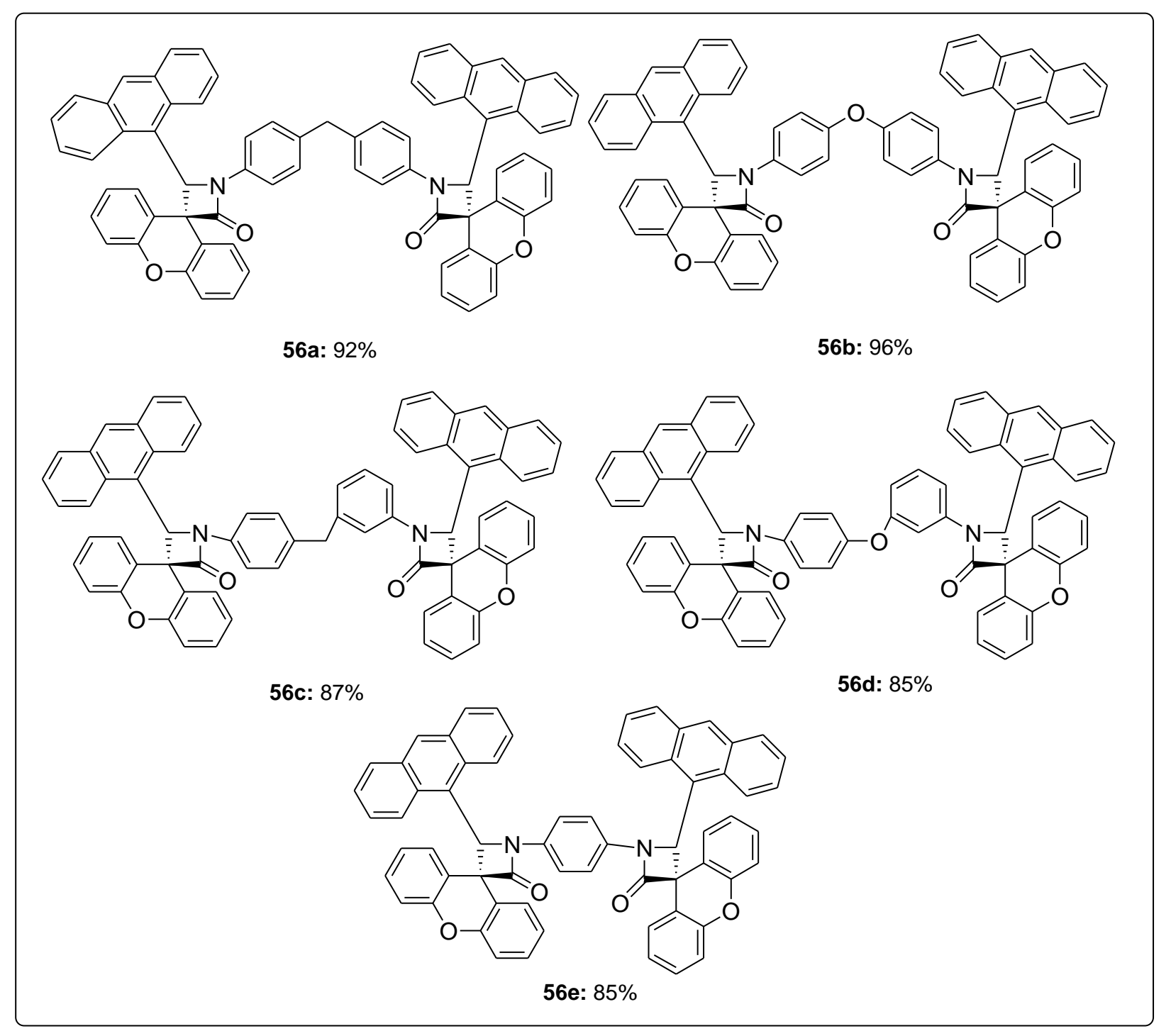

Figure 3 


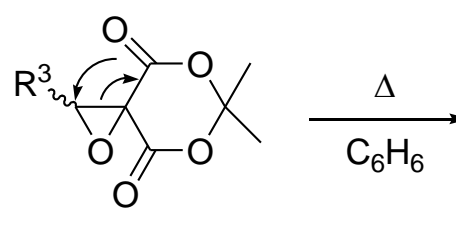

57

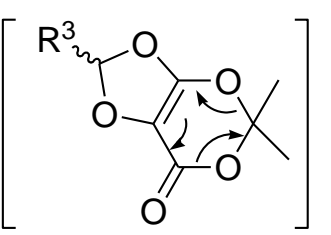

58

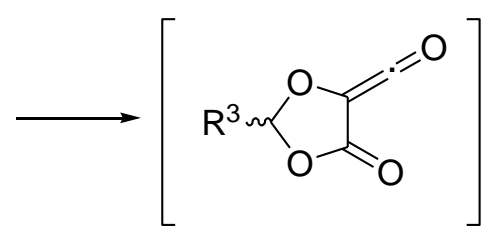

$\mid \begin{gathered}\mathrm{R}^{1}-\mathrm{C}=\mathrm{N}-\mathrm{R}^{2} \\ \mathrm{H}_{\mathbf{3}}\end{gathered}$<smiles>[R]C1OC(=O)[C@]2(O1)C(=O)N([R])[C@@H]2[R]</smiles>

59<smiles>[R7]C1OC(=O)[C@@]2(O1)C(=O)N([R])[C@@H]2[PH]</smiles>

60

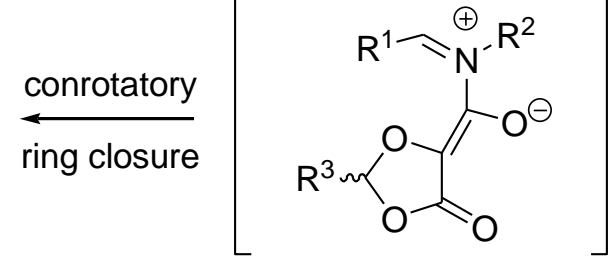

\section{Scheme 19}

Table 2. Synthesis of spiro-fused $\beta$-lactams 59 and 60

\begin{tabular}{ccccc}
\hline $\mathbf{R}^{3}$ & $\mathbf{R}^{\mathbf{2}}$ & $\mathbf{R}^{\mathbf{1}}$ & $\begin{array}{c}\text { Yield } \mathbf{5 9} \\
\text { (\%) }\end{array}$ & $\begin{array}{c}\text { Yield 60 } \\
\text { (\%) }\end{array}$ \\
\hline $\mathrm{Ph}$ & $\mathrm{Ph}$ & $\mathrm{Ph}$ & 17 & 24 \\
$4-\mathrm{BrC}_{6} \mathrm{H}_{4}$ & $\mathrm{Ph}$ & $\mathrm{Ph}$ & 16 & 16 \\
$4-\mathrm{ClC}_{6} \mathrm{H}_{4}$ & $\mathrm{Ph}$ & $\mathrm{Ph}$ & 13 & 21 \\
$3-\mathrm{MeC}_{6} \mathrm{H}_{4}$ & $\mathrm{Ph}$ & $\mathrm{Ph}$ & 22 & 37 \\
$3-\mathrm{MeOC}_{6} \mathrm{H}_{4}$ & $\mathrm{Ph}$ & $\mathrm{Ph}$ & 31 & 40 \\
$\mathrm{Ph}_{4}$ & $\mathrm{Ph}$ & $4-\mathrm{ClC}_{6} \mathrm{H}_{4}$ & 13 & 12 \\
$3-\mathrm{MrC}_{6} \mathrm{H}_{4}$ & $\mathrm{Ph}$ & $4-\mathrm{ClC}_{6} \mathrm{H}_{4}$ & 41 & 37 \\
$3-\mathrm{MeOC}_{6} \mathrm{H}_{4}$ & $\mathrm{Ph}$ & $4-\mathrm{ClC}_{6} \mathrm{H}_{4}$ & 29 & 36 \\
$\mathrm{Ph}_{3-\mathrm{MeC}_{6} \mathrm{H}_{4}}$ & $\mathrm{Ph}$ & $4-\mathrm{ClC}_{6} \mathrm{H}_{4}$ & 32 & 40 \\
$4-\mathrm{BrC}_{6} \mathrm{H}_{4}$ & $\mathrm{Ph}$ & $4-\mathrm{MeOC}_{6} \mathrm{H}_{4}$ & 17 & 21 \\
$3-\mathrm{MeC}_{6} \mathrm{H}_{4}$ & $4-\mathrm{MeC}$ & 26 & 32 \\
\hline
\end{tabular}




\subsubsection{Reaction of isocyanates with ketene- $N, S$-acetals}

An example of isocyanate-alkene cycloadditions leading to spiro-fused 2-azetidinones has been reported by Zhou and coworkers. N-Methyl cyclic ketene-N,S-acetal 61 reacted with $(E)-1-$ isocyanato-2-phenylethene $\mathbf{6 2}(\mathrm{R}=\mathrm{Ph})$ or $(E)$-1-isocyanato-1-butene $\mathbf{6 2}(\mathrm{R}=\mathrm{Et})$ to form the corresponding spiro-fused 2-azetidinones 63 through zwitterionic intermediates A (Scheme 20). The highly nucleophilic nitrogen atom of the isocyanate moiety in the latter intermediates induced cyclisation at the ring carbon to furnish the observed products. ${ }^{36}$<smiles>CC(C)=C1SCCN1C</smiles>

61<smiles>[R]C=C[N+](=O)[O-]</smiles>

62

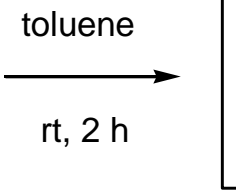

Scheme 20

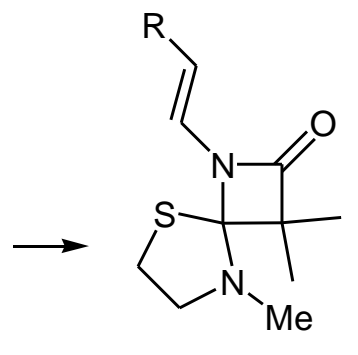

63
A

Cycloaddition reactions of ketenes and imines have been widely employed in the synthesis of spiro-fused 2-azetidinones, and diverse types of imines and ketene precursors have been used to accomplish this reaction. In recent years, heterocyclic ketene precursors have drawn considerable interest. For example, an equimolar reaction of diphenylketene with isocyanides afforded the [4+2] cycloaddition product, whereas a 2:1 molar reaction afforded 2-azetidinones as the $[2+2]$ cycloaddition products. ${ }^{18}$ In one case, theoretical calculations indicated torquoelectronic effects dominating, but the experimental findings suggested steric and other electronic factors determining the course of the reactions. ${ }^{23}$ The experimental findings of Deshmukh and coworkers showed that the torquoelectronic effects dominated the steric constraints. $^{33}$ It is thus evident that the product and stereochemical outcome of the Staudinger reaction depends on the nature of the substrates. Isatin-based spiro-2-azetidinones have drawn wide attention, probably due to biological activity associated with the indolinone ring, ${ }^{37}$ and also its presence in the naturally occurring chartellines. 


\subsection{Cyclisation reactions}

Cyclisations of $\beta$-amino acids and $\beta$-functionalised amides are old and classical methods to synthesise 2-azetidinones, and these approaches have been employed as well to prepare 2azetidinones bearing a spiro framework. Ikeda and coworkers have reported the photocyclisation of 2-(N-acyl- $N$-alkylamino)cyclohex-2-enones leading to the formation of spiro-fused 2azetidinones in $1986 .{ }^{38}$ Cyclisation reactions mostly afford 2-azetidinones with the C3 carbon as the spiro atom. Examples are known, however, of some oxidative cyclisations and radical reactions which lead to the formation of $\mathrm{C} 4$ spiro-fused 2-azetidinones.

An L-proline-catalysed Mannich reaction of cyclopentane carbaldehyde 64 with $\alpha$-iminoester 65 furnished $\beta$-formyl amino ester 66, which underwent oxidation to the carboxylic acid 67. The cyclodehydration of the latter compound with sodium hydroxide yielded the cyclopentane-spirofused azetidin-2-one 68 (Scheme 21). ${ }^{39}$

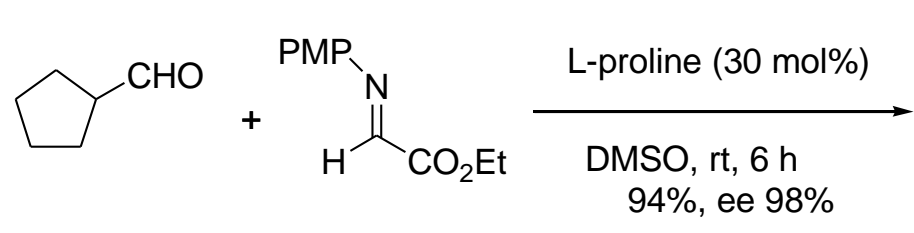

64
65<smiles>CCOC(=O)[C@H](NP)C1(C=O)CCCC1</smiles>

66

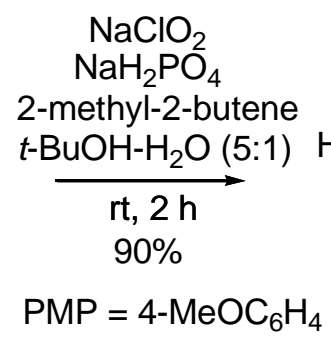

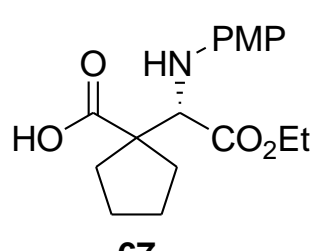

67 $\underset{\text { 1) } 1 \text { equiv. aq } \mathrm{NaOH}(1 \mathrm{M})}{\longrightarrow}$
$\begin{gathered}80 \% \\ \text { 2) }\end{gathered}$

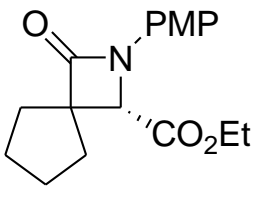

68

\section{Scheme 21}

Activation of the hydroxyl group in 3-hydroxy-3-arylpropanamide 69 by transformation into a phosphonate followed by cyclisation yielded spiroazetidin-2-one 70 (Scheme 22). ${ }^{40}$ The $\beta$-chloro amide 73, formed from chlorination and subsequent reaction of 1-benzyl-3(chloromethyl)azetidine-3-carboxylic acid 71 with amines $\mathbf{7 2}$, cyclised on treatment with sodium hydride in tetrahydrofuran to afford the spiro-fused 2-azetidinone 74 (Scheme 23). ${ }^{41}$ 
<smiles>O=C1CCC(C(=O)Nc2ccc(F)cc2)([C@H](O)c2ccc(OCc3ccccc3)cc2)CC1</smiles>

69

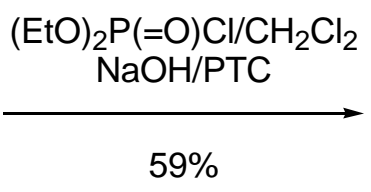

$\mathrm{PTC}=\mathrm{BnNEt}_{3} \mathrm{Cl}$

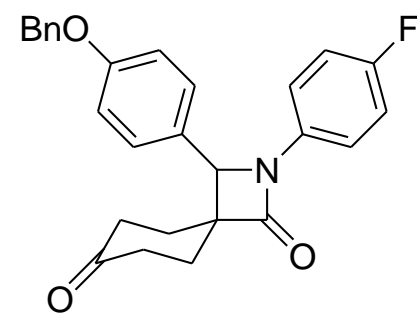

70

\section{Scheme 22}

1. $(\mathrm{COCl})_{2}, \mathrm{CH}_{2} \mathrm{Cl}_{2}$

2. $\mathrm{RNH}_{2} 72, \mathrm{Et}_{3} \mathrm{~N}$,<smiles>O=C(O)C1(CCl)CN(Cc2ccccc2)C1</smiles>

71
$\mathrm{CH}_{2} \mathrm{Cl}_{2}, 5^{\circ} \mathrm{C}$

Scheme 23

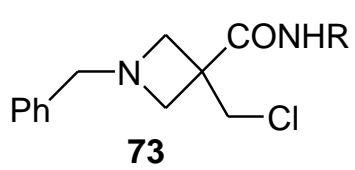

$\mathrm{NaH}, \mathrm{THF}, \mathrm{rt}$ $46-97 \%$

d. $2,6-\mathrm{Me}_{2} \mathrm{C}_{6} \mathrm{H}_{3}$, e. $4-\mathrm{MeOC}_{6} \mathrm{H}_{4}$,

f. $\mathrm{Et}_{2} \mathrm{~N}\left(\mathrm{CH}_{2}\right)_{3}$, g. $\mathrm{PhOCH}_{2}$

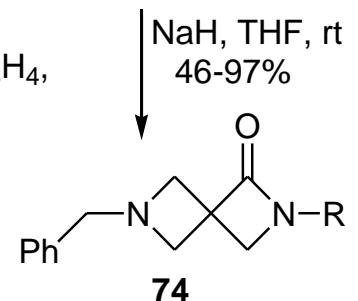

The cyclisation of enolates from glycine derivatives $75\left(R^{3}=H\right)$, generated from $N$-nicotinoyl and $N$-isonicotinoyl glycine, and the corresponding alanine derivatives $\left(R^{3}=M e\right)$ took place with dearomatisation of the pyridine ring forming 2-azetidinones $\mathbf{7 6}$ spiro-fused to a dihydropyridine moiety (Scheme 24). ${ }^{42}$ These reactions occur with a benzylic group at the amide nitrogen as well. ${ }^{43}$<smiles>[R]C(C)N(C(=O)c1ccncc1)C([R])C(C)OC(C)C</smiles>

75

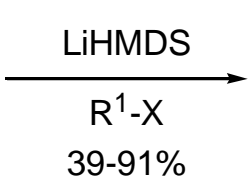

$39-91 \%$<smiles>[R7]OC1([R])N([C@H]([R])C)C(=O)C12C=CNC=C2</smiles>

76

a. $\mathrm{R}^{1}=\mathrm{CO}_{2} \mathrm{Me}, \mathrm{R}^{2}=t \mathrm{Bu}, \mathrm{R}^{3}=\mathrm{H}$; b. $\mathrm{R}^{1}=\mathrm{CO}_{2} \mathrm{Me}, \mathrm{R}^{2}=\mathrm{CH}_{2} \mathrm{Ph}, \mathrm{R}^{3}=\mathrm{H}$;

c. $\mathrm{R}^{1}=\mathrm{CO}_{2} \mathrm{Me}, \mathrm{R}^{2}=\mathrm{C}(\mathrm{Me})_{2} \mathrm{Ph}, \mathrm{R}^{3}=\mathrm{H}$; d. $\mathrm{R}^{1}=\mathrm{CO}_{2} \mathrm{Me}, \mathrm{R}^{2}=4-\mathrm{MeOC}_{6} \mathrm{H}_{4}$,

$\mathrm{R}^{3}=\mathrm{H}$; e. $\mathrm{R}^{1}=\mathrm{CO}_{2} \mathrm{Me}, \mathrm{R}^{2}=4-\mathrm{MeOC}_{6} \mathrm{H}_{4} \mathrm{CH}_{2}, \mathrm{R}^{3}=\mathrm{H}$; f. $\mathrm{R}^{1}=\mathrm{CO}_{2} \mathrm{Me}$, $\mathrm{R}^{2}=4-\mathrm{MeOC}_{6} \mathrm{H}_{4} \mathrm{CH}_{2}, \mathrm{R}^{3}=\mathrm{Me}$

Scheme 24 
The radical-initiated 4-exo-trig cyclisation of $\mathrm{N}, \mathrm{N}$-disubstituted trichloroacetamide 77 upon treatment with tributyltin hydride in toluene at room temperature yielded an azetidin-2-one $\mathbf{7 8}$ in $35 \%$ yield (Scheme 25 ). ${ }^{44}$<smiles>CN(C(=O)OC(Cl)(Cl)Cl)C1=C(S)CCCC1</smiles>

77

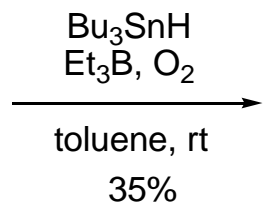

Scheme 25<smiles>COC(=O)C1(Cl)C(=O)N(Cc2ccccc2)C12CCCCC2=O</smiles>

78

4-Aminophenol-derived amides 79 have been reported to undergo oxidative dearomatisation upon treatment with iodobenzene diacetate and copper(II) sulfate pentahydrate, followed by cyclisation to form the spiro-fused 2-azetidinones 80 (Scheme 26). ${ }^{45}$ This reaction represents an example of carbon-carbon bond formation during the cyclisation step.

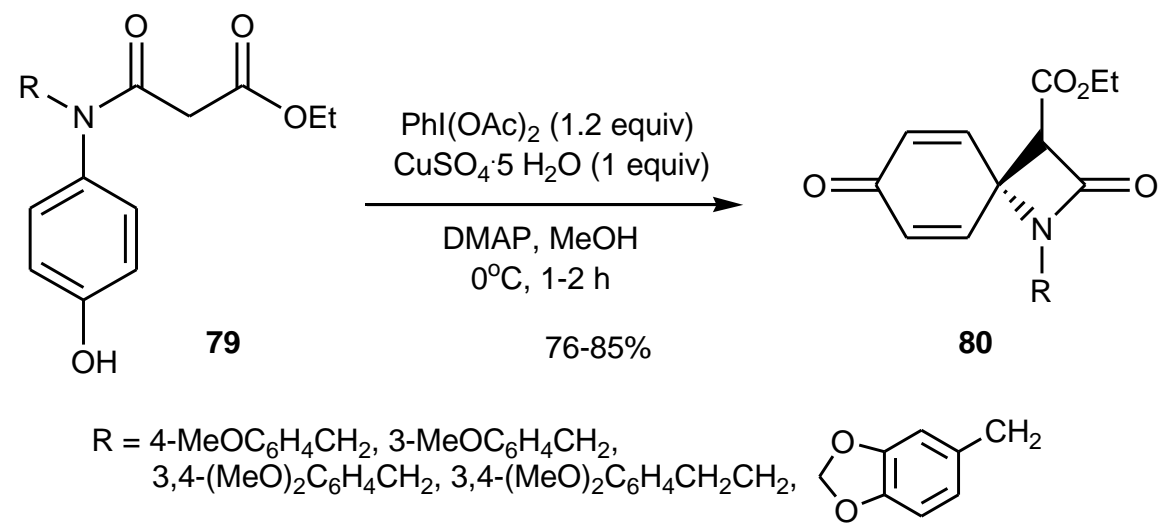

Scheme 26

Gmeiner and coworkers have devised a methodology to synthesise spiro-fused 2-azetidinones starting from natural prolines by using Seebach's self-reproduction of a chiral methodology in combination with a peptide-coupling reaction and Grubbs' ring-closing metathesis. ${ }^{46,47}$ Thus, $\alpha$ vinyl- $N$-Boc proline $\mathbf{8 1}$ has been converted via amides 82 and $\beta$-hydroxy amides 83 into spirofused 2-azetidinones 84 (Scheme 27). 
<smiles>C=CC1(C(=O)O)CCCN1C(=O)OC(C)(C)C</smiles>

81<smiles>COC(=O)C(C)N</smiles>

$R=\mathbf{a} \cdot H(64 \%)$

b. DCBB $(92 \%)$<smiles>C=C[C@]1(C(=O)NC(P)C(=O)OC)CCCN1C(=O)OC(C)(C)C</smiles>

82
1. $\mathrm{O}_{3}, \mathrm{CH}_{2} \mathrm{Cl}_{2}$

$-78^{\circ} \mathrm{C}$

2. $\mathrm{Na}\left[\mathrm{BH}(\mathrm{OAc})_{3}\right]$

$\mathrm{rt}, 6-24 \mathrm{~h}$

$\mathrm{R}=$ a. $\mathrm{H}(77 \%)$

b. DCBB $(86 \%)$

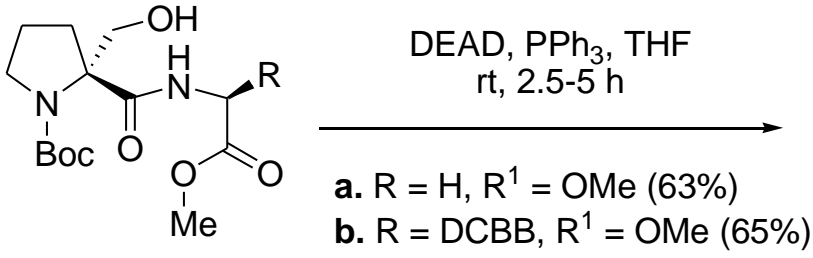

83 b. $R=D C B B, R^{1}=\mathrm{OMe}(65 \%)$

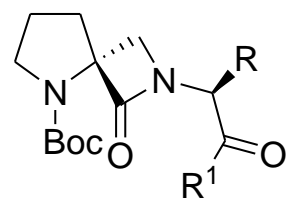

84

\section{Scheme 27}

The cyclisation of alkyl hydroxamates $\mathbf{8 5}$, mediated by phenyliodine(III) bis(trifluoroacetate), has been described to lead to the formation of spirodienone 2-azetidinones 86 (Scheme 28). ${ }^{48}$ Oxidative dearomatisation occured in this case, resulting in the formation of a carbon-nitrogen bond. When the reaction was carried out in dichloromethane and methanol, a minor amount (26\%) of spiroazetidinone 87 was also obtained by conjugate addition of methanol to the dienone system. The formation of this product was eliminated by carrying out the reaction in dichloromethane only. Benzylic strain in the nitrenium ion intermediate was responsible for the selective formation of anti-2-azetidinones.<smiles>[R7]NC(=O)[C@H]([R7])c1ccc(OC)cc1OC</smiles>

85

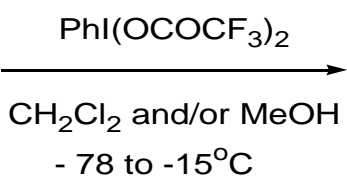

-78 to $-15^{\circ} \mathrm{C}$

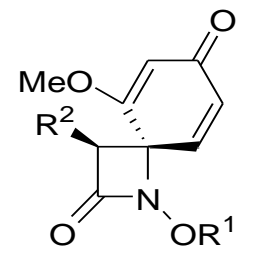

86

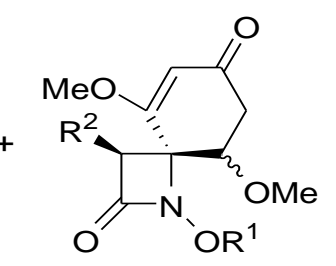

87

86. a. $\mathrm{R}^{1}=\mathrm{Me}, \mathrm{R}^{2}=\mathrm{H}\left(67 \% ; 53 \%\right.$ in $\left.\mathrm{CH}_{2} \mathrm{Cl}_{2}+\mathrm{MeOH}\right)$

b. $R^{1}=B n, R^{2}=H(86 \%)$

87. $R^{1}=M e, R^{2}=H(26 \%)$

\section{Scheme 28}

Baran's approach to synthesise chartelline started from a simple $\alpha$-amino ester $\mathbf{8 8}$, which was transformed into a complex amide 89 through a number of steps. ${ }^{49}$ The bromination of the 
latter amide 89 with $\mathrm{N}$-bromosuccinimide, followed by intramolecular cyclisation of the resulting $\beta$-bromo amide 90, led to the formation of spiro-fused 2-azetidinone 91 (Scheme 29). In the total synthesis of chartelline $C$ by the same group, $\beta$-bromo amide 89 was cyclised using potassium carbonate in the presence of 18 -crown- $6 .{ }^{5}$ It is worth mentioning that chartellines $A$, B, and C 1-3 (Figure 2) have been isolated in the 1980s from the marine bryozoans, Chartella papyracea, collected from the North sea. ${ }^{50}$ Although the chartellines lacked biological activity, they remained targets of interest, due to their novel and complex structure. The 2-azetidinone ring in chartellines is spiro-fused to the indoline ring and fused to the 10-membered imidazoazacyclodecadiene ring. The structure of chartelline A was confirmed by X-ray crystallography, showing the ten-membered ring to adopt a rigid tube-like conformation and the indoline ring to reside perpendicularly to the azetidinone ring and almost parallel to the imidazole ring.

OTBS

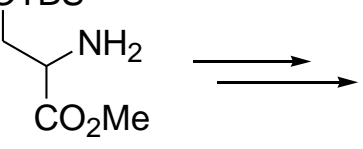

88

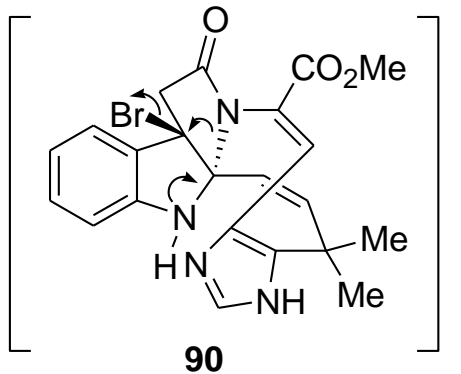

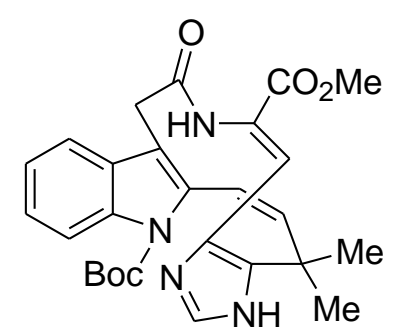

89
1. $180^{\circ} \mathrm{C}$

2. $\mathrm{NBS}, \mathrm{KHCO}_{3}$

$\mathrm{THF} / \mathrm{H}_{2} \mathrm{O}$
$[1,2]$

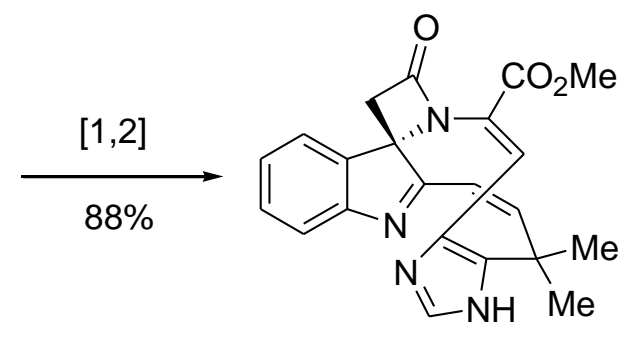

91

Scheme 29

\subsection{Transformations of substituents connected to monocyclic 2-azetidinones}

The chemistry of substituents at monocyclic 2-azetidinone rings has been explored frequently for the construction of spiro-fused frameworks. One of the first reports of such a strategy has been published by Bose and coworkers and consisted of the reaction of 4-oxo-1phenylazetidine-2,2-dicarboxylic acid with different carbodiimides to form spiro-fused 2- 
azetidinones. ${ }^{51}$ More recently, Alcaide and coworkers have explored a metal-catalysed, ringclosing metathesis of 2-azetidinone-tethered $\alpha$-allenols 92 for the synthesis of spiroheterocycles including spiro-fused 2-azetidinones 93 and 94 (Scheme 30). ${ }^{52}$ In a different approach, the palladium-catalysed reaction of 2-azetidinone-tethered $\alpha$-allenols $95 \mathbf{a}, \mathbf{b}$ with Baylis-Hillman acetates $\mathbf{9 6 a , b}$ furnished enantiopure spiroazetidinones $\mathbf{9 7 a - d}$ in moderate-to-good yields (Scheme 31). ${ }^{53}$ When $\alpha$-allenol $95 a$ and acetate 98 containing a cyano group were subjected to this palladium-catalysed protocol, the reaction did not yield the expected adduct 99, which would have resulted from $\mathrm{S}_{\mathrm{N}} 2$ substitution by attack at the methylene position remote from the leaving group, followed by migration of the double bond (Scheme 32). In contrast, the reaction exclusively led to spiroazetidinone 100 , which was explained considering a regio- and diastereospecific $\mathrm{S}_{\mathrm{N}} 1$ substitution protocol.

1. allyl bromide (1.6 equiv), TBAI (cat), $\mathrm{NaOH}$ (aq. 50\%), $\mathrm{CH}_{2} \mathrm{Cl}_{2}, \mathrm{rt}, 16 \mathrm{~h}$

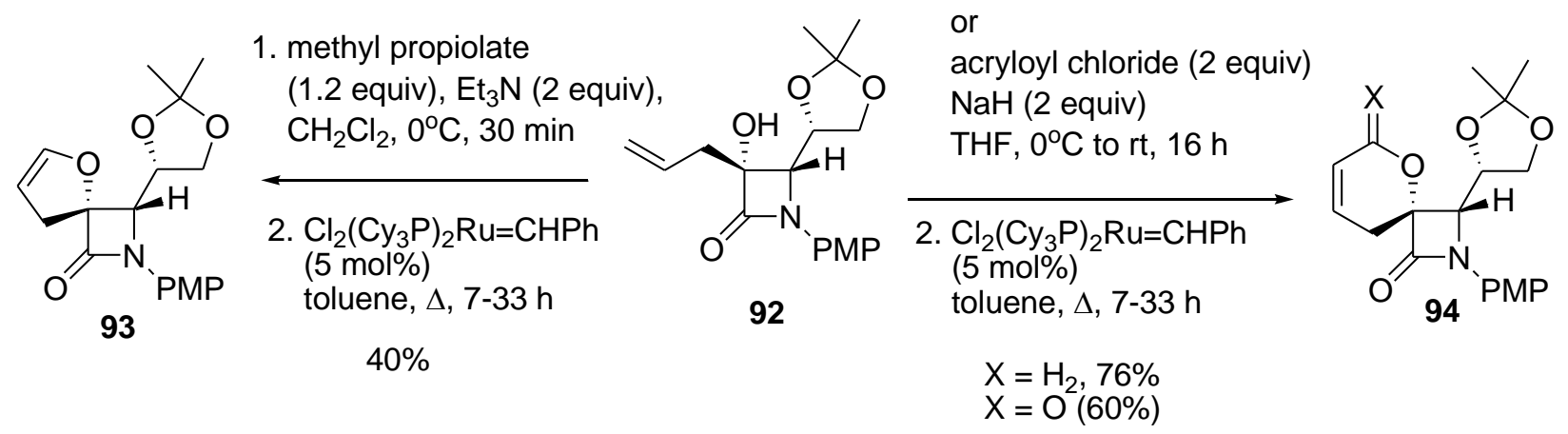

Scheme 30

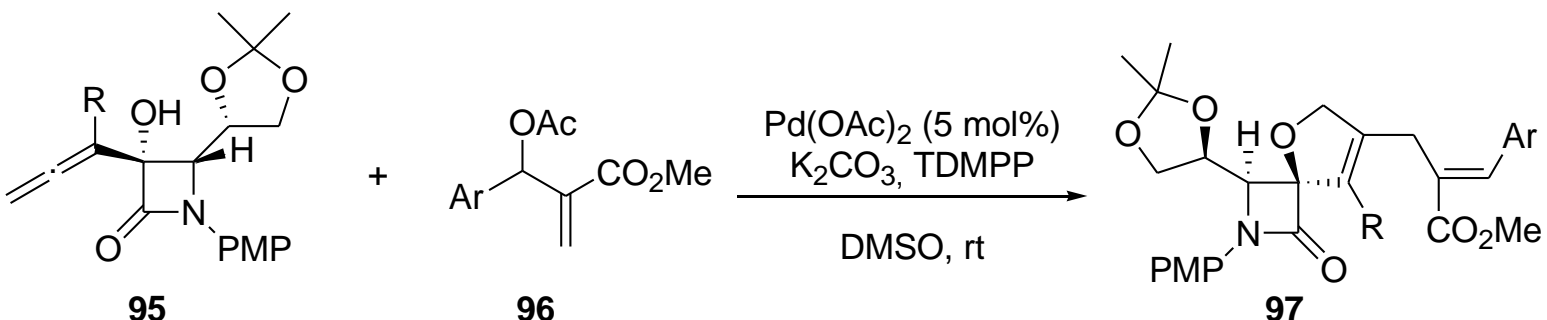
$\mathrm{R}=\mathbf{a} \cdot \mathrm{Me}, \mathbf{b} \cdot \mathrm{Ph}$
$\mathrm{Ar}=\mathbf{a} . \mathrm{Ph}, \mathbf{b} \cdot 4-\mathrm{MeC}_{6} \mathrm{H}_{4}$
$(+)-97 \mathrm{a} \mathrm{R}=\mathrm{Me}, \mathrm{Ar}=\mathrm{Ph}(71 \%)$
(+)-97b R $=\mathrm{Me}, \mathrm{Ar}=4-\mathrm{MeC}_{6} \mathrm{H}_{4}(44 \%)$
(+)-97c $\mathrm{R}=\mathrm{Ar}=\mathrm{Ph}(51 \%)$
$(+)-97 \mathrm{~d} \mathrm{R}=\mathrm{Ph}, \mathrm{Ar}=4-\mathrm{MeC}_{6} \mathrm{H}_{4}(50 \%)$
Scheme 31 
<smiles>C=CC(=O)C1(O)C(=O)N([Pb])C1C1COC(C)(C)O1</smiles>

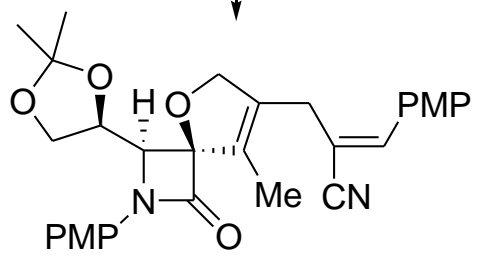

99

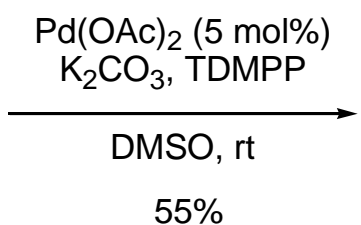

$55 \%$

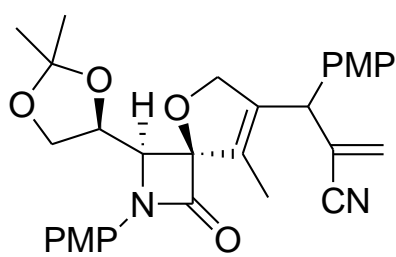

100

Scheme 32

Furthermore, the same group has recently disclosed a novel methodology for the metalcatalysed cycloetherification of 2-azetidinone-tethered homopropargylic alcohols towards the synthesis of spiranic tetrahydrofuryl $\beta$-lactams in good yields. ${ }^{54}$

Halocyclisation of cis-3-(prop-2-ynyloxy/-enyloxy)-2-azetidinones to synthesise spiroazetidinones has been reported by Bari and coworkers. ${ }^{55}$ This work has recently been extended further with 3-allyl-3-(phenyl/benzylthio)-2-azetidinones. ${ }^{56}$ Only cis-3-allyl-3benzylthio-2-azetidinones 101 underwent cyclisation upon reaction with bromine or iodine (Schemes 33 and 34), and both C7 $\alpha$ - and $\beta$-epimers of the spiro systems 103-106 were obtained. In the reaction with bromine, a side product 102 was obtained due to bromine addition across the carbon-carbon double bond. The reaction employing bromine favoured the formation of the $\beta$-epimer, whereas the reaction using iodine favoured the $\alpha$-epimer. The preferential formation of the $\beta$-epimer indicated that bromocyclisation occurred by initial bromine addition across the double bond, and the complete mechanism involved coordination by halogen to form a $\pi$-complex followed by nucleophilic attack of the sulfur atom. The bromide retained a more stable pseudoequatorial position during the nucleophilic attack of sulfur on the carbon of the olefin-halogen complex. In the case of iodocyclisation, however, the sulfur atom was transformed into an electrophilic species first, which then interacted with the olefinic moiety followed by nucleophilic attack of a halide anion to form the five-membered ring. Halocyclisation of the 3-benzylselanyl-substituted 2-azetidinone 107 with bromine and with 
iodine occurred by a 5-exo ring-closure process affording 2-azetidinones 108 spiro-fused to a 1,3-oxaselenolane ring (Scheme 35). ${ }^{57}$

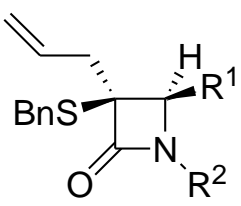

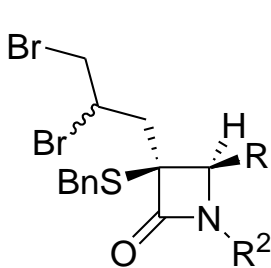

$102(5-23 \%)$

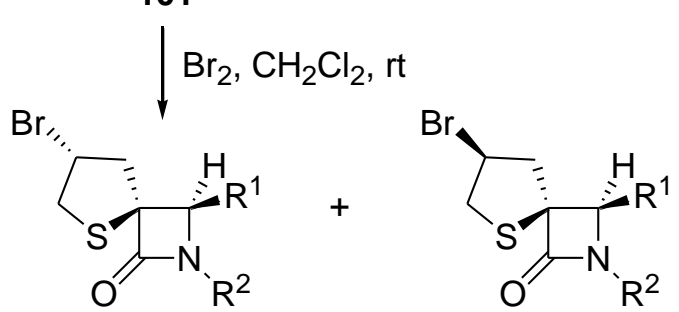

$103(15-28 \%)$

$104(27-66 \%)$

a. $\mathrm{R}^{1}=\mathrm{Ph}, \mathrm{R}^{2}=4-\mathrm{MeOC}_{6} \mathrm{H}_{4} ;$ b. $\mathrm{R}^{1}=4-\mathrm{MeOC}_{6} \mathrm{H}_{4}, \mathrm{R}^{2}=4-\mathrm{MeOC}_{6} \mathrm{H}_{4}$;

c. $\mathrm{R}^{1}=4-\mathrm{ClC}_{6} \mathrm{H}_{4}, \mathrm{R}^{2}=4-\mathrm{MeC}_{6} \mathrm{H}_{4} ;$ d. $\mathrm{R}^{1}=\mathrm{R}^{2}=\mathrm{Ph}$; e. $\mathrm{R}^{1}=\mathrm{Ph}, \mathrm{R}^{2}=4-\mathrm{ClC}_{6} \mathrm{H}_{4}$

Scheme 33

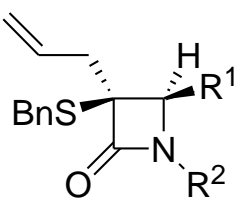

101

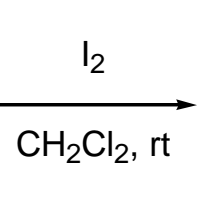

$105(34-63 \%)$
1,<smiles>[R7]N1C[C@@]2(CC(C)CS2)C1=O</smiles><smiles>[R2]N1C[C@@]2(C[C@@H](C)CS2)C1=O</smiles>

$106(14-20 \%)$

a. $\mathrm{R}^{1}=\mathrm{Ph}, \mathrm{R}^{2}=4-\mathrm{MeOC}_{6} \mathrm{H}_{4} ;$ b. $\mathrm{R}^{1}=4-\mathrm{MeOC}_{6} \mathrm{H}_{4}, \mathrm{R}^{2}=4-\mathrm{MeC}_{6} \mathrm{H}_{4}$;

c. $\mathrm{R}^{1}=4-\mathrm{ClC}_{6} \mathrm{H}_{4}, \mathrm{R}^{2}=4-\mathrm{MeC}_{6} \mathrm{H}_{4} ;$ d. $\mathrm{R}^{1}=\mathrm{R}^{2}=\mathrm{Ph} ; \mathbf{e}$. $\mathrm{R}^{1}=\mathrm{Ph}, \mathrm{R}^{2}=4-\mathrm{ClC}_{6} \mathrm{H}_{4}$

Scheme 34

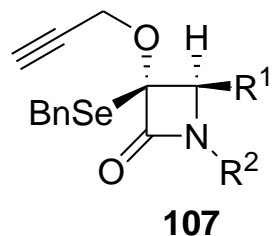

107

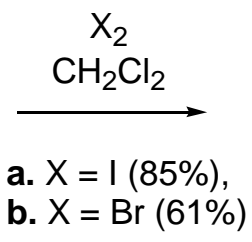

a. $X=I(85 \%)$,

b. $X=\operatorname{Br}(61 \%)$

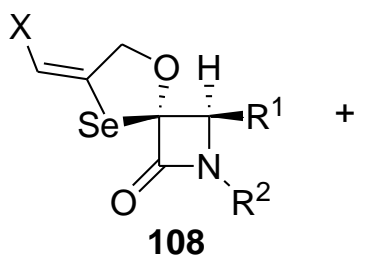<smiles>[X]Cc1ccccc1</smiles>

$\mathrm{R}^{1}=\mathrm{Ph}, \mathrm{R}^{2}=4-\mathrm{MeC}_{6} \mathrm{H}_{4}$

\section{Scheme 35}


The ring closure of amines 110, obtained by addition of the enolates derived from substrate 109 across an imine, afforded 2-azetidinone 111. The cyclisation of the C3 substituent in the latter 2azetidinone 111 was performed via transformation of the hydroxyl group into the corresponding bromide followed by $\alpha$-deprotonation with respect to the $\beta$-lactam carbonyl group utilizing LDA and subsequent intramolecular nucleophilic substitution, leading to spiro-fused 2-azetidinones 112 with cholesterol absorption inhibition activity (Scheme 36). ${ }^{58}$

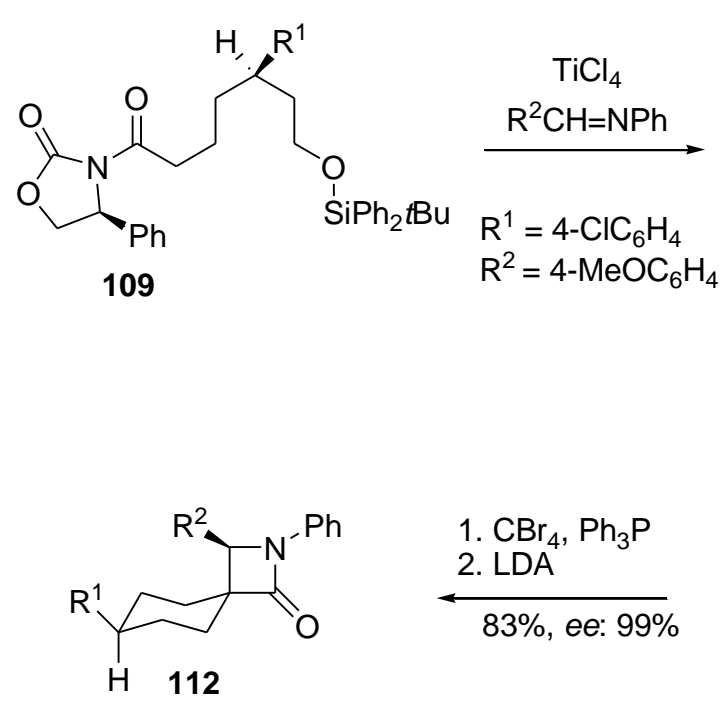

Scheme 36
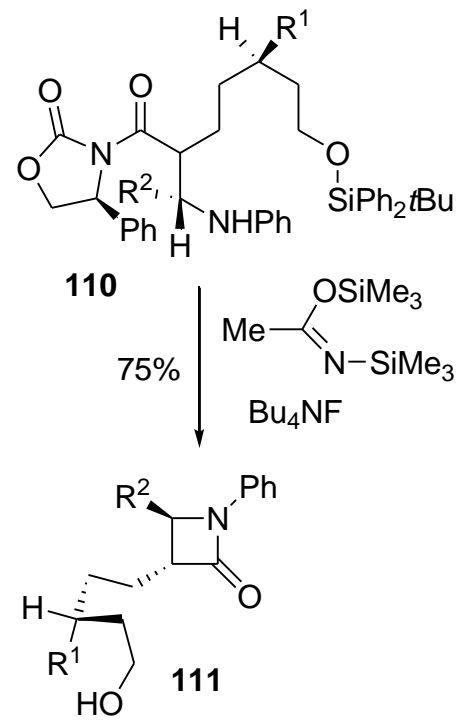

A good example of the application of monocyclic 2-azetidinones bearing an unsaturated side chain at C3 for the synthesis of spiro-fused 2-azetidinones has been reported by Tolomelli and coworkers. ${ }^{59,60}$ The carbon-carbon double bond present in the butenyl group of 2-azetidinone 113 was transformed into epoxide 114 using mCPBA, and treatment of the latter epoxide 114 with one equivalent of $\mathrm{BF}_{3} \cdot \mathrm{Et}_{2} \mathrm{O}$ led to ring opening followed by cyclisation towards 2azetidinones spiro-fused to an oxetane ring (115) and a tetrahydrofuran ring (116) in a 90:10 ratio (Scheme 37). The effect of the configuration at C4 was studied by carrying out the reactions of enantiomerically pure epoxide-substituted 2 -azetidinones $117 \mathbf{a}$ and $\mathbf{1 1 7 b}$. The former compound afforded a 2-azetidinone system 118a, spiro-fused to an oxetane ring, as the major product and the $\mathbf{2}$-azetidinone $\mathbf{1 1 8} \mathbf{b}$ as the minor product, whereas the latter compound (117b) afforded 2-azetidinone 119b, spiro-fused to a tetrahydrofuran unit, as the major product and the 2-azetidinone 119a as the minor product (Schemes 38 and 39). 


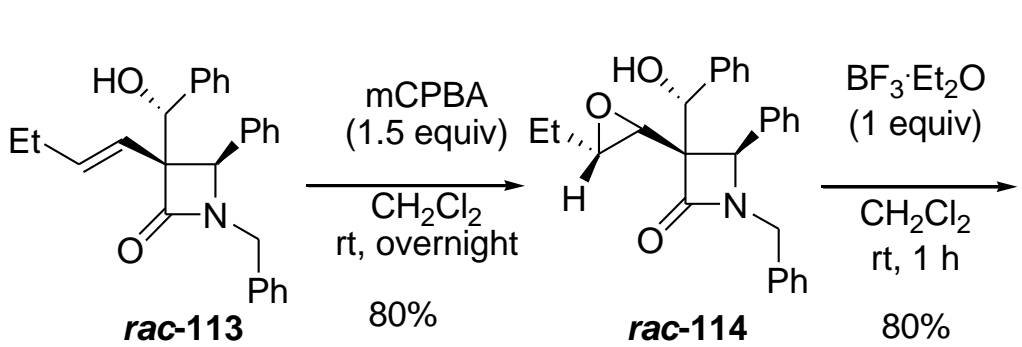

Scheme 37

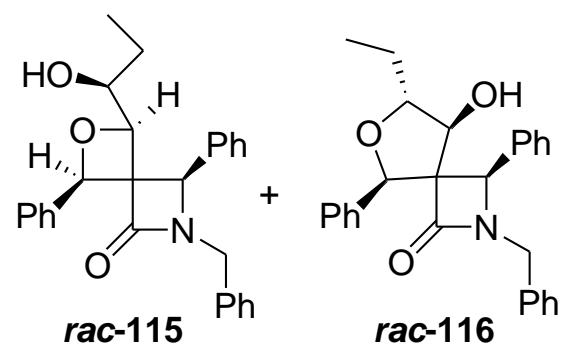

$115: 11690: 10$

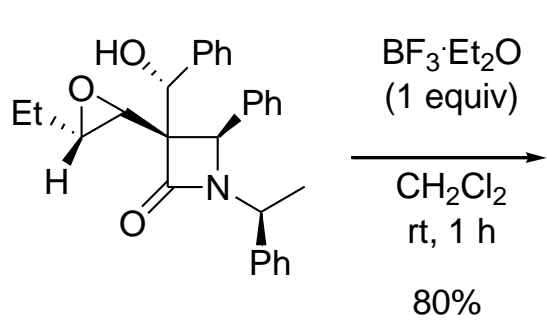

$117 a$<smiles>CC[C@H](O)[C@H]1O[C@@H](c2ccccc2)C12C(=O)N(C(C)c1ccccc1)C2c1ccccc1</smiles>

118a<smiles>CC[C@H]1O[C@@H](c2ccccc2)C2(C(=O)N(C(C)c3ccccc3)C2c2ccccc2)[C@H]1O</smiles>

$118 b$

Scheme $38 \quad 118 a: 118 b 72: 28$<smiles>CCO[C@@H]1C(=O)[C@H](c2ccccc2)[C@H]1[C@H](O)c1ccccc1</smiles>

117b
$\mathrm{BF}_{3} \cdot \mathrm{Et}_{2} \mathrm{O}$

(1 equiv)

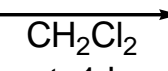

rt, $1 \mathrm{~h}$

$80 \%$<smiles>CCC(O)[C@H]1O[C@@H](c2ccccc2)C12C(=O)N(C(C)c1ccccc1)C2c1ccccc1</smiles>

$119 a$<smiles>CC[C@H]1O[C@@H](c2ccccc2)C2(C(=O)N(C(C)c3ccccc3)C2c2ccccc2)[C@H]1O</smiles>

$119 b$

Scheme 39

119a : 119b $34: 66$

In related research, the carbon-carbon double bond of 3-methylidene-2-azetidinones has been subjected to epoxidation, cyclopropanation, Diels-Alder reaction and 1,3-cycloadditions, producing a variety of spiroazetidinones. ${ }^{61,62}$ The study of the steric course indicated that reactions with the double bond occurred from the side opposite to the bulkier substituent at C4 of the starting 2-azetidinones. Epoxidation of the electron-poor, carbon-carbon double bond at C-3 of 2-azetidinones 120 occurred readily with a large variety of reagents, e.g. $\mathrm{H}_{2} \mathrm{O}_{2}$ in alkali, tert-BuOOH, $\mathrm{KClO}$, 3-chloroperbenzoic acid, or urea/ $\mathrm{H}_{2} \mathrm{O}_{2}$ complex, forming spiroazetidinones 
121 in 65-90\% yields (Scheme 40). ${ }^{61}$ The reactions of hydrazines with 120 led to the formation of adducts 122 which cyclised upon acidic treatment forming spiroazetidinone 123 (Scheme 41).

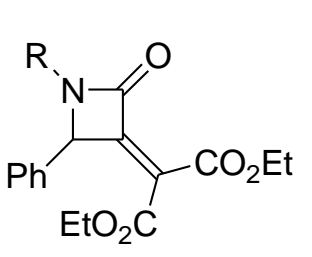

120
1. $\mathrm{Bu}_{4} \mathrm{NBr} / \mathrm{CH}_{2} \mathrm{Cl}_{2}$

2. $\mathrm{H}_{2} \mathrm{O}_{2}$ (30\% soln)

3. $\mathrm{KOH} / \mathrm{EtOH}(0.5 \mathrm{~N})$

rt, $12-14 \mathrm{~h}$

$65-90 \%$

$\mathrm{R}=4-\mathrm{MeOC}_{6} \mathrm{H}_{4},(t-\mathrm{Bu}) \mathrm{Ph}_{2} \mathrm{Si}, \mathrm{Ph}, 4-\mathrm{BrC}_{6} \mathrm{H}_{4}, 3,4-(\mathrm{MeO})_{2} \mathrm{C}_{6} \mathrm{H}_{3}$

\section{Scheme 40}

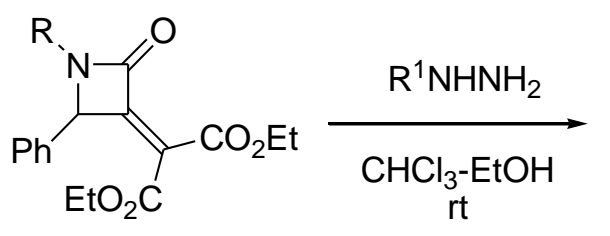

$120 R=P M P$

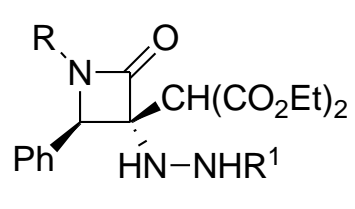

122

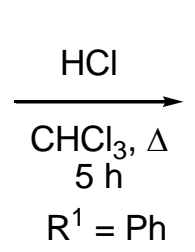

$79 \%$<smiles>[R]N1C(=O)[C@@]2(NN(c3ccccc3)C(=O)C2c2ccccc2)C1c1ccccc1</smiles>

123

122. $\mathrm{R}^{1}=4-\mathrm{HOOCC}_{6} \mathrm{H}_{4}(57 \%)$, MeOOC (41\%), $t$-BuOOC (65\%)

\section{Scheme 41}

2-Azetidinones 120 have also been subjected to cyclopropanation and Diels-Alder reaction. ${ }^{61,62}$ Cyclopropanation of $\mathbf{1 2 0}$ in THF with the ylide derived from trimethylsulfoxonium iodide 124 in DMF formed 2-azetidinones 125, spiro-fused to a cyclopropane ring (Scheme 42). In the DielsAlder reaction of 120 with Danishefsky's diene 126, a single product 127 was obtained in 95\% yield. The Diels-Alder reaction with cyclopentadiene 128 yielded endo product 129 (Scheme 43) with cis-stereoselectivity suggesting that the reaction occurred at the side opposite to the bulkier substituent at $\mathrm{C} 4$.

$$
\begin{aligned}
& \text { 1. } \mathrm{NaH} / \mathrm{DMF} \text {, } \\
& \mathrm{Me}_{3} \mathrm{SO}^{\oplus} \mathrm{I}^{\ominus} \underset{\text { 2. } 120 \mathrm{in} \mathrm{THF}}{\mathrm{rt}, 20 \mathrm{~min} \text { then } 0-5^{\circ} \mathrm{C}} \\
& 124 \\
& \mathrm{R}=4-\mathrm{MeOC}_{6} \mathrm{H}_{4}(67 \%),(t-\mathrm{Bu}) \mathrm{Ph}_{3} \mathrm{Si}(18 \%), 3,4-(\mathrm{MeO})_{2} \mathrm{C}_{6} \mathrm{H}_{3}(48 \%)
\end{aligned}
$$

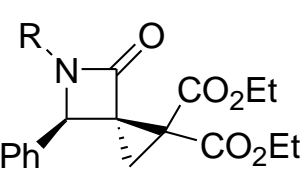




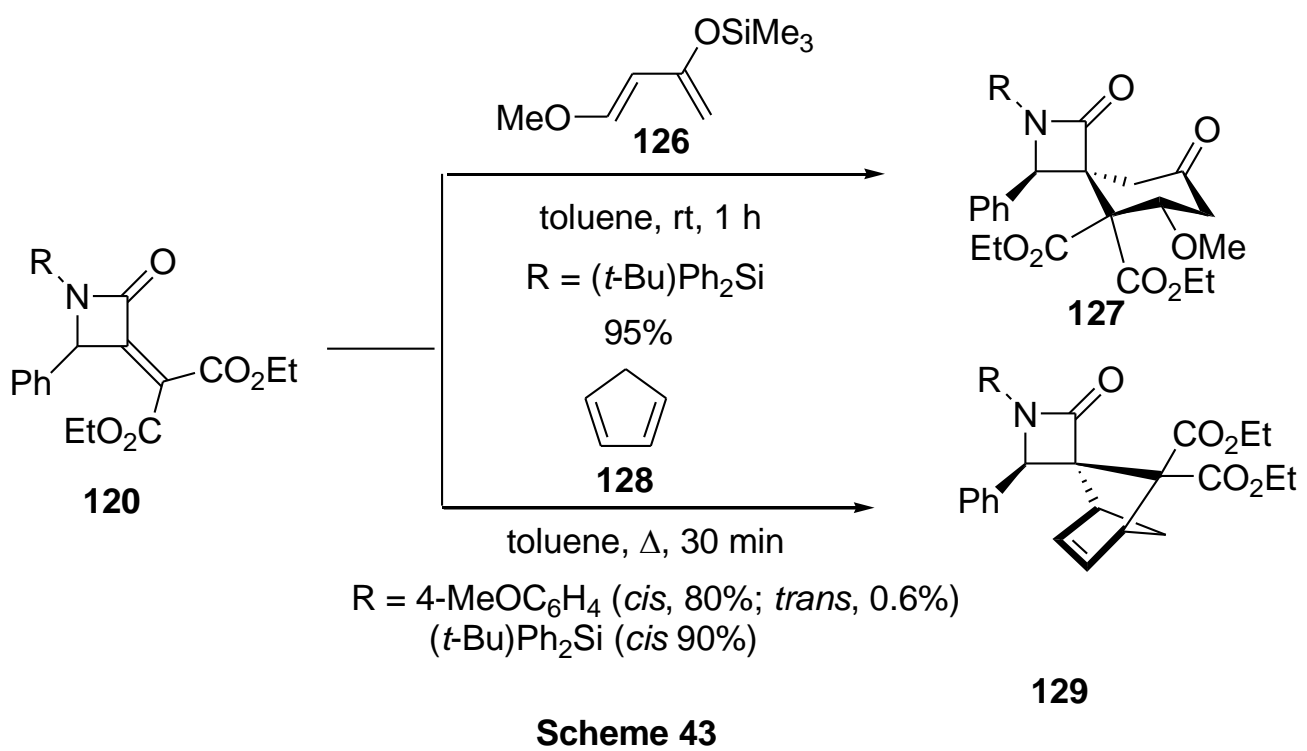

Diazomethane reacted cleanly with $\alpha$-methylidene-substituted 2-azetidinone 130 through antiaddition with respect to the $\mathrm{CH}_{2}$ OTBS group present at $\mathrm{C4}$, forming diastereomeric 2azetidinones $\mathbf{1 3 1}$ a,b, spiro-fused to a pyrazoline ring (Scheme 44$).{ }^{63}$ Reactions of 3-silylated 2azetidinones with $\alpha, \beta$-unsaturated ketones are known to form propylidene 2-azetidinones, which undergo Diels-Alder reaction yielding the corresponding spiroazetidinones. ${ }^{64}$

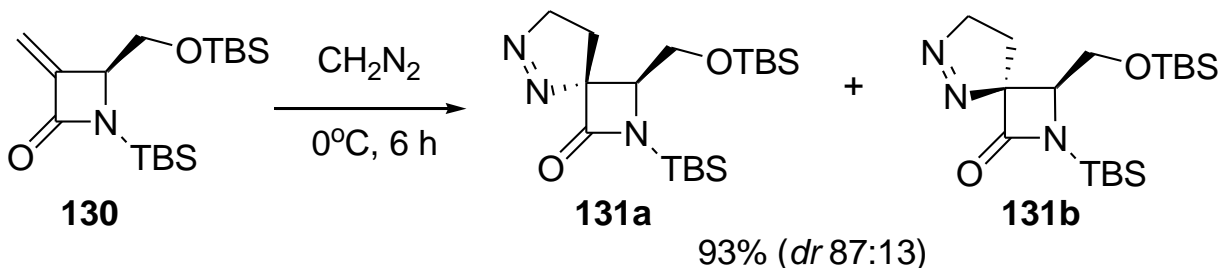

Scheme 44

\section{$2.4 \quad$ Other methods}

The synthesis of 1,4-disubstituted spiro(azetidine-3,1'-cyclopropanes) has been reported via a [3+2] dipolar cycloaddition of nitrones 132a-f with bicyclopropylidene 133 in benzene at ambient or elevated temperature, forming the corresponding bis-spirocyclopropanated isoxazolidines 134a-f. Treatment of the latter compounds with trifluoroacetic acid in acetonitrile furnished 3spirocyclopropanated azetidin-2-ones 135a-f (Scheme 45) with concomitant extrusion of ethylene, in excellent yields (Table 3). ${ }^{65}$ A similar acid-catalysed fragmentative rearrangement of 
spirocyclopropanated cyclohexane-fused isoxazolidines 136 afforded spirocyclopropanated 2azetidinones 137, fused to a cyclohexane ring (Scheme 46). ${ }^{66} \mathrm{~A}$ mechanism was proposed involving cleavage of the protonated $\mathrm{N}-\mathrm{O}$ bond of the isoxazolidine ring for its rearrangement to an azetidinone ring . ${ }^{67}$ In an improved procedure, the one-pot, three-component reaction for the direct conversion of certain alkyl hydroxylamine hydrochlorides 139 formaldehyde 138 or an alkyl glyoxalate and bicyclopropylidene 133 to furnish 3-spirocyclopropanated 2-azetidinones 140 has been carried out by microwave irradiation (Scheme 47). ${ }^{68}$

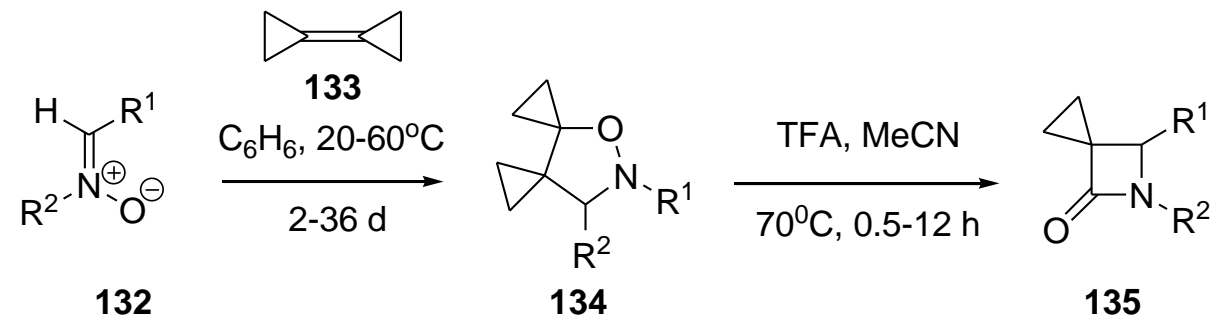

Scheme 45

Table 3. Preparation of spirocyclopropanated isoxazolidines 134 and $\beta$-lactams 135

\begin{tabular}{|c|c|c|c|c|c|c|}
\hline 132 & $\mathrm{R}^{1}$ & $\mathrm{R}^{2}$ & 134 & $\begin{array}{c}\text { Yield } \\
(\%)\end{array}$ & 135 & $\begin{array}{r}\text { Yield } \\
\text { (\%) }\end{array}$ \\
\hline a & $\mathrm{CO}_{2} \mathrm{Me}$ & $\mathrm{Bn}$ & a & 100 & $a$ & 78 \\
\hline b & $\mathrm{Ph}$ & $\mathrm{Bn}$ & b & 95 & b & 75 \\
\hline c & $\mathrm{CN}$ & $\mathrm{Bn}$ & c & 94 & C & 75 \\
\hline d & $\mathrm{CN}$ & PMB & d & 100 & d & 94 \\
\hline e & $\mathrm{Ph}$ & $\mathrm{Me}$ & e & 93 & e & 96 \\
\hline$f$ & 2-Py & $\mathrm{Me}$ & $f$ & 71 & $f$ & 96 \\
\hline
\end{tabular}


<smiles>PN1CCCCCC2(CC2)C2(CC2)O1</smiles>

136

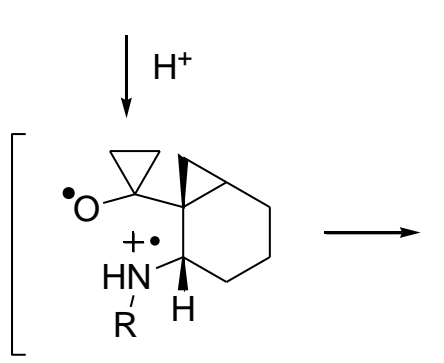

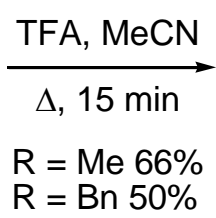

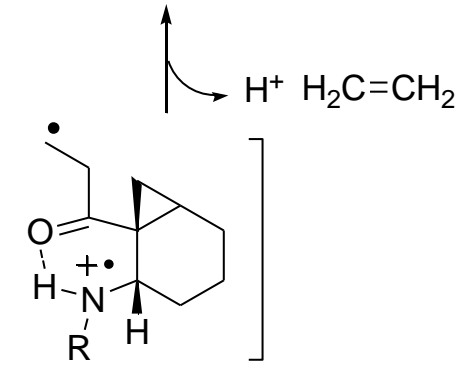

Scheme 46

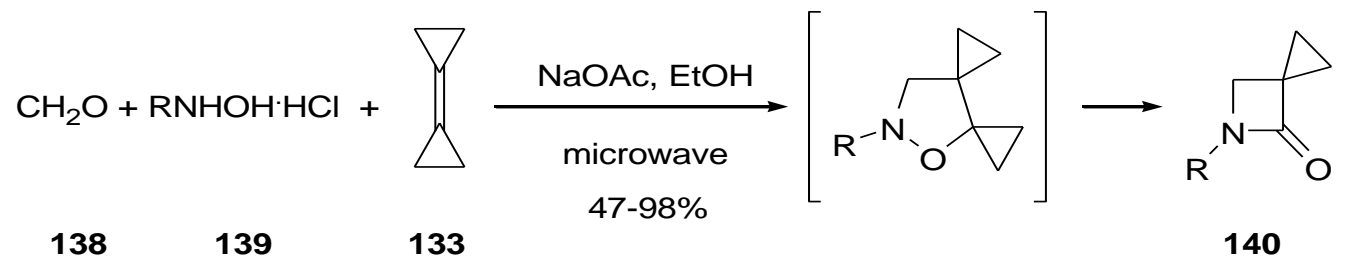

$\mathrm{R}=\mathrm{Bn}, 4-\mathrm{MeOC}_{6} \mathrm{H}_{4} \mathrm{CH}_{2}, \mathrm{Ph}_{2} \mathrm{CH}, t$-butyl

Scheme 47

\section{Reactions of Spiro-fused $\beta$-Lactams}

\subsection{Ring-opening reactions}

Ring-opening reactions of spiro-fused 2-azetidinones have been investigated utilising various hydrolytic, oxidative and reducing agents, and amino acids to get diverse types of ring-opening products. Although cleavage of the N1-C2 bond comprises the main ring-opening reaction of $\beta$ lactams, cleavage of other bonds is also known.

The cleavage of azetidin-2-ones 141, spiro-fused to a tetrahydrofuran ring, by potassium cyanide in methanol at room temperature has been reported to yield $\beta$-amino esters 142 through methanolysis of the cyclic amide (Scheme 48). ${ }^{69} \mathrm{~A} \beta$-amino ester and a $\beta$-amino acid have also been formed by cleavage of a pyrrolidine spiro-fused 2-azetidinone ring by potassium 
cyanide in methanol and by sodium hydroxide in tetrahydrofuran, respectively. ${ }^{28}$ In contrast, 4oxoazetidine-2-carbaldehyde 143 undergoes a C4-N1 bond fission using 2(trimethylsilyl)thiazole (TMST) yielding amide 144 (Scheme 49). ${ }^{70}$ The azetidinones 37, spirofused to an $\mathrm{N}$-acyl/benzoyl thiazolidine ring, have been selectively hydrolysed by acid to form 2substituted 1,3-thiazolidine-2-carboxylic acids 145 (Scheme 50). ${ }^{24 \mathrm{e}}$ Similar cleavage of the 2azetidinone ring has also been reported with hydrochloric acid in ethanol or with potassium hydroxide in ethanol. ${ }^{71}$<smiles>[R]C1N(C(=O)OC(C)(C)C)C(=O)[C@@]12CCCO2</smiles>

141

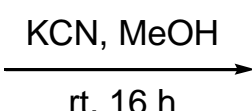

rt, $16 \mathrm{~h}$<smiles>[R]C(NC(=O)OC)C1(C(=O)OCc2ccccc2)CCCO1</smiles>

142

$\mathrm{R}=\mathrm{Ph}(93 \%)$

$\mathrm{R}=\mathrm{PhCH}=\mathrm{CH}(95 \%)$<smiles>[R16]N1C(=O)[C@@]2(CC=CCO2)[C@@H]1C=O</smiles>

143
TMST, $\mathrm{CH}_{2} \mathrm{Cl}_{2}$

$0^{\circ} \mathrm{C}, 16 \mathrm{~h}$<smiles>N#CNC(=O)C1(CC(=O)c2nccs2)CC=CCO1</smiles>

144 (52\%)

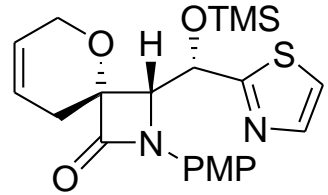

$12 \%$

Scheme 49<smiles>[R]OCN1CCS[C@]12C(=O)N(S(=O)(=O)Oc1ccccc1)[C@H]2c1ccccc1</smiles>

37

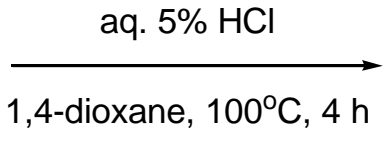

$\mathrm{R}=\mathrm{Me}(56 \%)$

$\mathrm{R}=\mathrm{Ph}(84 \%)$<smiles>O=C(O)C(NS(=O)(=O)c1ccccc1)[C@@H]1SCCN1C(=O)O</smiles>

145

Scheme 50

Hydrogenolysis of spiro $\beta$-lactams 146 bearing a formyl group has led to the rearranged bicyclic systems 147 via a C3-C4 $\beta$-lactam ring cleavage (Scheme 51). ${ }^{26}$ The products were racemic 
because the process took place with racemisation at C3 of the initial 2-azetidinone ring. According to the proposed mechanism, after initial removal of the Cbz group of the pyrrolidine ring, a retro-Mannich type reaction resulted in ring opening of the 2-azetidinone ring. Hydrogenation of the cyclic imine and further nucleophilic addition of the secondary amine to the aldehyde group led to a bicyclic enamine, which underwent hydrogenation to afford the products 147. Theoretical calculations were performed to study the ring-opening step.

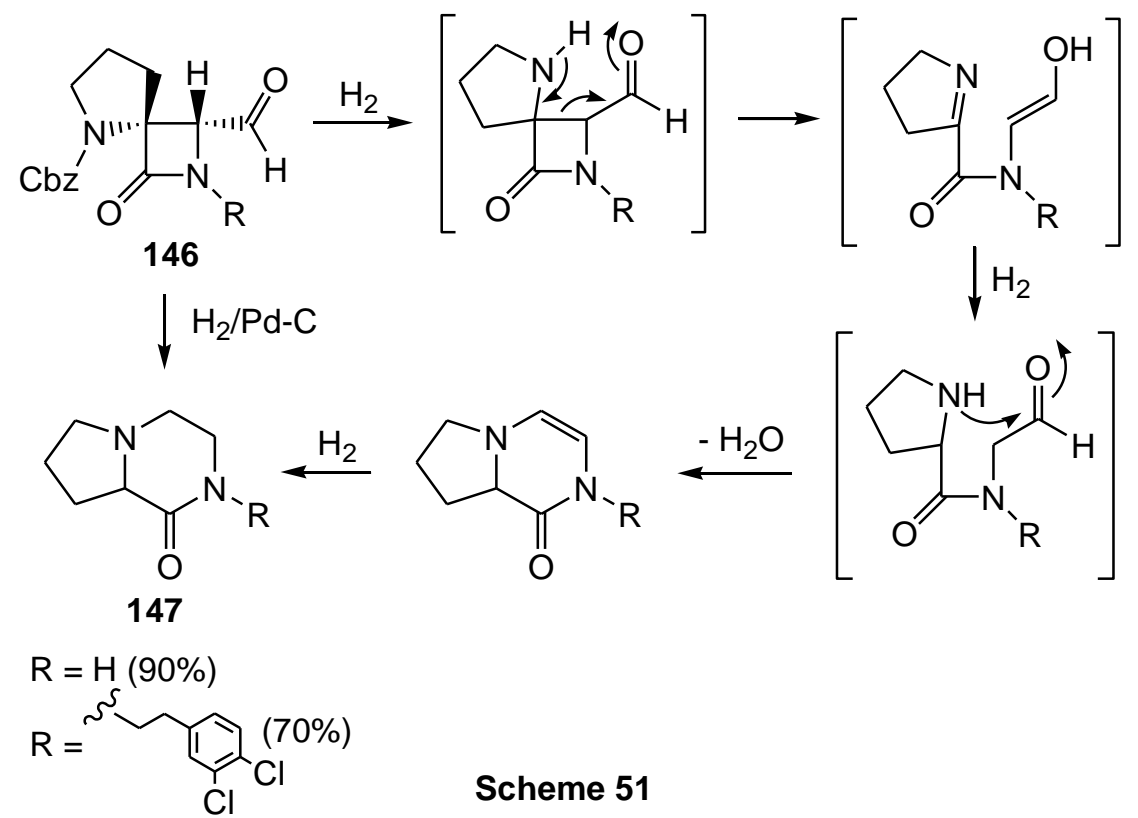

Hydrogenolysis of 2-azetidinones $\mathbf{3 7 / 3 8}$ spiro-fused to a 1,3-thiazolidine ring in ethyl acetate using Raney nickel as a catalyst has been reported to result in cleavage of both rings, forming an acyclic $N$-phenylsulfonamide 148 and an imidazole 149 (Scheme 52). This reaction did not occur when $10 \% \mathrm{Pd} / \mathrm{C}$ was used as a catalyst in various solvents such as ethanol, acetic acid and ethyl acetate. $^{71}$

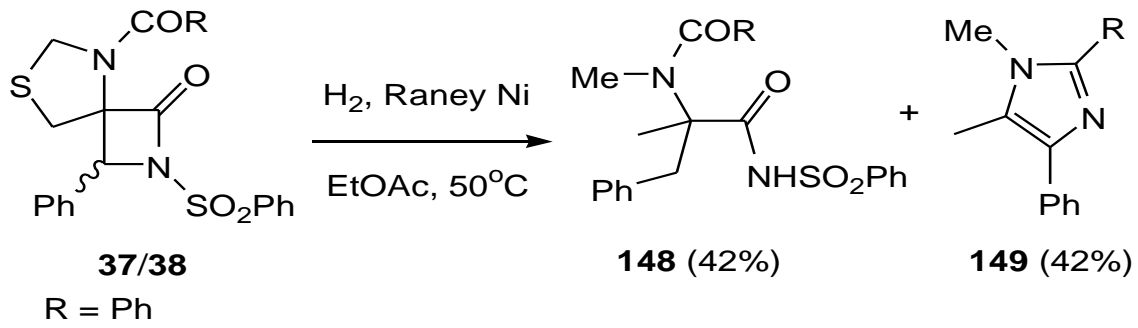

Scheme 52 
Treatment of 2-azetidinones 135, spiro-fused to a cyclopropane unit, with tert-butyl glycinate or with tert-butyl (S)-phenylalaninate 150 in DMF led to ring opening of the 2-azetidinone moiety to give $\beta$-peptides 151a-c in good yields (Scheme 53 ). ${ }^{65} \mathrm{~A}$ spiroazetidinone from the same series with a methyl carboxylate group at $\mathrm{C} 4$, however, failed to undergo ring opening, even upon prolonged heating, and afforded a new spiroazetidinone by transformation of the ester group. ${ }^{62}$<smiles>[R]C1N([R7])C(=O)C12CC2</smiles>

135<smiles>[R]C(N)C(=O)OCC(=O)OC(C)(C)C</smiles>

150<smiles>[R7]NC([R2])C1(C(=O)N[C@@H]([2H])C(=O)OC(C)(C)C)CC1</smiles>

151

151: a. $R^{2}=C O P h, R^{1}=P h ; R=H(61 \%)$

b. $R^{2}=\mathrm{CO}_{2} t \mathrm{Bu}, \mathrm{R}^{1}=\mathrm{CN} ; \mathrm{R}=\mathrm{H}(84 \%)$

c. $\mathrm{R}^{2}=\mathrm{CO}_{2} t \mathrm{Bu}, \mathrm{R}^{1}=\mathrm{CN} ; \mathrm{R}=\mathrm{Bn}(81 \%)$

Scheme 53

An acid-catalysed fragmentative rearrangement of oxazolidines $\mathbf{1 5 2}$ has been described to result in the formation of spirocyclopropanated 2-azetidinones 153 , fused to a cyclopentane ring, which underwent N1-C2 ring opening to furnish $N$-acylated $\beta$-amino acids 154 (Scheme 54). ${ }^{66}$

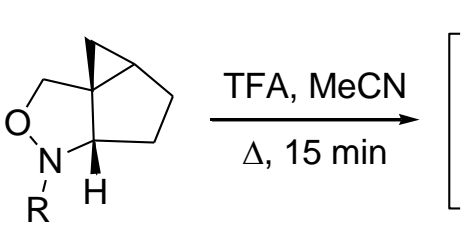

152

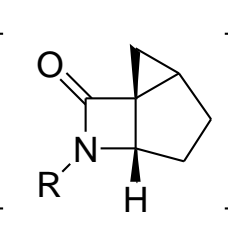

153

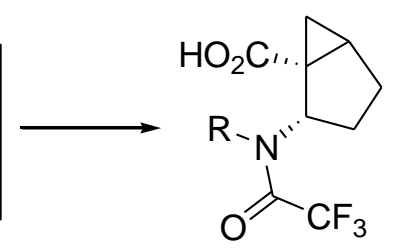

154

$$
\begin{aligned}
& R=\operatorname{Me}(71 \%) \\
& R=\operatorname{Bn}(68 \%)
\end{aligned}
$$

\section{Scheme 54}

Treatment of 2-azetidinone 155 with trifluoroacetic acid in a study directed towards the synthesis of naturally occurring chartellines led to N1-C4 fission of the 2-azetidinone ring, together with cyclisation of the substituent on the indoline ring to oxazinone 156 (Scheme 55). ${ }^{72}$ 
<smiles>[Y16]N1C(=O)CC12/C(=C/[C@@H](O)C(C)(C)C)Nc1ccccc12</smiles>

155

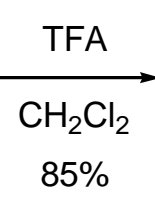

Scheme 55

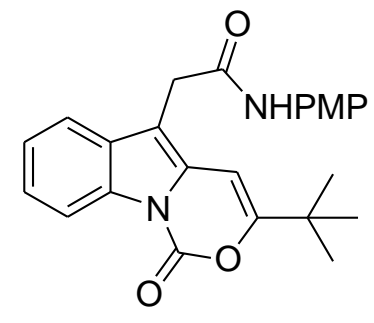

156

\subsection{Reactivity of substituents attached to the ring nitrogen atom}

The removal of 4-methoxyphenyl, benzyl and bis(4-methoxyphenyl)methyl groups from the nitrogen atom of 2-azetidinone rings has been reported by means of various reagents. A commonly used reagent in this respect is cerium(IV) ammonium nitrate, e.g. for the removal of the 4-methoxyphenyl group from 2-azetidinones 157 to afford 158a-c (Scheme 56). ${ }^{23,27,72 a,}$ The $\mathrm{N}$-unsubstituted spiro-fused 2-azetidinones thus obtained are useful for transformation into other spiro-fused 2-azetidinones through $N$-functionalisation, e.g. $N$-sulfonylation of azetidin-2ones 158 has been achieved using a sulfur trioxide-pyridine complex, forming sulfamate tetrabutylammonium salts $\mathbf{1 5 9 a - c}$ (Scheme 57). ${ }^{23}$ Similar reactions have been performed on 2azetidinones spiro-fused to pyrrolidine. ${ }^{28}$ Another example of 2-azetidinone (160) nitrogen deprotection followed by reaction of the corresponding product 161 with phenylacetaldehyde 162 affording the spiroazetidinone 163 is shown in Scheme $58 .^{72 a}$
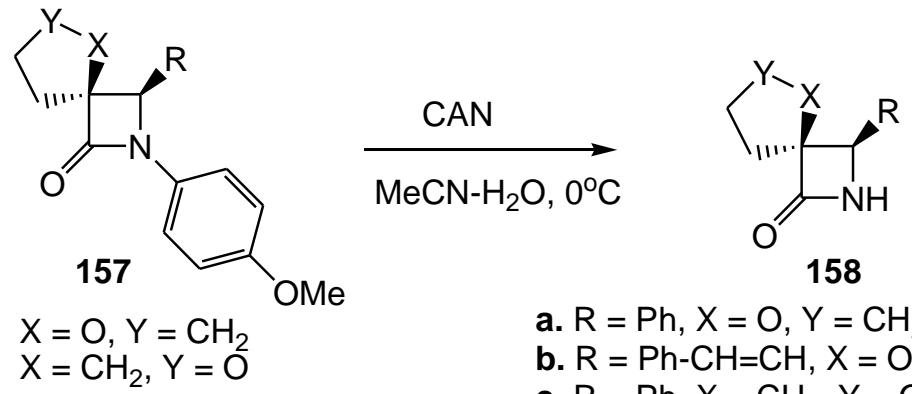
a. $\mathrm{R}=\mathrm{Ph}, \mathrm{X}=\mathrm{O}, \mathrm{Y}=\mathrm{CH}_{2}(82 \%)$
b. $\mathrm{R}=\mathrm{Ph}-\mathrm{CH}=\mathrm{CH}, \mathrm{X}=\mathrm{O}, \mathrm{Y}=\mathrm{CH}_{2}(42 \%)$
c. $\mathrm{R}=\mathrm{Ph}, \mathrm{X}=\mathrm{CH}_{2}, \mathrm{Y}=\mathrm{O}(93 \%)$

Scheme 56 


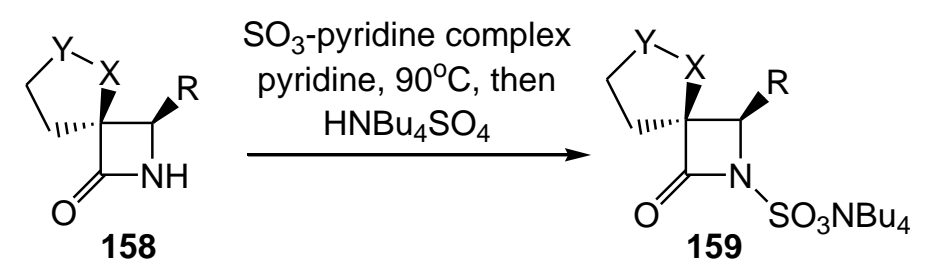

a. $\mathrm{R}=\mathrm{Ph}, \mathrm{X}=\mathrm{O}, \mathrm{Y}=\mathrm{CH}_{2}(76 \%)$

b. $\mathrm{R}=\mathrm{PhCH}=\mathrm{CH}, \mathrm{X}=\mathrm{O}, \mathrm{Y}=\mathrm{CH}_{2}(82 \%)$

c. $\mathrm{R}=\mathrm{Ph}, \mathrm{X}=\mathrm{CH}_{2}, \mathrm{Y}=\mathrm{O}(85 \%)$

Scheme 57<smiles>[14CH3]N1C(=O)C2(CC(=O)N2Cc2ccccc2)c2ccccc21</smiles>

160<smiles>O=C1CC2(C1)NC(=O)N2C(=O)OCc1ccccc1</smiles>

161

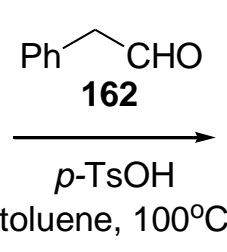

$67 \%$<smiles>O=C(OCc1ccccc1)N1C(=O)C2(CC(=O)N2/C=C/c2ccccc2)c2ccccc21</smiles>

163

\section{Scheme 58}

$N$-Benzyl-2-azetidinones 135, spiro-fused to a cyclopropane unit, have been reacted with different oxidizing agents such as $\mathrm{Cr}(\mathrm{VI})$ oxide, potassium permanganate and CAN. With the former two reagents, oxidation took place at the benzylic carbon atom leading to the formation of $\mathrm{N}$-benzoyl-substituted spiroazetidinones 164a-c (Scheme 59) (Table 4). ${ }^{65}$ The reaction with CAN led to the formation of a mixture of $N$-benzoyl spiroazetidinone $164 \mathrm{c}(39 \%)$ and the corresponding $N$-unsubstituted spiroazetidinone (38\%).

A) $\mathrm{CrO}_{3}$ (2 equiv), $\mathrm{AcOH}$ $60^{\circ} \mathrm{C}, 3 \mathrm{~d}$

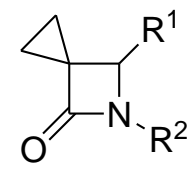
or

B) $\mathrm{KMNO}_{4}$ (4 equiv) $\mathrm{AcOH} / \mathrm{Me}_{2} \mathrm{CO}(15: 85)$ 18-crown-6, $60^{\circ} \mathrm{C}, 1 \mathrm{~d}$

or

C) $\mathrm{CAN}, \mathrm{MeCN} / \mathrm{H}_{2} \mathrm{O}(1: 2)$ $0-20^{\circ} \mathrm{C}, 1.3 \mathrm{~h}$<smiles>[R]c1ccc(C(=O)N2C(=O)C3(CC3)C2[R])cc1</smiles>

\section{Scheme 59}


Table 4. Synthesis of spiro $\beta$-lactams 164 from 135

\begin{tabular}{cccccc}
\hline 135 & $\mathbf{R}^{\mathbf{1}}$ & $\mathbf{R}^{\mathbf{2}}$ & Reagent & $\mathbf{1 6 4}$ & $\begin{array}{c}\text { Yield } \\
\mathbf{( \% )}\end{array}$ \\
\hline a & $\mathrm{CO}_{2} \mathrm{Me}$ & $\mathrm{Bn}$ & $\mathrm{A}$ & $\mathbf{a}$ & 44 \\
$\mathbf{b}$ & $\mathrm{Ph}$ & $\mathrm{Bn}$ & $\mathrm{B}$ & $\mathbf{b}$ & 28 \\
$\mathbf{d}$ & $\mathrm{CN}$ & $\mathrm{PMB}$ & $\mathrm{C}$ & $\mathbf{c}$ & 39 \\
\hline
\end{tabular}

An $\mathrm{N}$-H spiroazetidinone 165 was transformed into the $\mathrm{N}$-boc-protected derivative 166 using a standard protocol (Scheme 60). ${ }^{65}$<smiles>N#CC1NC(=O)C12CC2</smiles>

165

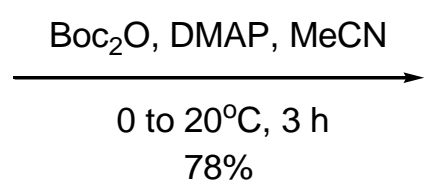

Scheme 60<smiles>CCOC(=O)N1C(=O)C2(CC2)C1C#N</smiles>

166

Weinreb and coworkers have described the $\mathrm{Cu}(\mathrm{I})$-catalysed coupling of spiro-fused 2azetidinone 167 with (E)-chloroiodovinylimidazole 168 to furnish the corresponding $\beta$ chloroenamide 169 (Scheme 61) en route to chartelline. ${ }^{73}$<smiles>COC(=O)N1C(=O)NC2(CC(=O)N2)c2c1cc(Br)c(Br)c2Br</smiles>

167<smiles></smiles>

168

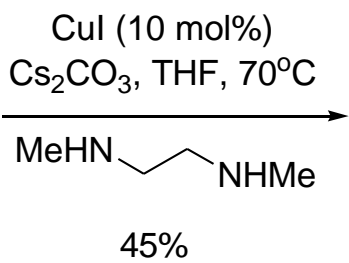

$45 \%$<smiles>[R6]N1C(=O)C2(CC(=O)N2/C=C(/Cl)c2ncn([R6])c2[R6](=O)OC)c2c1cc(Br)c(Br)c2Br</smiles>

169

\section{Scheme 61}

\subsection{Reactivity of substituents attached to the ring carbon atoms}

The reduction of 2,6-diazaspiro[3.3]heptan-1-one 74 has been investigated with monochloroalane (formed in situ from $\mathrm{LiAlH}_{4}$ and $\mathrm{AlCl}_{3}$ ) and with borane under different reaction conditions. No reduction occurred using one equivalent of the former reagent in tetrahydrofuran at $40^{\circ} \mathrm{C}$, whereas reversible complexation to borane was observed with the 
latter reagent. With five equivalents of monochloroalane, the reductive removal of the carbonyl group was achieved, forming 2,6-diazaspiro[3.3]heptane 170 in $78 \%$ yield (Scheme 62). ${ }^{41}$ Treatment of 2,6-diazaspiro[3.3]heptan-1-one $\mathbf{7 4}$ under transfer hydrogenation conditions resulted in removal of the benzyl group present at the azetidine nitrogen atom, affording a new 2-azetidinone 171 spiro-fused to a $\mathrm{N}$-unsubstituted azetidine ring (Scheme 63).
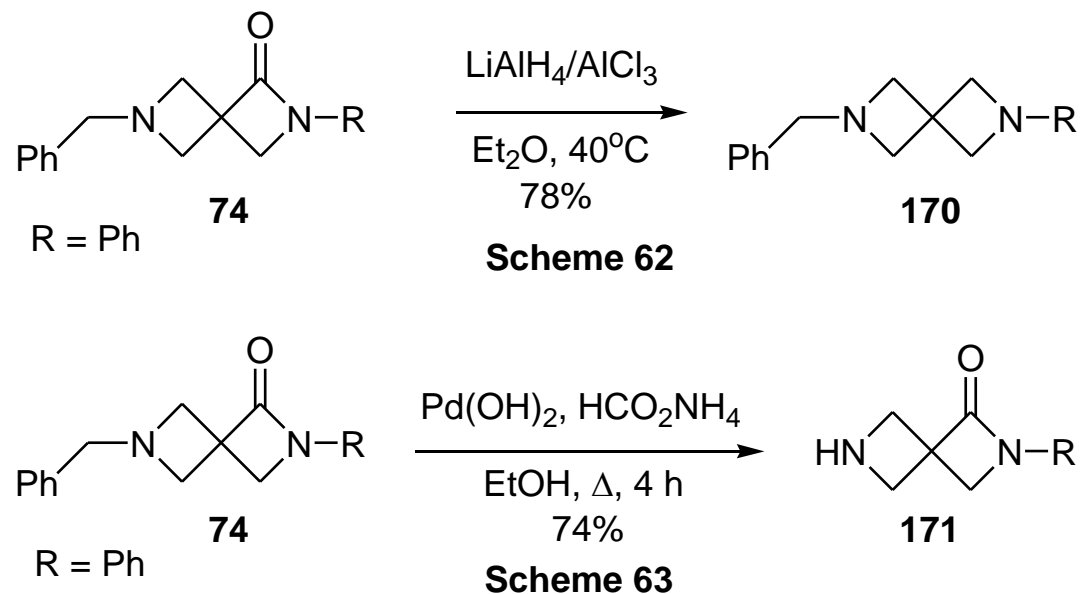

The 2-azetidinones, obtained from the reaction of diphenylketene with imines, are known to be fairly stable compounds. Reactions of such $\beta$-lactams with various reagents in which the 2azetidinone ring is retained at the cost of transformation of other functional group(s) in the molecule have been reported in the literature, e.g. treatment of spiro-2-azetidinone 172 with sodium borohydride led to reduction of the ketone to alcohol forming 173 (Scheme 64). ${ }^{11}$ Treatment of spiro-fused 2-azetidinones $\mathbf{1 7 4}$ with sodium hydroxide in ethanol resulted in cleavage of the $\mathrm{N}$-diarylacyl group of the indolinone ring, leading to 2 -azetidinones 175 , spirofused to $\mathrm{N}$-unsubstituted indolinone, in quantitative yields (Scheme 65$).{ }^{74}$<smiles>[R]N1C(=O)C(c2ccccc2)(c2ccccc2)C12C(=O)c1cccc3cccc2c13</smiles>

172

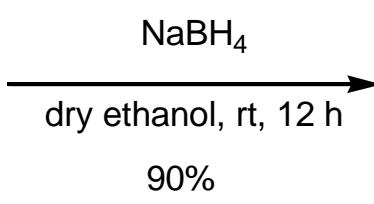

$\mathrm{R}=\mathrm{Ph}, 4-\mathrm{MeC}_{6} \mathrm{H}_{4}$<smiles>[R]N1C(=O)C(c2ccccc2)(c2ccccc2)C12c1cccc3cccc(c13)C2O</smiles>

173

\section{Scheme 64}




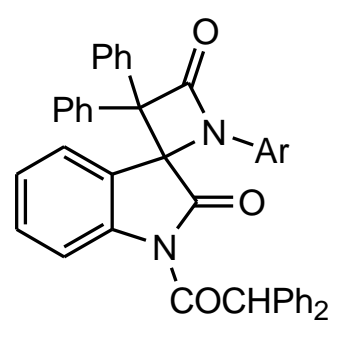

174
$\mathrm{NaOH}, \mathrm{EtOH}, \Delta$ $>95 \%$

$\mathrm{Ar}=\mathrm{Ph}, 4-\mathrm{EtOC}_{6} \mathrm{H}_{4}, 1$-naphthyl, $c$-Hex<smiles>O=C1Nc2ccccc2C12C(=O)N([Al])C2(c1ccccc1)c1ccccc1</smiles>

175

Scheme 65

The dioxalane ring present at the C4 side chain of the pyrrolidine-fused spiroazetidinones 45 and 176 has been reported to undergo ring opening upon treatment with $p$-TsOH to form new spiro-fused 2-azetidinones 177. Oxidation of the 1,2-diol group in the latter compounds upon treatment with sodium iodate afforded spiro-fused 2-oxoazetidine-4-carbaldehydes 178 (Scheme 66). ${ }^{26,27}$<smiles>[R]N1C(=O)[C@]2(CCCN2C(=O)OCc2ccccc2)[C@H]1C1COC(C)(C)O1</smiles>

45, 176

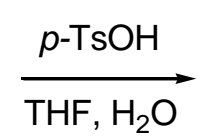

$\mathrm{R}=\mathrm{H}(\mathbf{1 7 6})$

$\mathrm{R}=\operatorname{Ar}(\mathbf{4 5})$<smiles>[Al]CCc1ccc(Cl)c(Cl)c1</smiles>

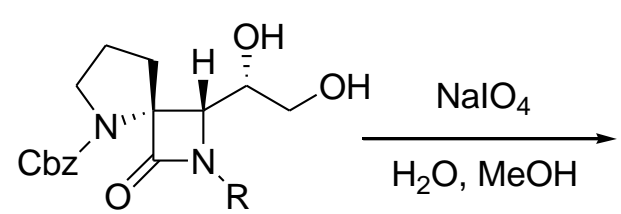

177

a. $70 \%(R=H)$

b. $80 \%(R=A r)$<smiles>[R]N1C(=O)[C@]2(CCCN2C(=O)OCc2ccccc2)[C@H]1C=O</smiles>

178

a. $50 \%(R=H)$

b. $87 \%(R=A r)$

\section{Scheme 66}

The racemate of 2-azetidinone $\mathbf{1 7 9}$, spiro-fused to $\mathrm{N}$-Boc pyrrolidine, has been resolved via reductive deprotection of the pyrrolidine nitrogen to afford enantiomerically pure spiroazetidinones 181 via the 2-azetidinone 180 (Scheme 67). ${ }^{28}$ 


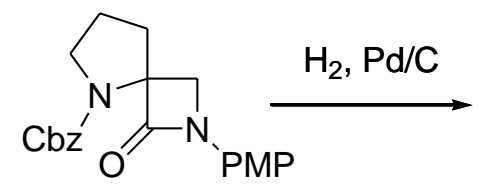

179

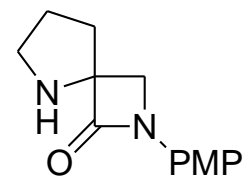

180
1) $\mathrm{D}-\mathrm{Boc}-\mathrm{Phe}-\mathrm{OH}$ EtOAc- $n$-hexane $(1: 2)$ -hexane<smiles>O=C1N(P)C[C@]12CCCN2</smiles>

$(+)-181$
2) recryst

3) $\mathrm{NaHCO}_{3}$ (aq)
1) L-Boc-Phe-OH EtOAc- $n$-hexane $(1: 2)$

\section{Scheme 67}

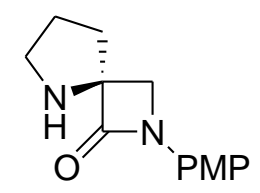

$(-)-181$

Treatment of $\mathrm{N}$-benzoyl spiroazetidinone 164a bearing an alkoxycarbonyl group at $\mathrm{C} 4$ with tertbutyl glycinate has been reported to afford a new spiroazetidinone 182 through an ester-toamide functional-group transformation (Scheme 68). ${ }^{65}$<smiles>COC(=O)C1N(C(=O)c2ccccc2)C(=O)C12CC2</smiles>

$164 a$

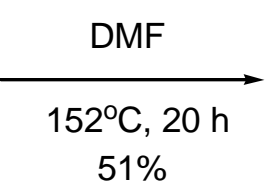

$51 \%$<smiles>CC(C)(C)OCC(=O)NCC(=O)N1C(=O)C2(CC2)C1c1ccccc1</smiles>

182

\section{Scheme 68}

The 1,3-thiazolidine ring spiro-fused to 2-azetidinones 183 and 184 has been described to undergo oxidative cleavage upon treatment with molecular iodine as an oxidant in the presence of wet alumina to afford the corresponding azetidin-2,3-diones 185a-e in fair-to-good yields (Scheme 69). ${ }^{75}$ The products were not very stable, and hence their enantiomeric excesses could be determined only by ${ }^{1} \mathrm{H}$ NMR spectroscopy - using (+)-Eu(hfc $)_{3}$ as a chiral shift reagent - and not by HPLC. In another report, the cleavage of the cyclohexadienone ring spiro-fused to 2azetidinones $\mathbf{8 6}$ has been realised through a series of reactions starting with ozonolysis, forming methyl $N$-alkoxy 4-hydroxymethyl-2-oxoazetidine-4-carboxylates 186 (Scheme 70). ${ }^{48}$ 


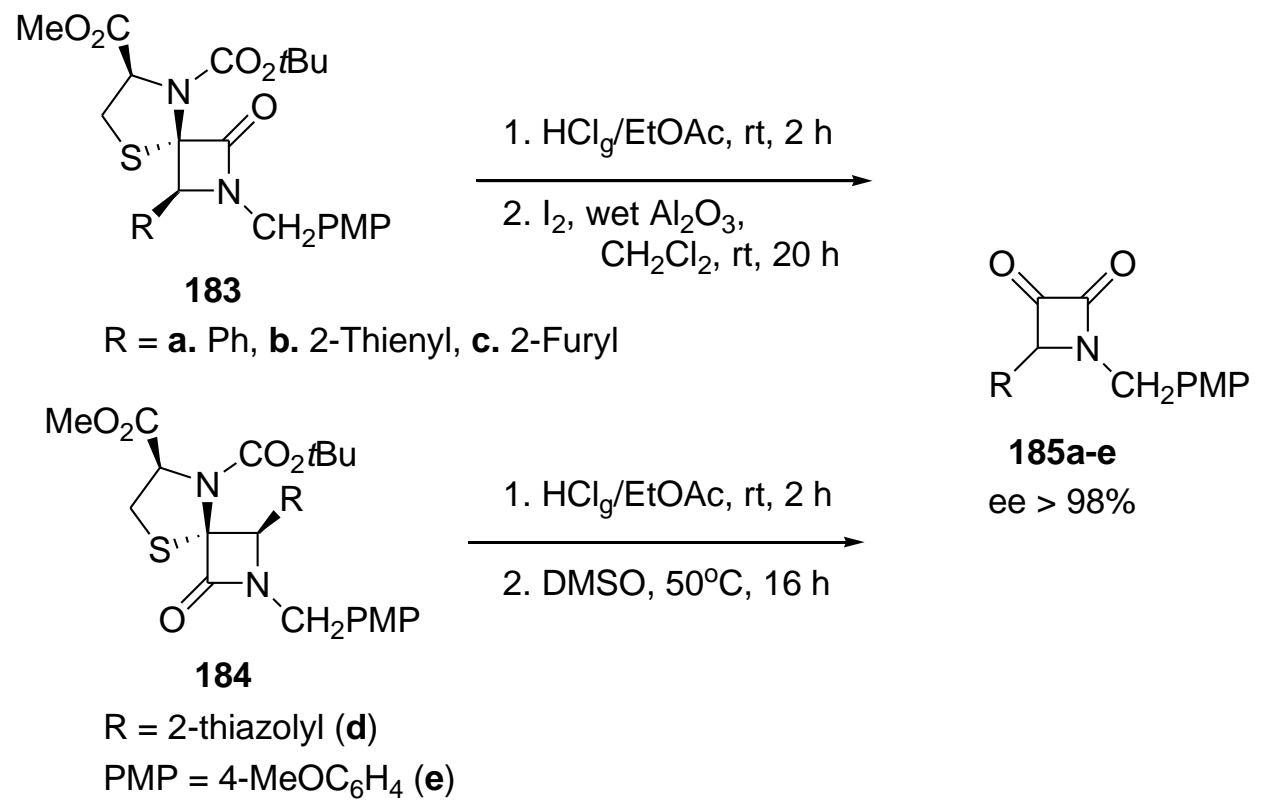

\section{Scheme 69}

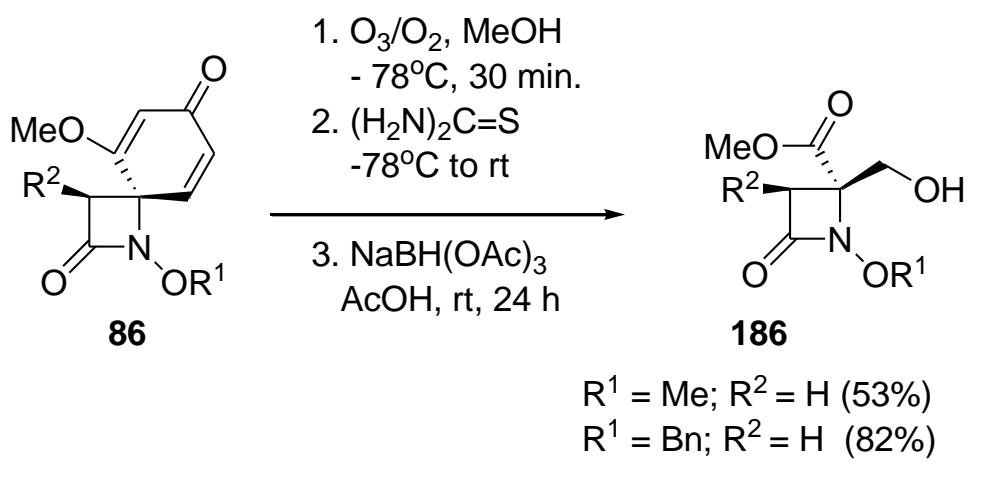

Scheme 70

The removal of the mesyloxy group from the pyrrolidine ring of spiroazetidinones $\mathbf{4 8}$ through elimination in a basic medium has been deployed to create a carbon-carbon double bond, resulting in a pyrroline ring system (Scheme 71). ${ }^{30}$ Thus, treatment of $\mathrm{N}$-Cbz-protected compounds $48 \mathrm{a}$ and $\mathbf{4 8} \mathrm{b}$ with potassium carbonate led to the formation of enantiomeric products $187 \mathrm{a}$ and $\mathbf{1 8 8}$, respectively. However, the corresponding $\mathrm{N}$-Boc-protected pyrrolidine 48c did not afford the desired pyrroline, even upon prolonged heating with potassium carbonate in methanol. Treatment of this $N$-Boc-protected compound with potassium tertbutoxide in tert-butanol, however, led to elimination of the mesyloxy group, forming the 
desired 2-azetidinone bearing a pyrroline ring. A similar removal of a mesyloxy group and conversion of a pyrrolidine into a pyrroline ring in the presence of potassium carbonate has been reported by Khasanov and coworkers as well. ${ }^{29}$

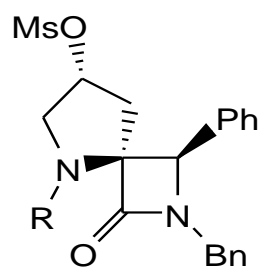

48a,c

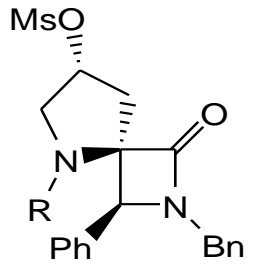

$48 b$

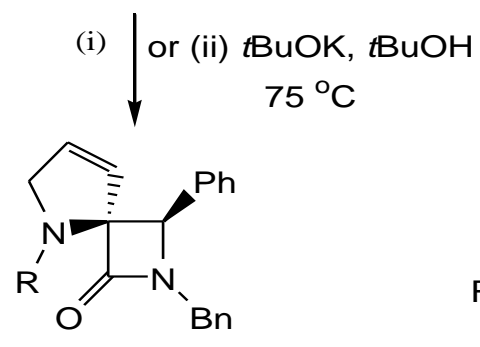

187a. $98 \%$ (i), c. $94 \%$ (ii)

$\mathrm{R}=\mathbf{a} \cdot \mathrm{Cbz}, \mathrm{c} \cdot t$-Boc

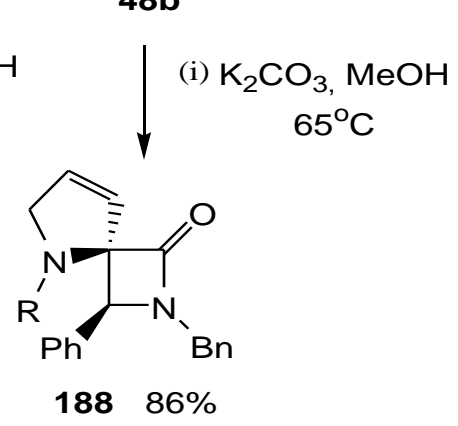

Scheme 71

Classical carbon-carbon double-bond transformations have been explored to synthesise various spiro-fused 2-azetidinones starting from spiroazetidinone 187 a. $^{30}$ Reactions with a nitrone, with ethyl diazoacetate in the presence of copper triflate, and with $m$-chloroperbenzoic acid led to [2+3] cycloaddition, cyclopropanation, and epoxidation forming new classes of spiro-fused 2azetidinones. Oxidative cleavage of alkene 187a with osmium tetroxide in the presence of sodium periodate led to pyrroline ring opening forming the monocyclic 2-azetidinone 189 containing two carbaldehyde groups. Reductive amination of this 2-azetidinone with $\mathrm{Na}(\mathrm{AcO})_{3} \mathrm{BH}$ in the presence of 4-methoxybenzylamine led to the synthesis of 2-azetidinone 190, spiro-fused to a piperazine ring (Scheme 72). ${ }^{30}$ 


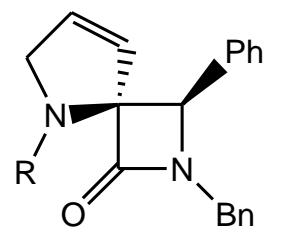

$187 a$
$\mathrm{OsO}_{4}(5 \mathrm{~mol} \%)$

$\mathrm{NaIO}_{4}(2.5$ equiv)

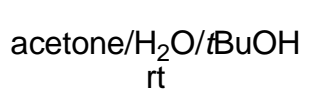

$98 \%$

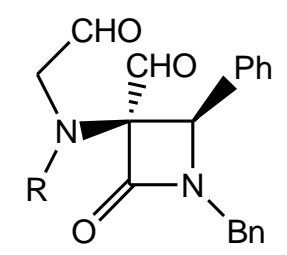

189

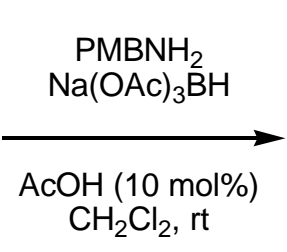

$60 \%$

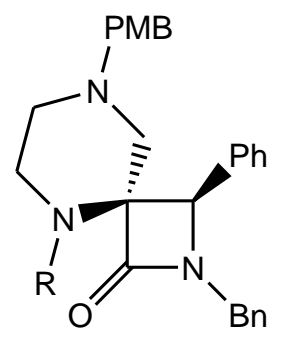

190

$\mathrm{R}=\mathrm{Cbz}$

Scheme 72

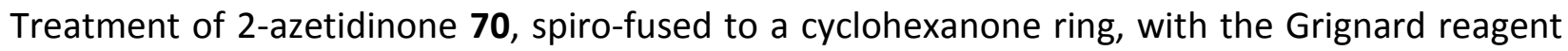
191 led to conversion into cyclohexanol 192. Reductive removal of the benzyl group in the latter compound 192 afforded the cholesterol absorption inhibitor 193 (Scheme 73). ${ }^{40}$<smiles>O=C1CCC2(CC1)C(=O)N(c1ccc(F)cc1)C2c1ccc(OCc2ccccc2)cc1</smiles>

70

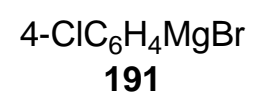

4- $\mathrm{ClC}_{6} \mathrm{H}_{4} \mathrm{MgBr}$

191

toluene, $48-52^{\circ} \mathrm{C}, 1 \mathrm{~h}$

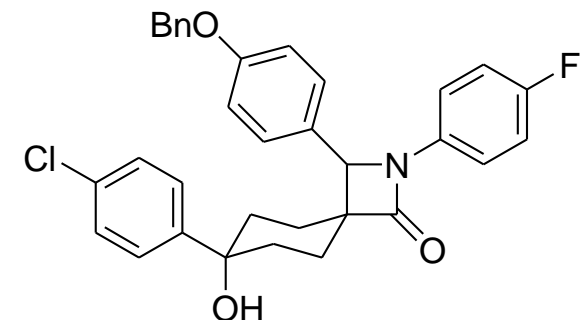

192

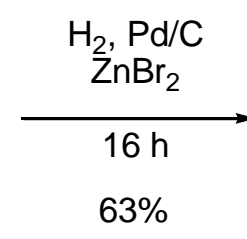

$\mathrm{HO}$<smiles></smiles>

193

Scheme 73

The spiro-fused 2-azetidinones 24, formed through Staudinger reaction of the imine derived from 7-oxanorbornenone with 2-alkoxyacetyl chlorides, underwent a sequence of ring-opening metathesis and cross metathesis (ROM-CM) upon treatment with Grubbs' ruthenium catalyst, forming new 2-azetidinones 194 spiro-fused to a tetrahydrofuran system (Scheme 74). ${ }^{76}$ By using $\beta$-lactams bearing different substituents at the C3 position of the 2-azetidinone ring, condensed bicyclic 2-azetidinones spiro-fused to another ring have been synthesised. The different C3 substituents were introduced by converting the 3-acetoxy derivative into the 
corresponding alcohol 195 (Scheme 75) and reacting the latter with allyl bromide, acryloyl chloride and 3-butenoic acid to afford the 2-azetidinones 196, 197 and 198, respectively (Scheme 76). ${ }^{76}$

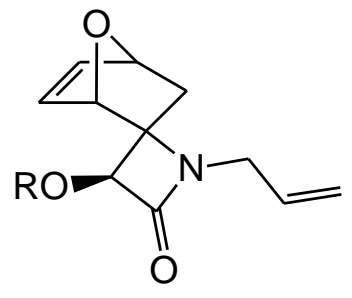

24

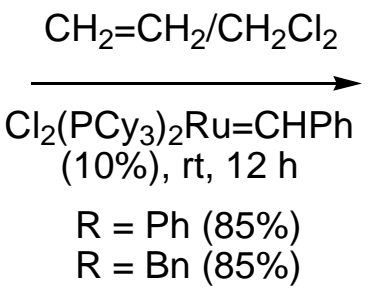

Scheme 74

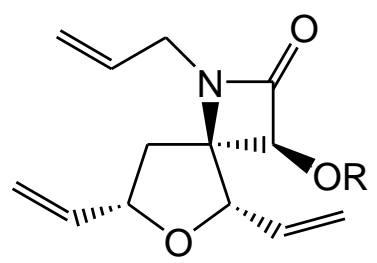

194<smiles>C=CCN1C(=O)[C@@H](OC(C)=O)C12CC1C=CC2C1</smiles>

24

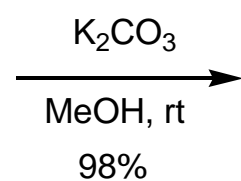

Scheme 75

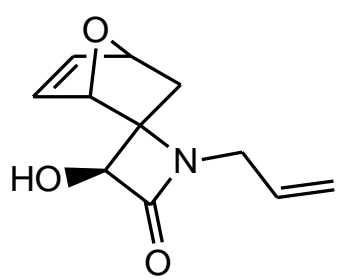

195 


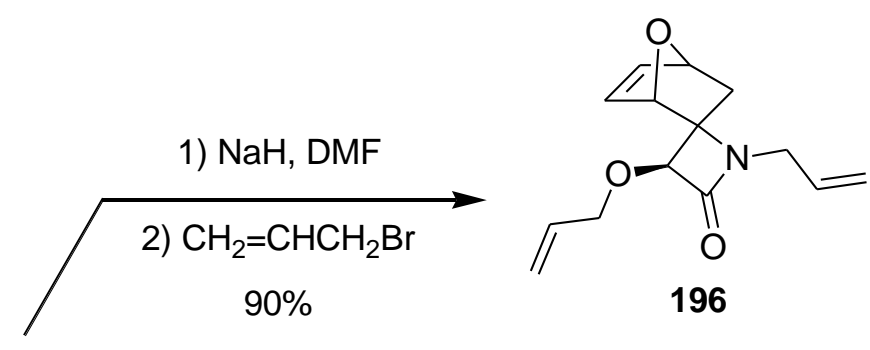

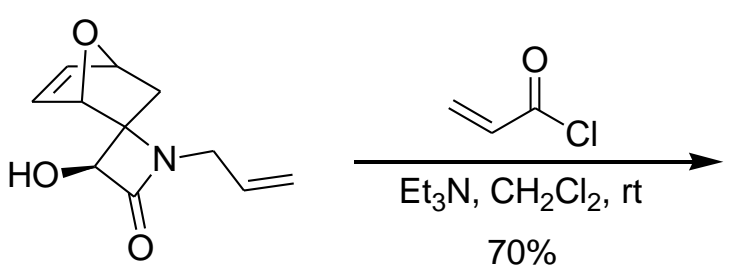

195

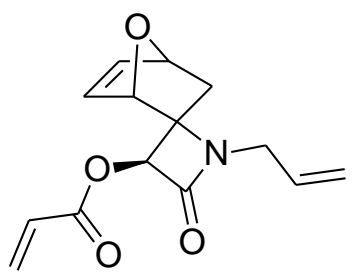

197

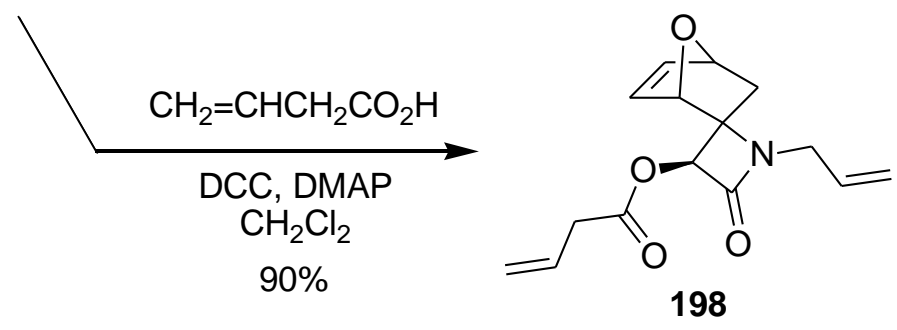

Scheme 76

Thermolysis of spiro-fused 2-azetidinone-oxadiazolines in the presence of alkenes has been reported to give 2-azetidinones, spiro-fused to cyclopropanes. ${ }^{77}$ The formation of these products was explained through a sequence of reactions beginning with a 1,3-dipolar cycloreversion of an oxadiazoline to form a carbonyl ylide. The latter fragmented to acetone and a 2-azetidinone-4-ylidene, which added to the alkene to afford spiro-fused 2-azetidinones. Thermolysis of 2-oxospiro(azetidine-4,2'-oxadiazoline) derivatives 199 in the presence of aryl isocyanates 201 afforded both $N$ - and $O$-lactam substituted spiro(azetidin-2-one-4,3'-indol-2'one) derivatives 202 and 204 (Scheme 77). ${ }^{78}$ The reaction occurred through addition of an intermediate cyclic acylaminocarbene $\mathbf{2 0 0}$, generated in situ by thermal decomposition of the oxadiazoline ring in the substrates 199 , to isocyanates 201 . The nature of the substituents on the phenyl group in both the carbenes and the isocyanates had a negligible effect on the outcome of these reactions. In all cases, the reaction afforded moderate-to-good overall yields $(65-86 \%)$ of 202 ( $N$-substituted) and 204 (O-substituted) adducts with the ratio of the latter over 
the former from 1:1 to $2: 1$. When the reaction was carried out with an equimolar amount of the substrate, spiroazetidinone $\mathbf{2 0 3}$ was also obtained as a product. The formation of this side product was eliminated by carrying out the reaction taking two moles of carbene precursors and one mole of isocyanates.

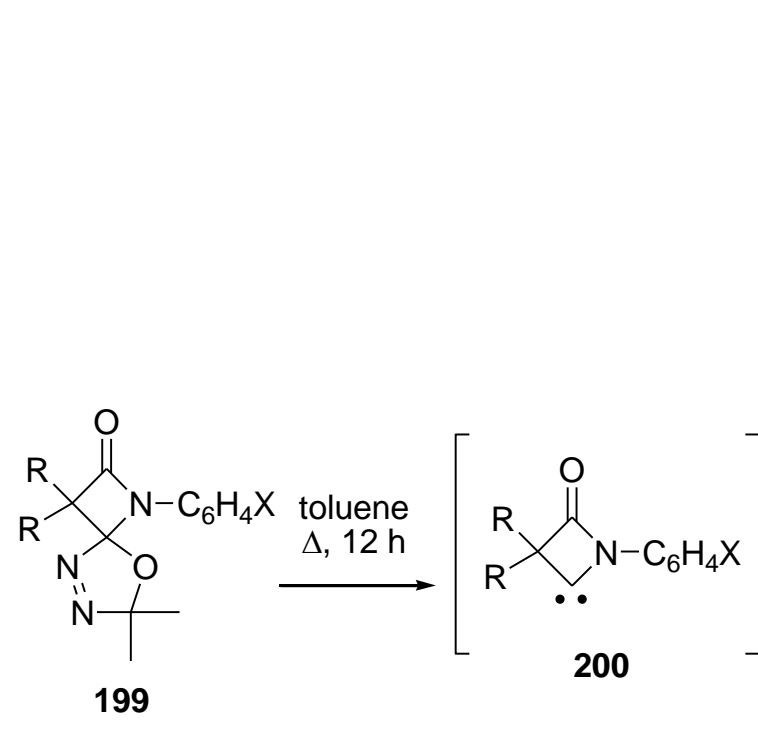

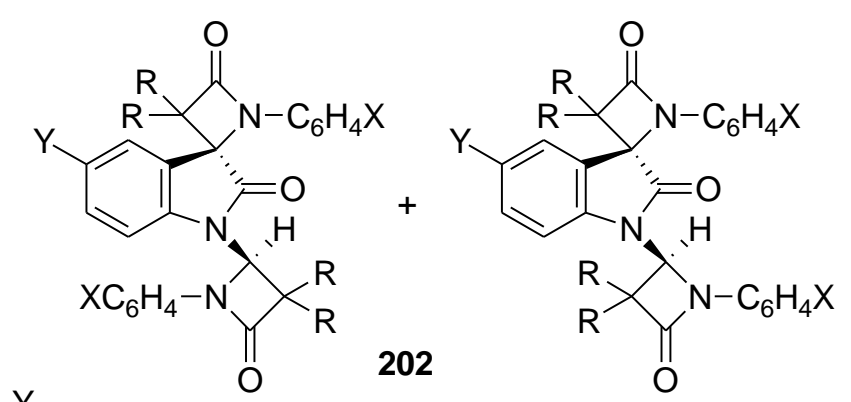

a. $\mathrm{R}=\mathrm{Me}$

$\mathrm{X}=\mathrm{H}$, 4-Me, 4-OMe,

b. $\mathrm{R}=\mathrm{Ph}$

$\mathrm{X}=4-\mathrm{Cl}, 4-\mathrm{Br}$

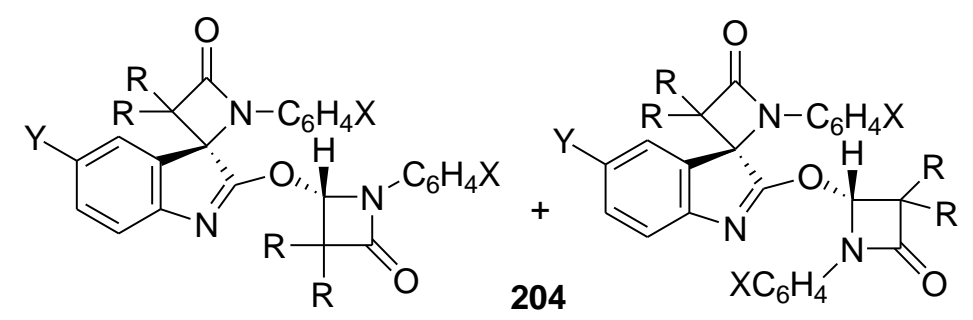

202 and 204

if $\mathrm{R}=\mathrm{Me}$ :

$\mathrm{X}=\mathrm{H}, \mathrm{Y}=\mathrm{Me} ; \mathrm{X}=\mathrm{H}, \mathrm{Y}=\mathrm{Cl} ; \mathrm{X}=4-\mathrm{Me}, \mathrm{Y}=\mathrm{Me} ; \mathrm{X}=4-\mathrm{Me}, \mathrm{Y}=\mathrm{Cl} ; \mathrm{X}=4-\mathrm{MeO}, \mathrm{Y}=\mathrm{H}$;

$\mathrm{X}=4-\mathrm{MeO}, \mathrm{Y}=\mathrm{Me} ; \mathrm{X}=4-\mathrm{MeO}, \mathrm{Y}=\mathrm{Cl} ; \mathrm{X}=4-\mathrm{Cl}, \mathrm{Y}=\mathrm{Me} ; \mathrm{X}=4-\mathrm{Br}, \mathrm{Y}=\mathrm{Me}$

if $\mathrm{R}=\mathrm{Ph}$ :

$\mathrm{X}=4-\mathrm{Cl}, \mathrm{Y}=\mathrm{Cl} ; \mathrm{X}=4-\mathrm{Br}, \mathrm{Y}=\mathrm{Cl}$

\section{Scheme 77}

Dehalogenation studies have been carried out on 2-azetidinones, spiro-fused to 3'-bromo-and 3'-iodotetrahydrothiophene. Treatment of these compounds 104 or 106 with n-tributyltin hydride (1.2 equiv) in the presence of a catalytic amount of AIBN in benzene under reflux led to removal of the halogen, affording spiroazetidinones 205 in good yields (Scheme 78). ${ }^{56}$ 


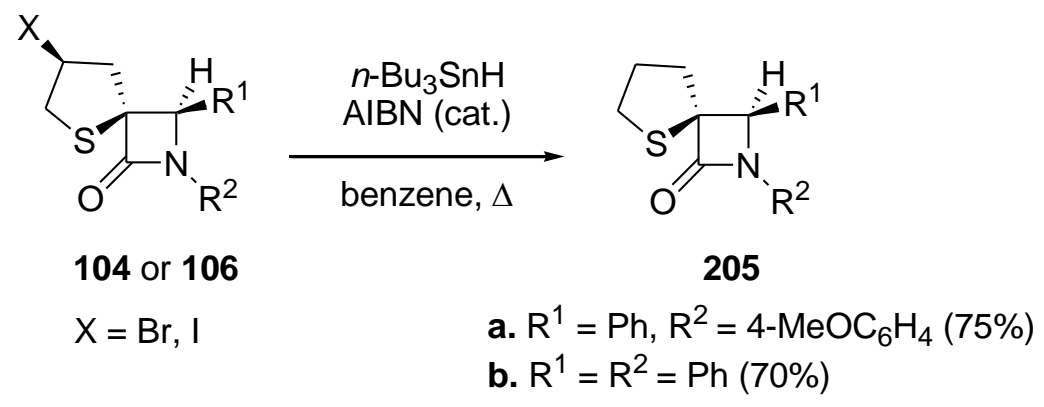

Scheme 78

Treatment of spiroazetidinone 206, synthesised applying Staudinger reaction conditions, with tris(trimethylsilyl)tin hydride resulted in dechlorination at C3, forming spiroazetidinone 207 (Scheme 79). The indolinone $\mathrm{NH}$ group in the latter compound was $\mathrm{Cbz}$ protected using a standard protocol furnishing $160{ }^{72}$<smiles>O=C1[C@H](Cl)C2(C(=O)Nc3ccccc32)N1P(=O)(F)F</smiles>

206

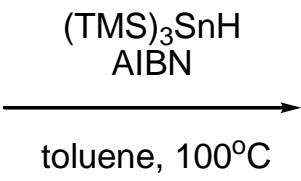

$91 \%$<smiles>NP(=O)(c1ccccc1)N1C(=O)CC12C(=O)Nc1ccccc12</smiles>

207

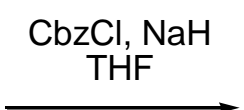<smiles>NP(=O)(c1ccccc1)N1C(=O)CC12CC(=O)N(C(=O)O)c1ccccc12</smiles>

160

\section{Scheme 79}

2-Azetidinone 211, spiro-fused to tribrominated indolinone, required in a synthetic approach to chartelline, was obtained by a sequence of reactions involving reductive removal of the chloro atom and reduction of the nitro group to an amino group, aromatic dibromination and replacement of the aromatic amino group by a bromo atom in spiroazetidinones 208, 209 and 210, respectively (Scheme 80 ). ${ }^{72}$ 


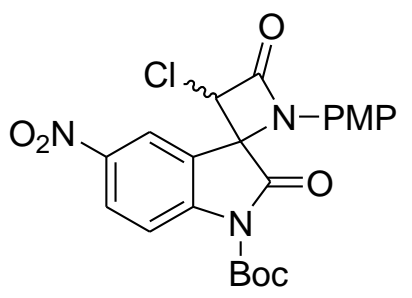

208<smiles>CC(C)(C)OC(=O)N1C(=O)C2(CC(=O)N2[18O])c2c1cc(Br)c(N)c2Br</smiles>

210
1) $\mathrm{Zn}-\mathrm{AcOH}$

THF

2) $(\mathrm{TMS})_{3} \mathrm{SnH}$

AIBN, toluene

$88 \%$

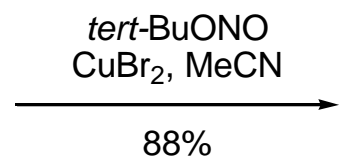

Scheme 80

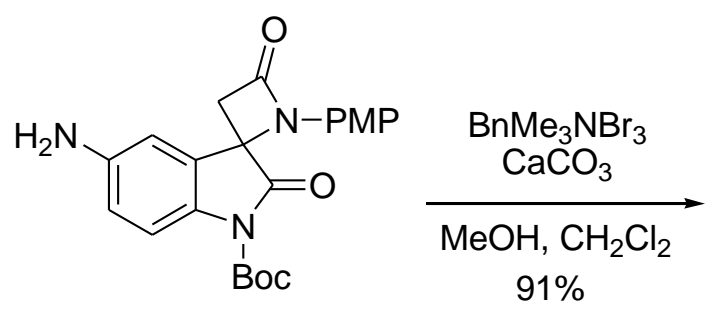

209

Selective addition of lithium tert-butylacetylide across the $\gamma$-lactam carbonyl moiety in spiroazetidinone $\mathbf{2 1 2}$ has been shown to result in the formation of a new spiro-fused 2-azetidinone 213. A further transformation of this azetidinone to azetidinone $\mathbf{2 1 5}$ via reduction of azetidinone $\mathbf{2 1 4}$ is shown in Scheme 81. ${ }^{72}$ A strategy to construct the ten-membered ring of the naturally occurring chartelline by intramolecular condensation of the $\beta$-lactam nitrogen atom with carboxaldehyde in $\mathbf{2 1 6}$ failed, due to formation of a seven-membered ring by the reaction of the aldehyde group with the activated carbon-carbon double bond, giving rise to compound 217 (Scheme 82). $^{72}$ 


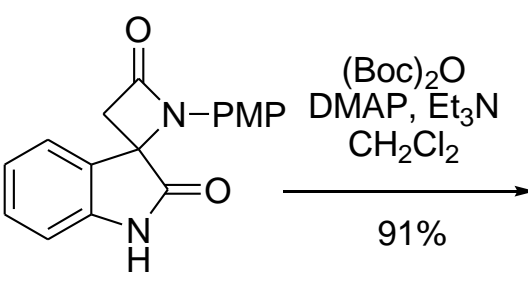

207<smiles>CC(C)(C)OC(=O)N1C(=O)C2(CC(=O)N2P(C)(=O)O)c2ccccc21</smiles>

212

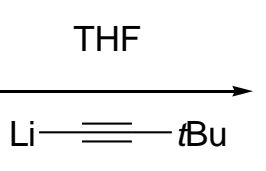

$-78^{\circ} \mathrm{C}$

$96 \%$<smiles>[R6]N1c2ccccc2C2(CC(=O)N2[18O])[C@]1(O)C#CC(C)(C)C</smiles>

213
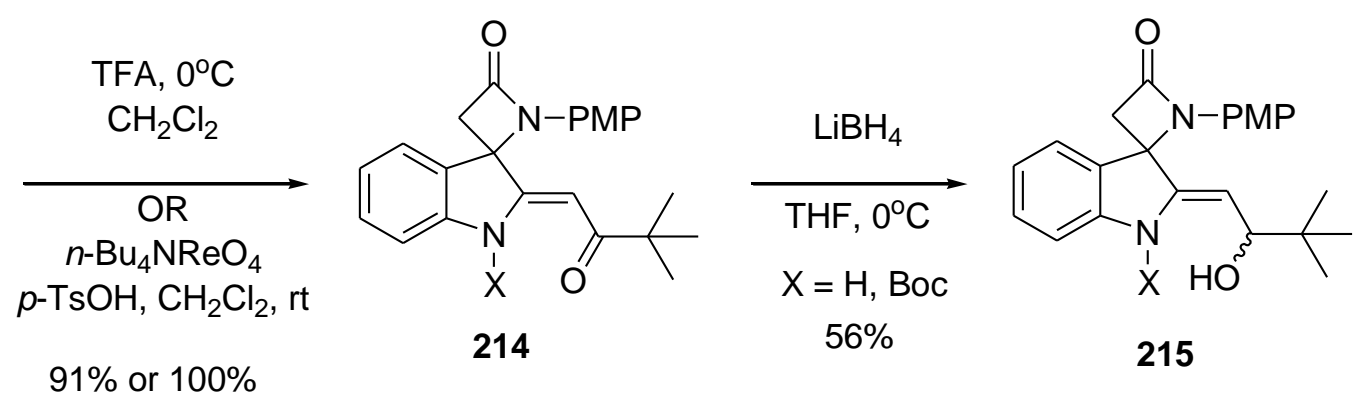

\section{Scheme 81}<smiles>CCc1c(C(C)(C)C#C[C@]2(O)N(C(=O)O)c3cc(Br)c(Br)c(Br)c3C23CC(=O)N3)nc(Br)n1[R6]O[Na]</smiles><smiles>CCc1c(C(C)(C)C(=O)/C=C2\N(C(=O)O)c3cc(Br)c(Br)c(Br)c3C23CC(=O)N3)nc(Br)n1OC(C)(C)C</smiles><smiles>COC(=O)n1c(Br)nc2c1C=CC(=C1N(C(=O)OC(C)(C)C)c3cc(Br)c(Br)c(Br)c3C13CC(=O)N3)C(=O)C2(C)C</smiles>
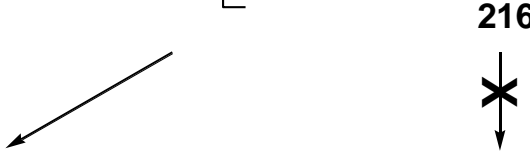<smiles>CC(=O)OC(=O)n1c(Br)nc2c1C=CN1C(=O)CC13C(=CC(=O)C(C)(C)c1cc(Br)c(Br)c(Br)c1-2)N3C(=O)OCc1ccccc1</smiles>

217

Scheme 82

\section{Bioactive Spiro-fused $\beta$-Lactams}

The antibacterial $^{79}$ and antiviral ${ }^{80}$ activities of spiroazetidinones have already been reported in 1978 and 1990, respectively. Spiroazetidinone 218 (Figure 4) has been found to be an inhibitor 
of both poliovirus and human rhinovirus 3C-proteinases. Spiroazetidinones have also been reported to act as cholesterol absorption inhibitors (CAIs), with spiroazetidinones SCH 54016 219 and SCH 58053220 (Figure 4) showing excellent cholesterol absorption inhibitory activity. ${ }^{81}$

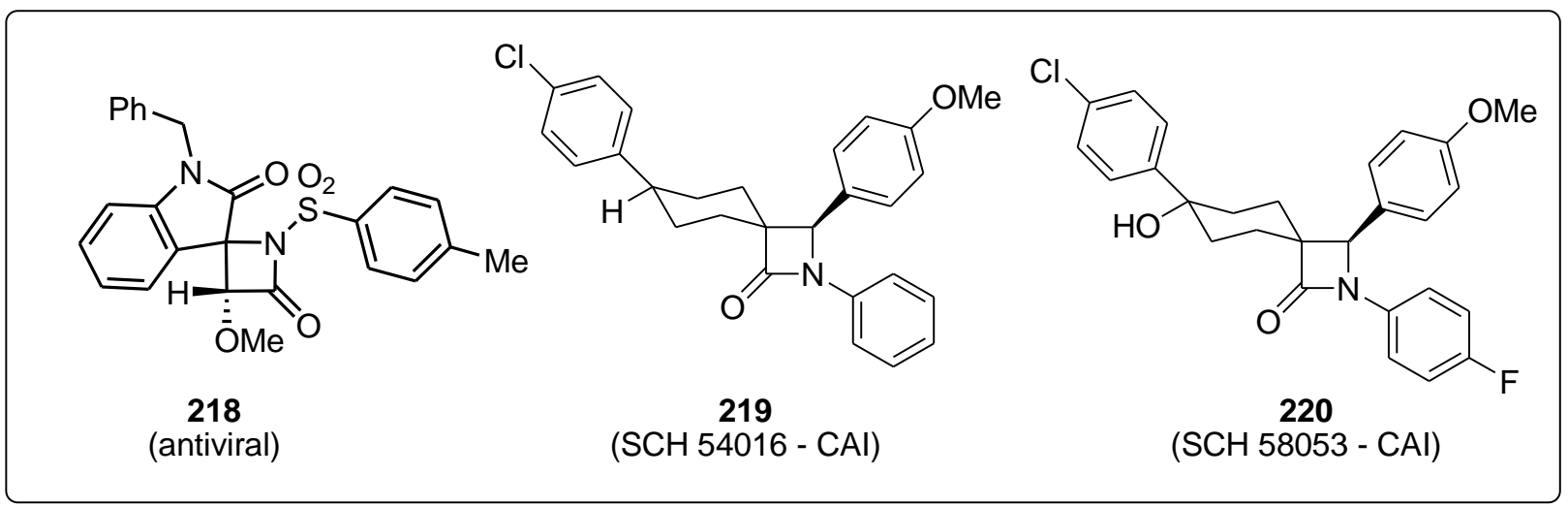

Figure 4

2-Azetidinones, spiro-fused to oxetane and tetrahydrofuran, (Figure 5), have been evaluated as acetyl-CoA cholesterol acyltransferase (ACAT) inhibitors, ${ }^{59}$ showing modest activity (23-66\% inhibition). Interestingly, oxetane-fused azetidinones (118a and 119a) showed higher activity in comparison to tetrahydrofuran-fused azetidinones (118b and 119b).

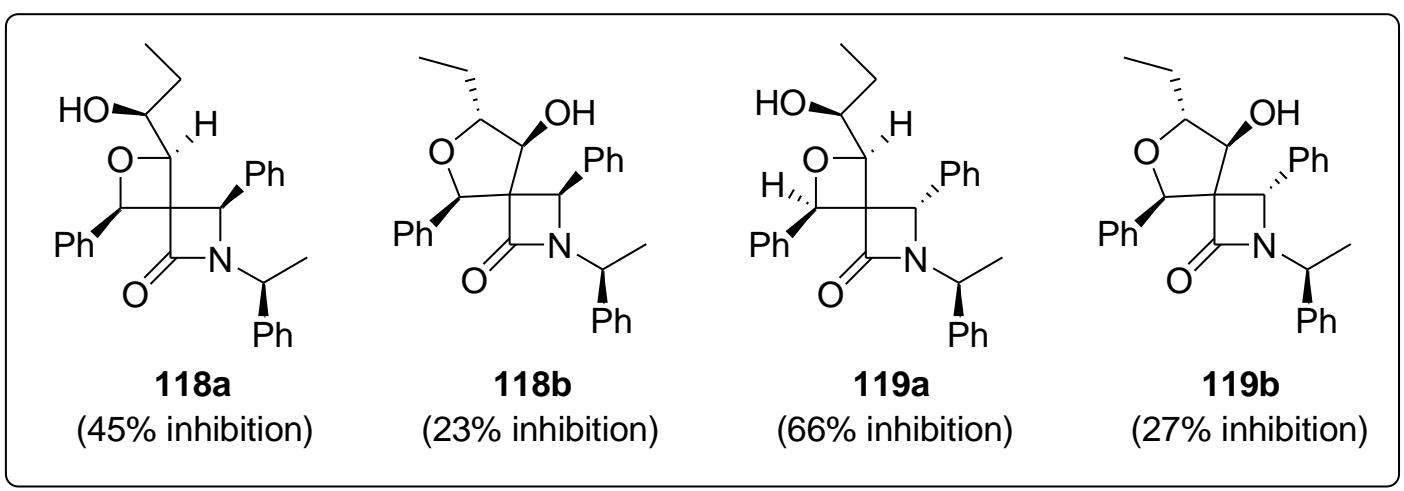

Figure 5 
N-Methylthio-2-azetidinone 221 (Figure 6) spiro-fused to tetrahydrofuran exhibits antibacterial activity against Bacilli. ${ }^{82}$ This $\beta$-lactam was screened according to the Kirby-Bauer method of well diffusion on agar plates.

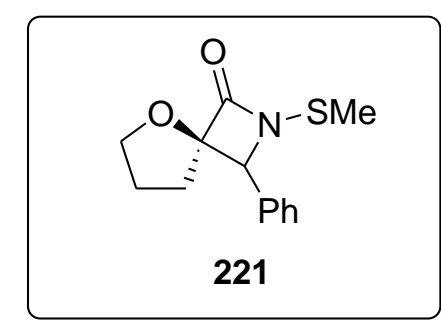

\section{Figure 6}

\section{Concluding Remarks}

Spiro-fused 2-azetidinones have drawn considerable interest in recent years, due to a number of biological activities associated with this class of compounds. Within the various approaches to the construction of the spiro framework, the Staudinger ketene-imine cycloaddition occupies a central place. Various cyclic ketenes, some derived from natural compounds such as L-proline, have been reacted with imines to afford spiro-fused 2-azetidinones, often in a stereoselective manner. The cyclisation of $\beta$-amino acids and $\beta$-functionalised amides under thermal and photochemical conditions has led to the synthesis of some novel spiro-fused 2-azetidinones. The cyclisation reactions of substituents present at monocyclic 2-azetidinones, e.g. halocyclisation of an allylic group, are newer approaches to create a spiro-carbon center, as well as the cycloaddition reactions of the exocyclic carbon-carbon double bond of methylidene-2azetidinones. Transformations of functionalities present at spiro-fused 2-azetidinones have further led to the discovery of many novel spiro-fused 2-azetidinones. Ring-opening reactions have contributed to the discovery of biologically important classes of compounds such as $\beta$ amino acids, $\beta$-amino esters and amides. The structures of some spiro-fused 2-azetidinones have been established by X-ray crystallography. The synthetic endeavours to chartellines have contributed to the discovery of many novel spiro-fused 2-azetidinones and their chemistry before the final synthesis of chartelline C was accomplished in 2006. Hopefully, the synthesis 
and chemistry of such spiro-2-azetidinones will continue to attract researchers in the near future and more interesting results will be forthcoming.

\section{Acknowledgements}

The authors are indebted to the chemistry Department at the University of Botswana, to the "Fund for Scientific Research - Flanders" (FWO-Vlaanderen) and to Ghent University (GOA), for financial support.

\section{References}

1 (a) The Organic Chemistry of $\beta$-lactams; George, G. I.; Ravikumar, B. T.; Eds. VCH, New, York, 1993, p 295; (b) Manhas, M. S.; Bose, A. K. Chemistry of Penicillin, Cephalosporin C and analogs, 1969, Mercel Dekker Inc. New York; (c) De Kimpe, N. Azetidines, Azetines and Azetes in Comprehensive Heterocyclic Chemistry-II, Katritzky, A. R.; Ramsden, C. A.; Scriven, E.; Taylor, R. eds. Vol. 1B, Padwa, A., Ed, Pergamon, Oxford, 1995, p. 507.

2 Singh, G. S. Mini-Rev. Med. Chem. 2004, 4, 69.

3 Singh, G. S. Mini-Rev. Med. Chem. 2004, 4, 92.

4 (a) Singh, G. S.; D’hooghe, M.; De Kimpe, N.; Azetidines, Azetines and Azetes in Comprehensive Heterocyclic Chemistry-III, Katritzky, A. R.; Ramsden, C. A.; Scriven, E.; Taylor, R. eds. Vol. 2 (Stevens, C. Ed.), Elsevier, UK, 2008, p. 1; (b) Singh, G. S.; Tetrahedron 2003, 59, 7631; (c) Deshmukh, A. R. A. S.; Bhawal, B. M.; Krishnaswami, D.; Govande, V. V.; Shinkre, B. A.; Jayanthi, A. Curr. Med. Chem. 2004, 11, 1889; (d) Alcaide, B.; Almendros, P. Curr. Med. Chem. 2004, 11, 1921; (e) Hwu, J. R.; Ethiraj, K. S.; Hakimelahi, G. H. Mini-Rev. Med. Chem. 2003, 3, 305; (f) Alcaide, B.; Almendros, P.; Aragoncillo, C. Chem. Rev. 2007, 107, 4437; (g) Ojima, I. Acc. Chem. Res. 1995, 28, 383; (h) Ojima, I.; Delaloge, F. Chem. Soc. Rev. 1997, 26, 377; (i) Alcaide, B.; Aragoncillo, C.; Almendros, P. Cephalosporins in Comprehensive Heterocyclic Chemistry-III, Katritzky, A. R.; Ramsden, C. A.; Scriven, E.; Taylor, R. eds. Vol. 2 (Stevens, C. ed), Elsevier, UK, 2008, p. 111; (j) Marchand-Brynaert, J.; Brulé, C. Penicillins in Comprehensive Heterocyclic Chemistry-III, Katritzky, A. R.; Ramsden, C. A.; Scriven, E.; 
Taylor, R. eds. Vol. 2 (Stevens, C. ed), Elsevier, UK, 2008, p. 173; (k) Fisher, J. F.; Meroueh S. O.; (I) Mobashery, S. Chem. Rev. 2005, 105, 395; France, S.; Weatherwax, A.; Taggi, A. E.; Lectka, T. Acc. Chem. Res. 2004, 37, 592.

5 Baran, P. S.; Shenvi, R. A. J. Am. Chem.Soc. 2006, 128, 14028

6 (a) J. Xu, Arkivoc 2009, (ix), 21; (b) L. Jiao, Y. Liang and J. X. Xu, J. Am. Chem. Soc. 2006, 128, 6060 .

7 Dandia, A.; Singh, R.; Sharma, P. Heteroatom Chem. 2003, 14, 468.

8 Bose, A. K.; Anjaneyulu, V.; Bhattacharya, S. K.; Manhas, M. S. Tetrahedron 1967, 23, 4769;

9 Fahr, E.; Doppert, K.; Konigsdorfer, K.; Scheckenbach, F. Tetrahedron 1968, 24, 1011.

10 Shridhar, D. R.; Ram. B.; Narayana, B. L.; Awasthi, A. K.; Reddy, G. J. Synthesis 1984, 846.

11 Singh, S. B.; Mehrotra, K. N. Can. J. Chem. 1982, 60, 1901.

12 Singh, G. S.; Mehrotra, K. N. Indian J. Chem. Section B 1985, 24, 129.

13 (a) Singh, G. S.; Singh, T.; Lakhan, R. Indian J. Chem. Section B 1997, 36, 951; (b) Singh, G. S.; Mmolotsi, B. J. J. Heterocycl. Chem. 2006, 43, 1665; (c) Singh, G. S.; Luntha, P. Eur. J. Med. Chem. 2009, 44, 2265.

14 Jarrahpour, A.; Khalili, D. Tetrahedron Lett. 2007, 48, 7140.

15 Azizian, J.; Sarrafi, Y.; Mehrdad, M. Indian J. Chem. Section B 2000, 39, 304.

16 Nishikawa, T.; Kajii, S.; Isobe, M. Synlett 2004, 2025.

17 Nishikawa, T.; Kajii, S.; Isobe, M. Chem. Lett. 2004, 33, 440.

18 Robertson, J.; Bell, S. J.; Krivokapic, A. Org. Biomol. Chem. 2005, 3, 4246.

19 Barba, V.; Hernandez, C.; Rojas-Lima, S.; Farfin, N.; Santillan, R. Can. J. Chem. 1999 , 77, 2025. 20 Arjona, O.; Csa'ky, A. G.; Murcia , M. C.; Plumet , J. Tetrahedron Lett. 2002, 43, 6405.

21 (a) Elkanzi, N. A. A. Phosphorus, Sulfur, Silicon and the Related Elements 2008, 183, 2040; (b) Khalafallah, A. K.; Elkanzi, N. A. A.; Soleiman, H. A.; Younis, M. Phosphorus, Sulfur, Silicon and the Related Elements 2006, 181, 2483; (c) Khalafallah, A. K.; Koraiem, A. I. M.; Abudooh, A. M.; Shindy, H. A.; Elmagid, N. A. Asian J. Chem. 1996, 8, 529.

22 Rojas-Lima, S.; Santillan-Sid, L.; Lopez-Ruiz, H.; Alvarez-Hernandez, A. Heterocycles 2007, 71, 531. 
23 Alonso, E.; del Pozo, C.; Gonzalez, J. J. Chem. Soc. Perkin Trans.1 2002, 571.

24 (a) Cremonesi, G.; Croce, P. D.; La Rosa, C. Tetrahedron 2004, 60, 93; (b) Croce, P. D.; Ferraccioli, R.; La Rosa, C. Tetrahedron 1995, 51, 9385; (c) Croce, P. D.; Ferraccioli, R.; La Rosa, C. Tetrahedron 1999, 55, 201; (d) Croce, P. D.; La Rosa, C. Tetrahedron: Asymmetry 1999, 10, 1193; (e) Cremonesi, G.; Croce, P. D; La Rosa, C. Helv. Chim. Acta 2005, 88, 1580.

25 Croce, P. D.; Cremonesi, G.; Fontana, F.; Forni , A.; La Rosa , C. Tetrahedron: Asymmetry $2005,16,3371$.

26 Macias, A.; Alonso, E.; Venturini, A.; Gonzalez, J. J. Org. Chem. 2004, 69, 7004.

27 Macias, A.; Alonso, E.; del Pozo, C.; Gonzalez, J., Tetrahedron Lett. 2004, 45, 4657.

28 Macias, A.; Ramallal, A. M.; Alonso, E.; del Pozo, C.; Gonzalez, J. J. Org. Chem. 2006, 71, 7721.

29 Khasanov, A. B.; Ramirez-Weinhouse, M. M.; Webb, T. R.; Thiruvazhi, M. J. Org. Chem. 2004, 69, 5766.

30 Cremonesi, G.; Croce , P. D.; Fontana, F.; La Rosa, C. J. Org. Chem. 2010, 75, 2010.

31 Alonso, E.; Lopez-Ortiz, F.; del Pozo, C.; Perlta, E.; Macias, A.; Gonzalez, J. J. Org. Chem. 2001, 66, 6333.

32 Trabocchi, A.; Lalli, C.; Guarna, F.; Guarna, A.; Eur. J. Org. Chem. 2007, 4594.

33 Chinchinalkar, P. M.; Puranik, V. G.; Deshmukh, A. R. A. S. Tetrahedron 2007, 63, 9179.

34 Jarrahpour, A.; Ebrahimi, E. Molecules 2010, 15, 515.

35 Tsuno, T.; Kondo, K.; Sugiyama, K. J. Heterocycl. Chem. 2006, 43, 21.

36 Zhou, A.; Cao, L.; Li, H.; Liu, Z.; Pittmann Jr., C. U. Synlett 2006, 201.

37 (a) Singh, G. S.; Siddiqui, N.; Pandeya, S. N. Asian. J. Chem. 1993, 4, 788; (b) Singh, G. S.; Siddiqui, N.; Pandeya, S. N. Boll. Chim. Farm. 1994, 133, 76; (c) Agrawal, R.; Agrawal, C.; Singh, C.; Mishra, V. S. Indian J. Chem. 1989, 28B, 893; (d) Singh, G. S.; Singh, T.; Lakhan, R. Indian J. Chem. 1997, 36B, 951.

38 Ikeda, M.; Uchino, T.; Yamano, M.; Watanabe, Y.; Ishibashi, H.; Kido, M. Chem. Pharm. Bull. 1986, 34, 4997.

39 Chowdary, N. S.; Suri, J. T.; Barbas, C. F. III Org. Lett. 2004, 6, 2507. 
40 Wu, G.; Tormas, W. J. Org. Chem. 1997, 62, 6412.

41 Stocks, M. J.; Hamza, D.; Pairaudeau, G.; Stonehouse, J. P.; Thorn, P. V. Synlett, 2007, 16, 2587.

42 Arnott, G.; Clayden, J.; Hamilton, S. D. Org. Lett. 2006, 8, 5325.

43 Clayden, J.; Hamilton, S. D.; Mohammed, R. T. Org. Lett. 2006, 8, 3673.

44 Ishibashi, H.; Higuchi, M.; Ohba, M.; Ikeda, M. Tetrahedron Lett. 1998, 39, 75.

45 Liang, J. X.; Chen, J. B.; Du, F. X.; Zeng, X. H.; Li, L.; Zhang, H. B. Org. Lett. 2009, 11, 2820.

46 Bittermann, H.; Boeckler, F.; Einsiedel, J.; Gmeiner, P. Chem. Eur. J. 2006, 12, 6315

47 Bittermann, H.; Gmeiner, P. J. Org. Chem. 2006, 71, 97.

48 Wardrop, D. J.; Burge, M. S. J. Org. Chem. 2005, 70, 10271.

49 Baran, P. S.; Shenvi, R. A.; Mitsos, C. A. Angew. Chem. Int. Ed. 2005, 44, 3714.

50 Carle, J. S.; Christophersen, C. J. Org. Chem. 1980, 45, 1586; Carle, J. S.; Christophersen, C. J. Am. Chem. Soc. 1979, 101, 492; Carle, J. S.; Christophersen, C. J. Am. Chem. Soc. 1980, 102, 5107; Christophersen, C. Acta Chem. Scand. 1985, B39, 517.

51 Bose, A. K.; Garrat, G.; Pelosi, J. J. J. Org. Chem. 1963, 28, 730.

52 Alcaide, B.; Almendros, P.; Campo, T. M.; Rodriguez-Acebes, R. Tetrahedron Lett. 2004, 45, 6429.

53 Alcaide, B.; Almendros, P.; del Campo, T. M.; Quiros, M. T. Chem. Eur. J. 2009, 15, 3344.

54 Alcaide, B.; Almendros, P.; Martínez del Campo, T.; Carrascosa, R. Eur. J. Org. Chem. 2010, 4912.

55 Bhalla, A.; Venugopalan, P.; Bari, S. S. Eur. J. Org. Chem 2006, 4943.

56 Arora, R.; Venugopalan, P.; Bari, S. S. J. Chem. Sci. 2010, 122, 1.

57 Bhalla, A.; Venugopalan, P.; Bhasin, K. K.; Bari, S. S. Tetrahedron 2007, 63, 3195.

58 Chen, L. Y.; Zaks, A.; Chakalmanni, S.; Dugar, S. J. Org. Chem. 1996, 61, 8341.

59 Benfatti, F.; Cardillo, G.; Gentilucci, L.; Tolomelli, A. Bioorg. Med. Chem. Lett. 2007, 17, 1946.

60 Benfatti, F.; Cardillo, G.; Gentilucci, L.; Tolomelli, A. Eur. J. Org. Chem. 2007, 3199.

61 Gurtler, S.; Johner, M.; Ruf, S.; Otto, H. H. Helv. Chim. Acta 1993, 76, 2958.

62 Strauss, A.; Otto, H. H. Helv. Chim. Acta 1997, 80, 1823. 
63 Anklam, S.; Liebscher, J. Tetrahedron 1998, 54, 6369.

64 Ruff, S.; Otto, H. H. Helv. Chim. Acta 1995, 78, 629.

65 Zanobini, A.; Gensini, M.; Magull, J.; Vidovic, D.; Kozhushkov, S. I.; Brandi, A.; de Meijere, A. Eur. J. Org. Chem. 2004, 4158.

66 Marradi, M.; Brandi, A.; Magull, J.; Schill, H.; de Meijere, A. Eur. J. Org. Chem. 2006, 5485.

67 (a) Cordero, F. M.; Pisaneschi, F.; Salvati, M.; Paschetta, V.; Ollivier, J.; Salaun, J.; Brandi, A. J. Org. Chem. 2003, 68, 3271.; (b) Cordero, F. M.; Salvati, M.; Pisaneschi, F.; Brandi, A. Eur. J. Org. Chem. 2004, 2271; (c) Cordero, F. M.; Pisaneschi, F.; Goti, A.; Ollivier, J.; Salaun, J. J. Am. Chem. Soc. 2000, 122, 8075.

68 Zanobini, A.; Brandi, A.; de Meijere, A. Eur. J. Org. Chem. 2006, 1251.

69 Alonso, E.; Pozo, C. D.; Gonzalez, J. Synlett 2002, 69.

70 Alcaide , B.; Almendros, P.; Redondo , M. C. Eur. J. Org. Chem. 2007, 3707.

71 Croce, P. D.; La Rosa, C. Heterocycles 2000, 53, 2653.

72 (a) Sun, C.; Lin, X.; Weinreb, S. M. J. Org. Chem. 2006, 71, 3159; (b) Nair, V.; Deepthi, A. Chem. Rev. 2007, 107, 1862; (c) Sridharan, V.; Menendez, J. C. Chem. Rev. 2010, 110, 3805. 73 Sun, C.; Camp, J. E.; Weinreb, S. M. Org. Lett. 2006, 8, 1779.

74 Singh, G. S. J. Heterocycl. Chem. 2000, 37, 1355.

75 Cremonesi, G.; Croce, P. D.; Fontana, F.; La Rosa, C. Tetrahedron: Asymmetry 2008, 19, 554.

76 Csaky, A. G.; Medel, R.; Murcia, M. C.; Plumet, J. Helv. Chim. Acta 2005, 88, 1387.

77 Zoghbi, M.; Horne, S. E.; Warkentin, J. J. Org. Chem. 1994, 59, 4090.

78 Cheng, Y.; Wang, B.; Cheng, L. -Q. J. Org. Chem. 2006, 71, 4418.

79 Sheehan, J. C.; Chacko, E.; Lo, Y. S.; Ponzi, D. R.; Sato, E. J. Org. Chem. 1978, 43, 4856.

80 Skiles, J. W.; McNeil, D. Tetrahedron Lett. 1990, 31, 7277.

81 Dugar, S.; Clader, J.; Chan, T. M.; Davis, H. J. Med. Chem. 1995, 38, 4875.

82Turos, E.; Long, T. E.; Heldreth, B.; Leslie, J. M.; Reddy, G. S. K.; Wang, Y.; Coates, C.; Konaklieva, M.; Dickey, S.; Lim. D. V.; Alonso, E.; Gonzalez, J. Bioorg. Med. Chem. Lett. 2006, 16, 2084. 